\title{
Transcriptional regulation of the human Zfm1/Sf1 gene
}

\author{
Dissertation \\ zur Erlangung des Doktorgrades \\ der Mathematisch-Naturwissenschaftlichen Fakultäten \\ der Georg-August Universität Göttingen
}

vorgelegt von

Nicole Alberta Nogoy

aus Quezon City, Philippines

Göttingen 2006 
D7

Referent:

Prof Dr. R. Hardeland

Koreferent:

Prof. Dr. D. Doenecke

Tag der mündlichen Prüfung: 5 Juli, 2006 
For my Father 


\section{Contents}

Abbreviations V

\begin{tabular}{ll}
$1 . \quad$ Introduction & 1 \\
\hline
\end{tabular}

$1.1 \quad$ The pathogenesis of atherosclerosis 1

1.1.2 Plasticity and phenotypes of SMC 3

$1.2 \quad$ Structure and function of the Sf1/Zfm1

Gene 4

$1.3 \quad$ Regulation of gene transcription 6

1.3.1 Basal transcription machinery 6

1.3.2 TAFIls can define functionally distinct

$\begin{array}{ll}\text { TFIID complexes } & 7\end{array}$

$\begin{array}{lll}1.4 & \text { Aims of the study } & 8\end{array}$

\begin{tabular}{ll}
2. & Materials \\
\hline
\end{tabular}

$\begin{array}{lll}2.1 & \text { Bacteria } & 10\end{array}$

$\begin{array}{lll}2.2 & \text { Plasmid vectors } & 10\end{array}$

$\begin{array}{lll}2.3 & \text { Primers } & 11\end{array}$

$\begin{array}{lll}2.4 & 12\end{array}$

$\begin{array}{lll}2.5 & \text { Cell culture } & 13\end{array}$

$\begin{array}{lll}2.6 & \text { SIRNA } & 13\end{array}$

$\begin{array}{lll}2.7 & \text { Decoy oligonucleotides } & 13\end{array}$

$\begin{array}{lll}2.8 & \text { Antibodies } & 14\end{array}$

$\begin{array}{lll}2.9 & 15\end{array}$

$2.10 \quad$ Sequence analysis tools and software 16

\begin{tabular}{ll}
$3 . \quad$ Methods & 17 \\
\hline
\end{tabular}

$\begin{array}{lll}3.1 & \text { Cell biology } & 17\end{array}$

3.1.1 Culturing of human SMC from thymus veins 17

$\begin{array}{lll}3.1 .2 & \text { Plating and passaging of cells } & 17\end{array}$

$\begin{array}{lll}3.1 .3 & \text { Transfection with siRNA }\end{array}$

3.1.4 Pre-stimulation of hSMC with cytokines and

$\begin{array}{ll}\text { growth factors } & 18\end{array}$

$\begin{array}{lll}3.1 .5 & \text { hSMC cell proliferation } & 18\end{array}$

$\begin{array}{lll}3.1 .6 & \text { Harvesting of cells }\end{array}$ 
3.1.7 Antibody generation 19

$3.2 \quad$ Molecular biology methods 20

3.2.1 PCR 20

3.2.2 Isolation of total RNA 20

3.2.3 Semi-quantitative RT-PCR 20

3.2.4 Sequencing of the PCR product 21

3.2.5 siRNA technique 22

3.2.6 Cloning 22

3.2.6.1 Topo-cloning 22

3.2.6.2 Cloning into pGL3 22

3.2.6.3 Amplification of plasmid 23

3.2.6.3.1 Transformation of competent cells 23

3.2.6.4 Plasmid mini-culture 23

3.2.6.5 Plasmid purification 23

3.2.7 Nucleofection 24

3.2.8 Preparation of decoy oligonucleotides 24

3.2.8.1 Re-hydration of decoy oligonucleotides 24

3.2.8.2 Hybridisation of decoy oligonucleotides 24

3.2.8.3 Decoy oligonucleotide experiments 25

3.2.9 Site-directed mutagenesis 25

3.2.10 Luciferase reporter-gene assays 26

3.3 Protein biochemistry methods 26

3.3.1 Bradford protein assay 26

3.3.2 Ethanol precipitation of protein samples 26

$\begin{array}{lll}\text { 3.3.3 Protein analysis by SDS-PAGE } & 27\end{array}$

3.3.4 Western blot analysis 27

3.3.4.1 Development of membranes 27

3.3.5 Immunoprecipitation (IP) of hSMC 27

3.4 Chromosome immunoprecipitation 28

$3.5 \quad$ Stastical analysis 28

$3.6 \quad$ Buffers and stock solutions 28

3.6.1 Cell biology buffers and stock solutions 28

3.6.2 Protein biochemistry buffers and stock solutions 29

3.6.3 Molecular biology recipies 31 
4. Results 32

4.1

Production of the Zfm1 antibodies

4.3 Proliferation of human vascular smooth muscle cells

4.4 Effects of PDGF and IL-1 $1 /$ TNF $\alpha$ on Zfm1 Protein expression

4.5 Cloning of the Zfm1 promotor

4.5.1 Screening the chromosome 11 BAC clone library

4.5.2 Amplification of Zfm1 promotor fragments

4.6 Generation of the Zfm1 promotor reporter Gene construct

4.7 Analysis of the Zfm1 promotor

4.7.1 PDGF down-regulates Zfm1 promotor Activity

4.7.2 TRANSFAC analysis of the hZfm1 short promoter

Analysis of the Zfm1 promotor with decoy ODN

4.8.2 Zfm1 double deletion construct

4.9 Chromosome immunoprecipitation (ChIP) analysis

4.10 Co-immunoprecipitation of $\mathrm{Zfm} 1$

5. Discussion

5.1 Zfm1 antibodies and Zfm1 siRNA - the development of experimental tools

Zfm1 is involved in the repression of cell proliferation in hSMC 
Decoy ODN characterization of the $\mathrm{Zfm} 1$

Promoter

5.6

Transcription factor binding site characterization using Zfm1 promotor deletion constructs

A role of $\mathrm{Zfm} 1$ in atherosclerosis?

An outlook

6.

Summary 


\section{Abbreviations}

aa

Acc. No.

AP-1

APS

BASMC

bp

cDNA

ChIP

DNA

DMEM

DMSO

dNTP

ds

dODN

ECM

EDTA

EGR-1

EMSA

FCS

FGF-2

GTF

HFM

hSMC

HUVEC

IL-1

$\mathrm{KH}$

LB

LDL

MEN1

MMPs

MCP-1

MCS

mRNA

NFAT amino acid

accession number

activator protein - 1

ammonium persulfate

bovine aortic SMC

base pair

complementary deoxyribose nucleic acid

chromosome immunoprecipitation

deoxyribose nucleic acid

Dulbecco's modified Eagle's medium

Dimethyl sulfoxide

deoxynucleotide triphosphate

double-stranded

decoy oligonucleotide

extracellular matrix

ethylendinitrilo-N, N, N', N'-tetra-acetate

early growth response 1

electro-mobility shift assay

fetal calf serum

basic fibroblast growth factor-2

general transcription factors

histone fold motif

Human smooth muscle cell

Human vascular endothelial cell

interleukin -1

hnRNP K homology

Luria Bertani broth

low density lipoprotein

multiple endocrine neoplasia 1

matrix metalloproteinases

monocyte chemoattractant protein 1

multiple cloning site

messenger ribose nucleic acid

nuclear factor of activated $T$ cells 
NO

NLS

NTD

NTP

$\mathrm{Nt}$

PBS

PCR

PDGF

PIC

pol

PVDF

RNA

RT

RT-PCR

SDS-PAGE

SD

Sf1

SP-1

SiRNA

SMC

SS

$\mathrm{TAF}_{\| \mathrm{S}}$

TBP

TEMED

TF

TLS/FUS

TNFa

Tris

VCAM-1

WT1

Zfm1 nitric oxide

nuclear localisation signal

$\mathrm{N}$-terminal transcription activation domain

nuclear tri-phosphate

nucleotide

phosphate buffered saline

polymerase chain reaction

platelet derived growth factor

pre-initiation complex

polymerase

polyvinylidene fluoride

ribose nucleic acid

room temperature

reverse transcription- polymerase chain reaction

sodium dodecyl sulphate polyacrylamide gel

electrophoresis

standard deviation

splicing factor 1

specificity protein 1

small interfering RNA

smooth muscle cell

single stranded

TATA-binding protein associated factors

TATA-binding protein

$\mathrm{N}, \mathrm{N}, \mathrm{N}$ ', N'-tetramethylethylenediamine

transcription factor

translocated in liposcarcoma

tumour necrosis factor $\alpha$

Tris-(hydroxymethyl)-aminomethan

vascular cell adhesion molecule 1

Willm's tumour 1

zinc finger motif 1 


\section{Atherosclerosis and inflammation}

\subsection{The pathogenesis of atherosclerosis}

Atherosclerosis is a chronic inflammatory disease characterized by the accumulation of lipids and fibrous elements in the vessel wall of large arteries (Ross, 1999 (a) and Plutzky, 2001). Despite lifestyle changes and new pharmacological approaches to lower plasma cholesterol concentrations; cardiovascular disease continues to be the principle cause of death in many industrialized nations (Ross, 1999 (a)).

The response-to-injury hypothesis of atherosclerosis states that the principally protective inflammatory response to vascular injury, followed by a fibroproliferative process, by way of continuous insult, may become excessive (Ross, 1999 (b)); where in which both the inflammatory response and proliferation of the fibrous connective tissue become the disease process.

However, endothelial dysfunction is proposed to be the first step in atherosclerosis. The possible causes are elevated or modified LDLs; free radicals caused by smoking; hypertension; diabetes mellitus and infectious microorganisms such as Chlamydia pneumoniae (Fig. 1a, Ross, 1999 (b)).

The earliest nature of atherosclerotic lesions are called 'fatty streaks' and can be described as purely inflammatory, consisting of only monocyte derived macrophages and $T$ lymphocytes (Fig. 1b). If the inflammatory response does not neutralize or remove offending agents, it can continue indefinitely, leading to migration and proliferation of SMC that eventually combine within the site of injury forming an advanced lesion (Fig. 1c, Lavezzi et al., 2005 and Ross, 1999 (b)). 

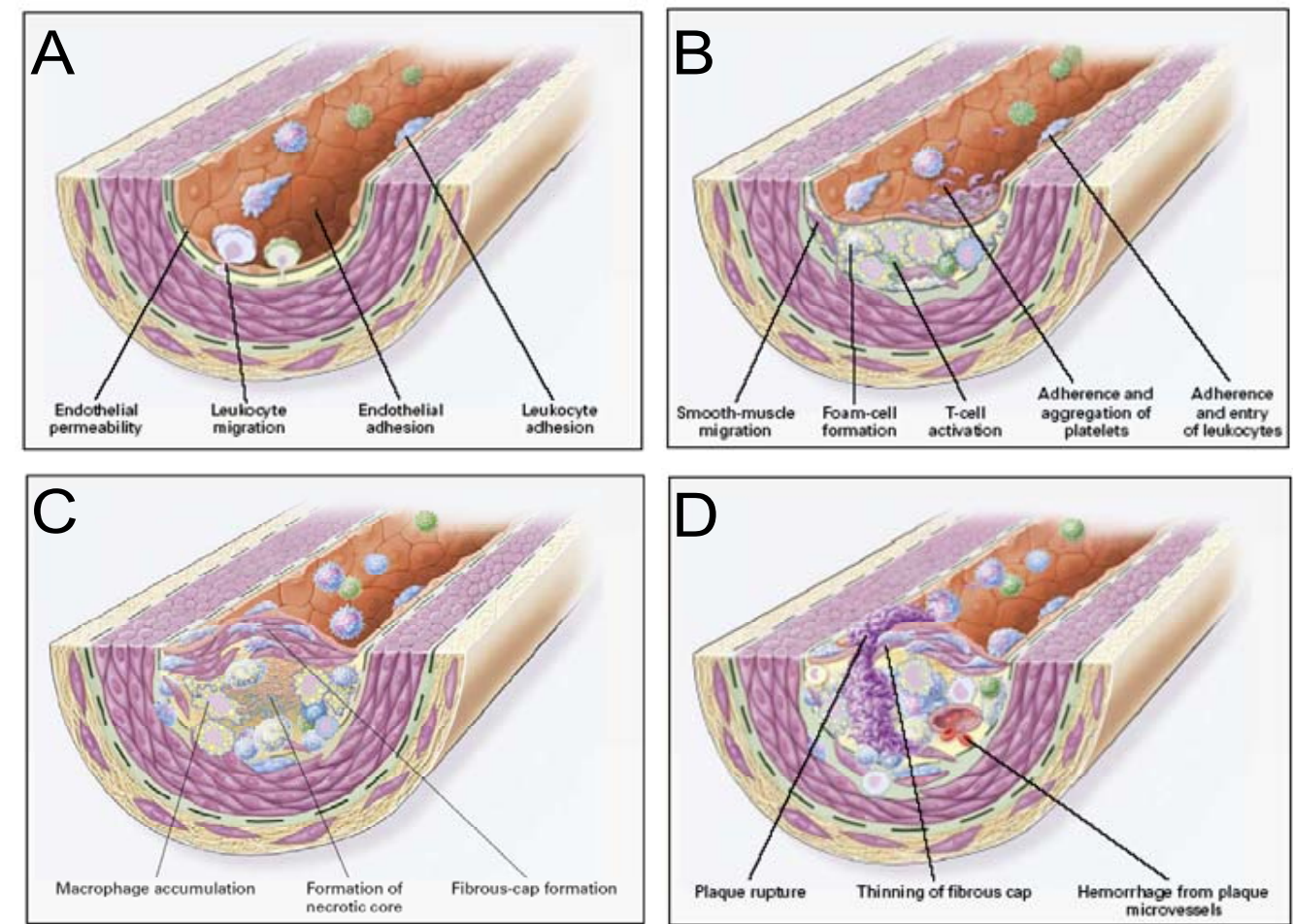

Figure 1. The response-to-injury hypothesis of atherosclerosis (taken from Ross, 1999 (B). A) Endothelial dysfunction - caused by offending agents e.g. increase in plasma LDL concentrations, free radicals and hypertension. B) Fatty streaks - earliest recognizable lesions of atherosclerosis, the aggregation of lipids, macrophages and $\mathrm{T}$ lymphocytes can be observed. C) Advanced lesion - fatty streaks progress to form intermediate/ advanced lesions. A fibrous cap tends to form due to an increase in proliferating SMC mediated by PDGF and pro-inflammatory cytokines. The fibrous cap conceals the lesion from the lumen and represents a 'wound healing response' to the injury. D) Unstable fibrous plaques - where rupture can occur due to thinning of the fibrous cap caused by continuous influx and activation of macrophages and release of metalloproteinases at theses sites; resulting in thrombus formation and occlusion of the artery.

Mediators in response to injury involve a vast number of cytokines implicated in immunity and inflammation along with growth factors implicated in chemotaxis and proliferation (Plutzky, 2001). In cardiovascular disease, these two roles are closely inter-related, where in which the same mediator acts as a pro-inflammatory agent and as a growth factor. Examples of mediators that have such pleiotropic effects are PDGF, IL1 $\beta$, TNF- $\alpha$ and TGF- $\beta$. All these stimuli induce SMC proliferation and are usually not expressed in healthy arteries, but are up-regulated in atherosclerotic lesions (Ross, 1999 (b)).

Whilst IL1 $1 \beta / T N F \alpha$ are released by macrophages at the site of inflammation; on the other hand, PDGF is a potent mitogen and is generally not expressed in normal healthy arteries, but is up-regulated in atherosclerotic lesions. 
These pro-inflammatory cytokines in turn stimulate secondary gene expression of other growth regulatory molecules such as PDGF in endothelial cells; which evidently increase connective tissue proliferation, SMC proliferation and chemotaxis (Pintucci et al., 2005). The dysfunctional endothelium releases more pro-inflammatory cytokines and PDGF, which continues to drive secondary gene expression of PDGF in the endothelium and SMC; leading to long-term stimulatory effects of these cytokines and growth factors on the SMC and endothelium (Ross, 1999. (a)).

An important point to consider is that long-term effects of these cytokines, growth factors and adhesion molecules can lead to changes in gene expression patterns of macrophages and SMC. Thus, the long-lasting phenotypic changes are important for the pathogenesis and disease progression of atherosclerosis (Ross, 1999 (a) and Plutzky 2001).

\subsubsection{Plasticity and phenotypes of SMC}

A principle function of mature vascular SMC is regulation of vascular tone. And like a majority of somatic cells, SMC contain a complete set of genetic material, but express only a sub-set of genes (Owens, 1995). Once vascular SMC are fully mature and differentiated, they proliferate at a very low rate and produce a very small amount of ECM proteins. However, during atherosclerosis vascular SMC phenotypically have accelerated rates of proliferation, and produce a large amount of matrix constituents such as collagen and fibronectin.

Based on the distribution of myosin filaments and formation of large amounts of secretory organelles such as ER and golgi apparatus, at least two different phenotypes of SMC have been described (Ross, 1993). Contractile, fully differentiated SMC respond to agents that induce either vasoconstriction or dilation such as catecholamines or NO. In contrast, SMC in the synthetic phenotypic state are capable of expressing genes for various growth regulatory molecules and cytokines, and can respond to growth factors via expression of appropriate receptors. Numerous observations suggest that $\mathrm{SMC}$ in atherosclerotic lesions have changed from a contractile to a synthetic phenotype (Ross, 1993 (b)). Thus, phenotypic changes can 
lead to extreme effects on the capacity of cells within an atherosclerotic lesion to respond to various agonists. Since SMC plasticity is important under normal physiological conditions, and the contractile phenotype is essential for haemodynamic stability of the vessel wall, it would be important to discover genes essential in maintaining the contractile phenotype of vascular SMC.

\subsection{Structure and functions of the Sf1/Zfm1 gene}

Cattaruzza et al. (2002) have previously shown that stimulating rat SMC with pro-inflammatory cytokines or PDGF leads to a decrease in Zfm1/Sf1 gene expression, an increase in cell proliferation both in vitro and in vivo, as well as an up-regulation of pro-inflammatory gene products. This data suggests that $\mathrm{Zfm} 1$ may play a role in preventing the pathogenesis of atherosclerosis, by repressing pro-inflammatory gene expression in vascular SMC, stabilizing the differentiated state of these cells.

Zinc Finger Motif 1 (Zfm1), also known as Splicing Factor 1 (Sf1) was first cloned as a nuclear protein at a locus linked to Multiple Endocrine Neoplasia Type 1 (MEN1), within the region q13 of chromosome 11 (Toda et al., 1994). The Zfm1/ Sf1 gene spans approximately $15 \mathrm{~kb}$ which consists of 14 exons and encodes a protein comprising approximately 623 amino-acids. Two major splice variants of Zfm1 exist: Zfm1 A $70 \mathrm{kDa}$ and Zfm1 E $55 \mathrm{kDa}$ which differ in length of the C-terminal proline rich region (Fig. 2; Toda et al., 1994 and Arning et al., 1996). The first functional characterization of $\mathrm{Zfm} 1 / \mathrm{Sf} 1$ was made by Kramer et al. (1992) following purification of Zfm1 as a heat stable protein from HeLa cells, and revealed its ability to function as a kinetic factor in the assembly of the ATP dependent pre nuclear-mRNA splicing complex (Guth et al., 2000, Liu et al., 2001, Covini et al., 1999). 


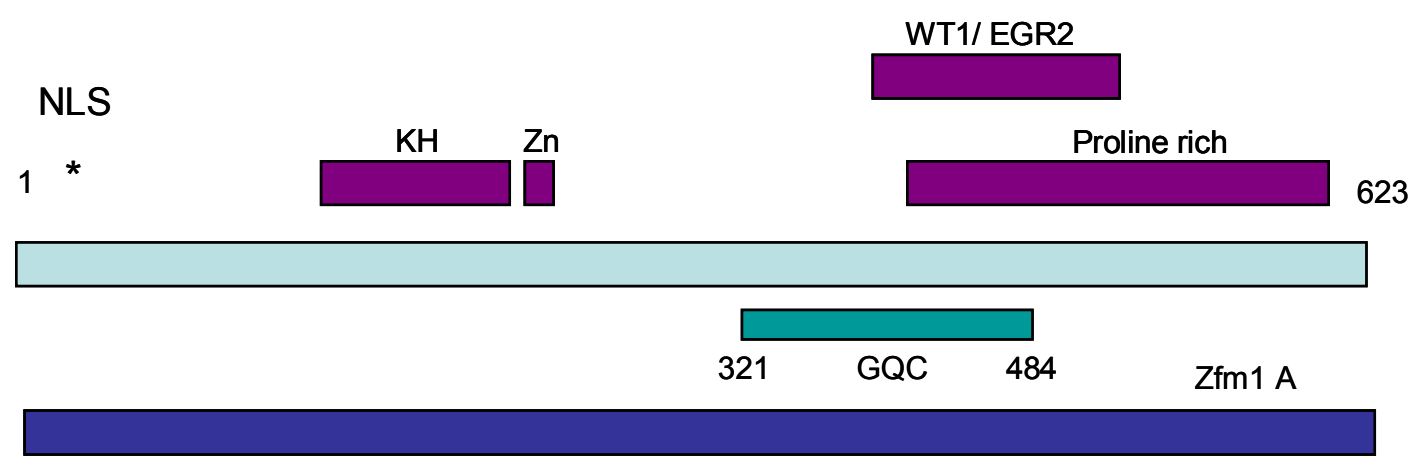

Zfm1 E

Figure 2. Schematic representation of the domains of $\mathrm{Zfm} 1 / \mathrm{Sf} 1$. The protein domains of $\mathrm{Zfm} 1 / \mathrm{Sf} 1$ consists of a $\mathrm{C}$-terminal proline rich domain, a zinc knuckle and a hnRNP K homology $(\mathrm{KH})$ domain both of which are implicated in binding nucleic acid and a putative nuclear localization signal (NLS) at the $\mathrm{N}$-terminus (Berglund et al., 1998). Additionally a GQC-interaction domain exists that recognizes sequences rich in glutamine, glycine, serine and threonine. A functionally important region homologous to Willms tumour 1 suppressor (WT1) gene and the early growth response (Egr-2) gene also exists

A second function of $Z \mathrm{fm} 1 / \mathrm{Sf1}$ (defined in sea urchins) was its ability to be a repressor of the stage specific activator protein (SSAP) transcription factor which is essential for embryogenesis (Fig. 2; Zhang et al., 1998 (a)). Zfm1 repression of SSAP requires both a repression domain found in the $\mathrm{N}$ terminus consisting of 137 amino acids as well as the GQC-interaction region.

A human protein homologous to SSAP is EWS, known to be involved in cellular transformation in Ewing's sarcoma tumours. EWS contains an $\mathrm{N}$ terminal transcription activation domain (NTD) which resembles that of SSAP in amino acid sequence (Zhang et al., 1998 (a)). Interestingly, Zhang et al. have also shown that Zfm1/Sf1 represses EWS through an interaction between a region of 37 amino acids situated within the NTD of EWS. Two other proteins, translocated in liposarcoma (TLS/FUS) and the human TBPassociated factor 68 (hTAF $\left.\mathrm{h}_{11} 68\right)$ have extensive homology to EWS and also interact with Zfm1. Both EWS and TLS/FUS are human pro-oncoproteins and products of genes which are commonly translocated in human sarcomas (Ladomery et al., 2002 and Lee et al., 2004). EWS/TLS/hTAF „68 
are also present in the basal transcription machinery, more commonly in distinct TFIID complexes (see below; Bertolotti et al.,1996).

\subsection{Regulation of gene transcription}

\subsubsection{Basal transcription machinery}

Gene transcription can be divided into several functional sequences of events that include promoter recognition and binding, assembly of the preinitiation complex (PIC), RNA chain initiation, RNA chain elongation and finally termination of RNA synthesis. In higher eukaryotes, transcription initiation at promoters recognized by RNA polymerase II (RNA pol II) is carried out by the ordered binding of general transcription factors (GTFs) and the RNA polymerase core subunits; recruitment of Srb/Med proteins allow RNA polymerases to respond to activators or repressors (Gaston et al., 2003). GTFs are initially recruited to promoters in an ordered fashion, and aid RNA polymerase binding to promoter DNA. The first GTF to bind is TFIID which is a complex containing TATA box-binding protein (TBP) and up to 13 TBP-associated factors $\left(T_{A F} \mid{ }^{S}\right)$. Assembly of GTFs forms the PIC, which can initiate transcription and transcription elongation in the presence of nuclear tri-phosphates (NTPs) (Gaston et al., 2003). A low level of transcription directed by these proteins is also known as basal transcription, but activated transcription levels require the presence of $\mathrm{TAF}_{\| \mathrm{S}}$ where different transcriptional activation domains, present in members of the multisubunit TFIID complex, interact with distinct TAF ${ }_{\| S}$ (Bertolotti et al., 1996). $\mathrm{TAF}_{\| S}$ can also function as co-activators for upstream DNA-binding TFs, and can recognize different elements such as Srb/Med proteins and/ or interact with other transcriptional activators, depending on their TFIID-TAF composition. Thus, specific stimuli may possibly drive transcriptional levels higher, via directing assembly of distinct $\mathrm{TAF}_{\|} \mathrm{S}$ at the basal transcriptional level.

\subsection{2 $\mathrm{TAF}_{\|} \mathrm{S}$ can define functionally distinct TFIID complexes}

Association of Zfm1/Sf1 with $\mathrm{hTAF}_{\| 68 / E W S / T L S}$ implies that normal cellular function of $Z \mathrm{fm} 1 / \mathrm{Sf} 1$ may be to negatively modulate transcription of target genes specifically coordinated by these cofactors (Zhang et al., 1998 (b)) 
(Fig. 3). A few examples of $T A F_{\| S}$ that define functionally distinct TFIID complexes are $\mathrm{hTAF}{ }_{\|} 68$ and $\mathrm{hTAF}_{\|} 80 \delta$. $\mathrm{hTAF}_{\|} 68$ can bind RNA and single stranded (ss) DNA homologous with the TLS/FUS and EWS binding sites. It has also been shown that $\mathrm{hTAF}_{\|} 68$ can enter the PIC together with RNA polymerase II (Bertolotti et al., 1996). TLS/FUS is further associated with a sub-population of TFIID complexes which are distinct from those containing hTAF ॥68 (Bertolotti et al., 1996) and therefore, it is possible that TLS/FUS and EWS may play specific roles during transcription initiation at distinct promoters.

Another interesting discovery was the linkage of apoptotic signaling pathways to TFIID function via an $\mathrm{hTAF}_{\|} 80$ isoform termed ' $\mathrm{hTAF} \mathrm{F}_{\|} 80 \mathrm{\delta}$ ', which differs from $\mathrm{hTAF}_{\|} 80 \delta$ due to a 10-amino acid (aa) deletion (Bell et al., 2001). It was shown that $\mathrm{hTAF}_{\|} 80 \delta$ could form distinct TFIID complexes lacking $\mathrm{hTAF}_{\|} 31$ under apoptotic stimuli. Moreover, an increase in expression of $\mathrm{hTAF}_{\|} 80 \delta$ could trigger apoptosis and induce expression of pro-apoptotic target genes such as gadd45 and p21. Thus, $\mathrm{hTAF}_{\|} 80 \delta$ can couple apoptotic signals in order to reprogram RNA polymerase II transcription at the 'transcriptome' level. Therefore, $\mathrm{TAF}_{\| S}$ may define disctinct TFIID complex formation and function under specific stimuli, and transcription itself is globally regulated at the so-called 'basal transcription machinery'. 


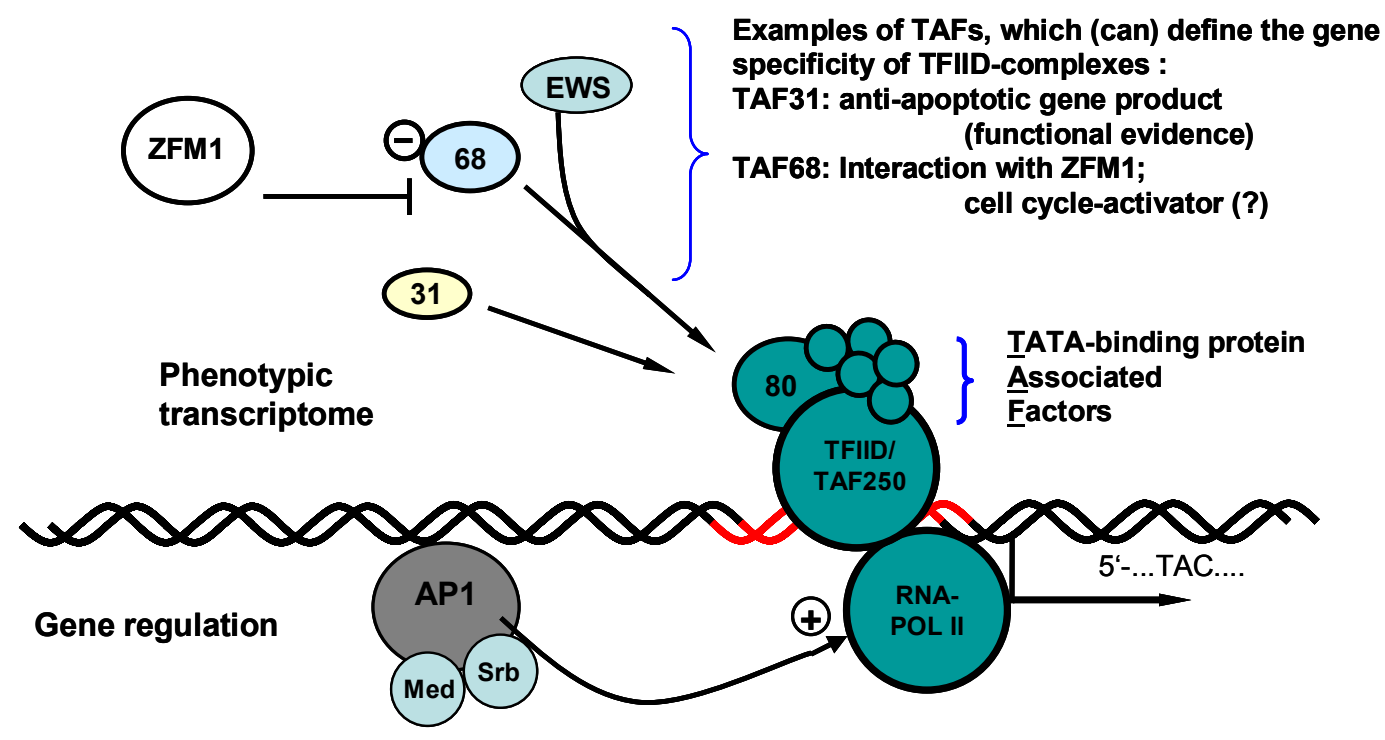

Figure 3. Phenotypic 'transcriptome' regulation of gene expression. Figure represents a schematic model of $\mathrm{TAF}_{\|} \mathrm{S}$ that may be able to define the formation of distinct TFIID complexes at the basal transcriptional level and how $\mathrm{Zfm} 1 / \mathrm{Sf} 1$ may play a role as a modulator of transcription.

\subsection{Aims of the study}

Taking into account the previous findings, Zfm1/Sf1 seems to be important in maintaining the phenotype of non-proliferating by-stander cells by acting as a 'brake' on the expression of pro-inflammatory gene products. The first aim of this study was to observe if pro-inflammatory cytokines more specifically IL-1 $\beta$ plus TNFa and PDGF have a similar effect on Zfm1/Sf1 gene expression in human vascular SMC; whether an increase in cell proliferation can be observed and whether the function of $\mathrm{Zfm} 1$ observed in rSMC holds true for human vascular SMC (see Fig. 4 below). The second aim was to characterize the human $\mathrm{Zfm} 1 / \mathrm{Sf} 1$ promotor and to understand how the human $\mathrm{Zfm} 1 / \mathrm{Sf} 1$ gene is regulated under pro-inflammatory conditions in hSMC. In this context, regions of the promoter essential for transcription factor (TF) binding should be identified, as well as the stimulus and signaling pathway responsible for Zfm1/Sf1 gene expression. 


\section{PDGF, IL1 $\beta$, TNF $\alpha$ ?}

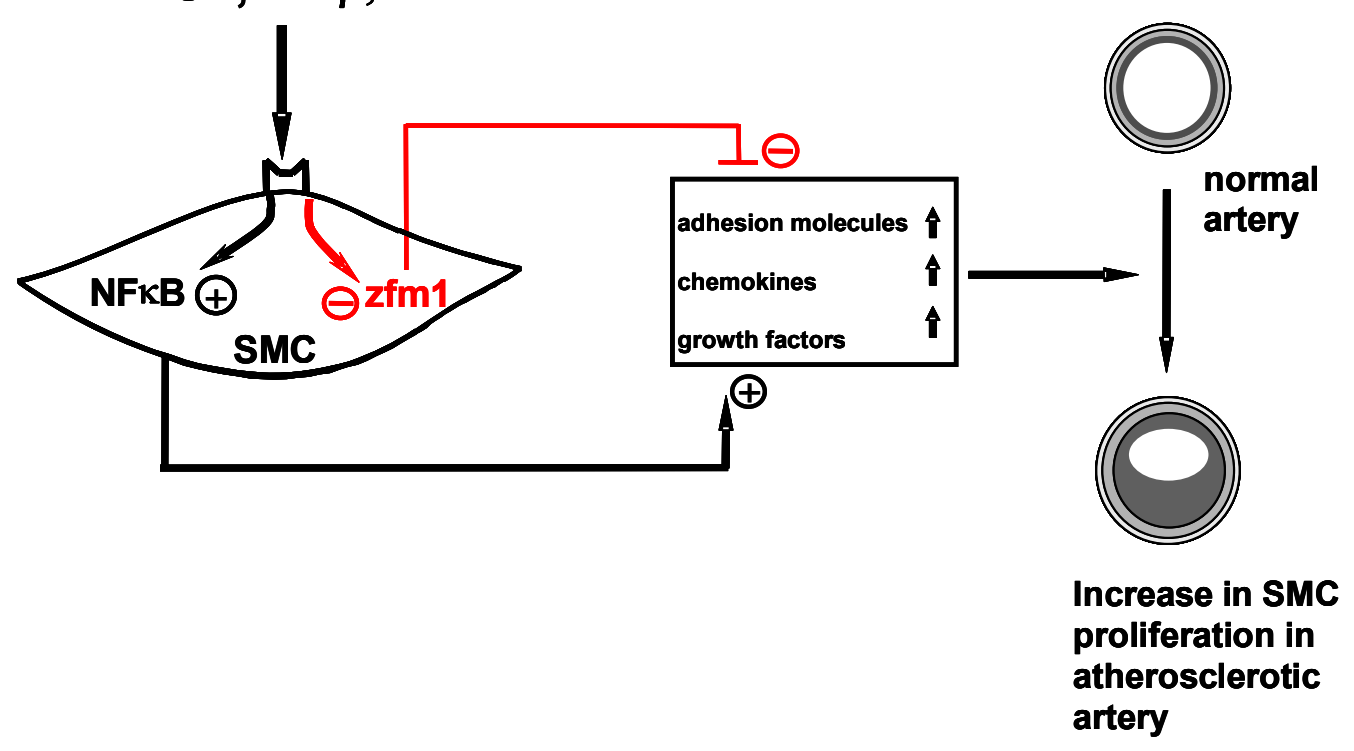

Figure 4. A schematic diagram of how PDGF or pro-inflammatory cytokines such as IL $1 \beta / T N F \alpha$ may play a role in the pathogenesis of atherosclerosis. Expression of Zfm1/Sf1 may act as a 'brake' on the expression of various proinflammatory gene products; whose expression under pro-inflammatory stimuli may contribute to the fibroproliferative remodeling of the vessel wall in atherosclerosis.

Previously published data by Zhang et al. $(1998$, b) show that Zfm1 interacts

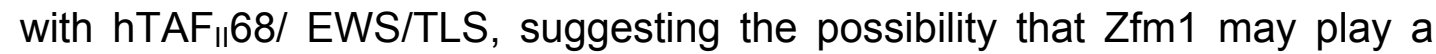
role in directing the formation of a functional phenotypic 'transcriptome' under pro-inflammatory cytokine and/or PDGF stimulation. Zfm1 may thus negatively modulate the transcription of certain target genes, specifically co-

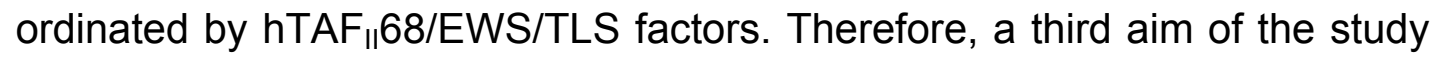
was to understand the function of Zfm1 by investigating whether Zfm1 interacts with other distinct $\mathrm{hTAF}_{\|} \mathrm{S}$ such as $\mathrm{hTAF}_{\|} 80$ or $\mathrm{hTAF}_{\|} 31$.

If successful, this study should provide new insights into Zfm1/Sf1 gene expression, function and stabilization of phenotype in human vascular SMC. It would thus contribute to a new understanding of how vascular SMC maintain their contractile, non-proliferative phenotype, paving the way towards reduction of fibroproliferative remodeling of the vessel wall, and slowing down progression of atherosclerosis and its complications. 


\section{Materials}

\subsection{Bacteria}

Bacterial strains used for cloning and maintenance of plasmids constructs are listed in Table 2.1

Table 2.1 Bacterial E. coli strains.

\begin{tabular}{|c|c|c|}
\hline Strain & Company & Genotype \\
\hline Top $10 \mathrm{~F}$ & Invitrogen & 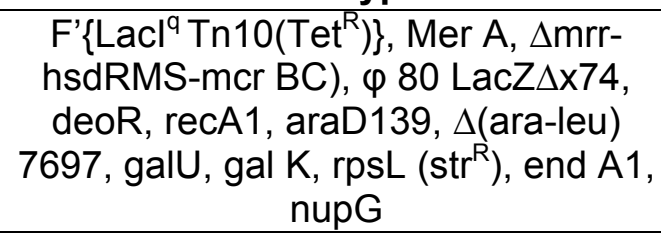 \\
\hline XL 1 Blue & Stratagene & $\begin{array}{c}\text { RecA1, endA1, gyr } \Delta 96 \text {, thi-1, hsdR17, } \\
\text { supE44, relA1, lac[F' proAB lacl }{ }^{\mathrm{q}} \\
\left.\text { Z } \Delta \mathrm{M} 15 \operatorname{Tn} 10\left(\text { Tet }^{\mathrm{R}}\right)\right]\end{array}$ \\
\hline
\end{tabular}

\subsection{Plasmid Vectors}

Table 2.2 Plasmid vectors

\begin{tabular}{|c|c|c|}
\hline Vector & Properties & Company \\
\hline $\begin{array}{c}\text { pCR } 2.1-T o p o ® \\
3.9 \mathrm{~Kb}\end{array}$ & $\begin{array}{c}\text { pUC origin, Ampicillin \& Kanamycin } \\
\text { resistance genes, lacZa reporter, T7 } \\
\text { RNA polymerase promoter, TA } \\
\text { cloning site. }\end{array}$ & Invitrogen \\
\hline pGL3 Basic & $\begin{array}{c}\text { ColE1 origin, Ampicillin \& } \\
\text { Kanamycin resistance genes, } \\
\text { luciferase gene (luc+). }\end{array}$ & Promega \\
\hline
\end{tabular}




\subsection{Primers}

Table 2.3 Primers

\begin{tabular}{|c|c|c|l|}
\hline \multicolumn{3}{|c|}{ A. Primers for cloning } \\
\hline $\begin{array}{c}\text { Primer } \\
\text { name }\end{array}$ & $\begin{array}{c}\text { Expected } \\
\text { fragment } \\
\text { length (bp) }\end{array}$ & $\begin{array}{c}\text { Annealing } \\
\text { temperature }\end{array}$ & \multicolumn{1}{c|}{ Primer (forward/ reverse) } \\
\hline Primer 1 & 2999 & $60^{\circ} \mathrm{C}$ & $\begin{array}{l}\text { AGCTGGGCATGATGGCAGGTGG } \\
\text { TGCGGCGGCGGGTACGAG }\end{array}$ \\
\hline Primer 2 & 1500 & $58^{\circ} \mathrm{C}$ & $\begin{array}{l}\text { CACCCAACTCCCTTTGCCTCTC } \\
\text { AGCCAGCGTGTTCCGATTCC }\end{array}$ \\
\hline Primer 3 & 860 & $58^{\circ} \mathrm{C}$ & $\begin{array}{l}\text { CACCGTGTTGGTCAGGTTGG } \\
\text { CTCTCTCGGCCCGACTCACCTTC }\end{array}$ \\
\hline Primer 4 & 670 & $58^{\circ} \mathrm{C}$ & $\begin{array}{l}\text { CGCGTTTGCTCCATCTACGCATGCGCAA } \\
\text { GGCGCCCCCGGGGACAG }\end{array}$ \\
\hline
\end{tabular}

\begin{tabular}{|c|c|c|c|}
\hline \multicolumn{2}{|c|}{ B. Primers for RT-PCR } \\
\hline Gene product & $\begin{array}{c}\text { Expected } \\
\text { fragment } \\
\text { length (bp) }\end{array}$ & $\begin{array}{c}\text { Annealing } \\
\text { temperature }\end{array}$ & Primer (forward/ reverse) \\
\hline GAPDH & 581 & $58^{\circ} \mathrm{C}$ & $\begin{array}{l}\text { TCACCATCTTCCAGGAGCG } \\
\text { CTGCTTCACCACCTTCTTGA }\end{array}$ \\
\hline $\mathrm{Zfm} 1$ & 100 & $58^{\circ} \mathrm{C}$ & $\begin{array}{l}\text { CACCCAACTCCCTTTGCCTCTC } \\
\text { AGCCAGCGTGTTCCGATTCC }\end{array}$ \\
\hline
\end{tabular}

\begin{tabular}{|c|c|l|}
\hline \multicolumn{2}{|l|}{ C. Primers for sequencing } \\
\hline Name of primer & Vector & \multicolumn{1}{|c|}{ Primer sequence (5'-3') } \\
\hline T7 Forward & 2.1 Topo ${ }^{\prime}$ & CCAGCACTTTGACAGGC \\
\hline SP6 Reverse & 2.1 Topo $®$ & GCCTGTCAAAGTGCT \\
\hline RV3 Forward & pGL3 Basic & CTAGCAAAATAGGCTGTCCC \\
\hline GL2 Reverse & pGL3 Basic & GGAAGACGCCAAAAACATAAAG \\
\hline
\end{tabular}


Table 2.3

D. Primers for mutagenesis and ChIP-analysis

\begin{tabular}{|c|c|c|}
\hline Primer name & Mutation site & Primer sequence (forward/ reverse) \\
\hline$\Delta 1$ & -191 to -186 & $\begin{array}{l}\text { CCCCGGTCCCGCCGGCCCGCCCCCGCGGTGC } \\
\text { GCACCGCGGGGGCGGGCCGGCGGGACCGGGG }\end{array}$ \\
\hline$\Delta 2$ & -179 to -174 & $\begin{array}{l}\text { CGCCCCCGGCCCGCGGTGCCCTCTCTCC } \\
\text { GGAGAGAGGGCACCGCGGGCCGGGGGCG }\end{array}$ \\
\hline Double Mutant & $\begin{array}{l}-191 \text { to }-186 \\
-179 \text { to }-174 \\
\end{array}$ & $\begin{array}{l}\text { CCCCGGTCCCGCCGGCCCGCGGTGCCCTCTC } \\
\text { GAGAGGGCACCGCGGGCCGGCGGGACCGGGG }\end{array}$ \\
\hline ChIP 1 & -216 to -193 & $\begin{array}{l}\text { CTCAGTTCACGCAGTAACAAATG } \\
\text { CGGCGGCTTCTCCTTCGCAAG }\end{array}$ \\
\hline ChIP 2 & -173 to -152 & $\begin{array}{l}\text { TCCCAGCCCACCGAACTCCGC } \\
\text { AAGGCACCGGCACCTGCTTTTC }\end{array}$ \\
\hline
\end{tabular}

\subsection{Enzymes}

All restriction enzymes were purchased from NEB GmbH (Frankfurt am Main, Germany). Various DNA polymerases were used according to the application (the polymerase used in each application is detailed in Methods) and were purchased from GeneCraft (Lüdinghausen, Germany) and Stratagene (Amsterdam Zuidoost, The Netherlands). T4 ligase \& Calf intestinal alkaline phosphatase were purchased from Fermentas MBI (St. Leon-Rot, Germany). 


\subsection{Cell Culture}

Table 2.5 Medium and substances for cell culture

\begin{tabular}{|c|c|}
\hline Medium and substance & Company \\
\hline SMC growth medium & Promocell (Karlsruhe, Germany) \\
\hline DMEM & Life Technologies (Karlsruhe, Germany) \\
\hline $0.05 \%$ Trypsin/ 0.2\% EDTA & Life Technologies \\
\hline Penicillin & Life Technologies \\
\hline Streptomycin & Life Technologies \\
\hline FCS & Life Technologies \\
\hline Heparin & Sigma-Aldridge (Deisenhofen, Germany) \\
\hline Gelatine & Sigma-Aldridge \\
\hline Collagenase & Sigma-Aldridge \\
\hline
\end{tabular}

\subsection{SIRNA}

All ds siRNAs were purchased from Dharmacon RNA technologies (Lafayette, CO, USA)

Table 2.6

\begin{tabular}{|c|c|}
\hline Name & \multicolumn{1}{|c|}{ Sequence $\left(\mathbf{5}^{\prime} \mathbf{-} \mathbf{3}^{\prime}\right.$ ) } \\
\hline Zfm1 Sense & CAG AAG ACA GUG AUU CCA G.dT.dT \\
\hline Zfm1 anti-sense & CUG GAA UCA CUG UCU UCU G.dT.dT \\
\hline
\end{tabular}

\subsection{Decoy oligonucleotides}

Decoy oligonucleotides used for decoy experiments are listed in table 2.7. Sequence specific decoys were manufactured by Eurogentec (Seraign, Belgium). 
Table 2.7 Decoy oligonucleotides

\begin{tabular}{|c|c|}
\hline Name of decoy & Sequence (forward/ reverse) \\
\hline EGR1 & $\begin{array}{l}G^{*} G^{*} A^{*} \text { TCCAGCGGGGGCGAGCGGGGG }{ }^{*} C^{*} G^{*} A \\
T^{*} C^{*} G^{*} C \text { CCCCGCTCGCCCCCGCTGGA }{ }^{*} T^{*} C^{*} C\end{array}$ \\
\hline SP1 & $\begin{array}{l}A^{*} T^{*} T^{*} \text { CGATCGGGGCGGGGCG }{ }^{*} A^{*} G^{*} C \\
G^{*} C^{*} T^{*} \text { CGCCCCGCCCCGATCG }{ }^{*} A^{*} A^{*} T\end{array}$ \\
\hline NFAT & 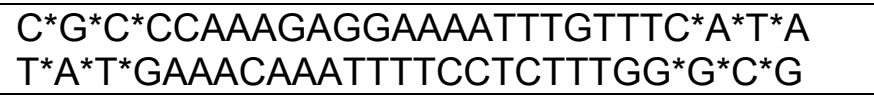 \\
\hline Scrambled & $\begin{array}{l}G^{*} C^{*} G^{*} \text { AGTGCGAGCGTGCGAG }{ }^{*} T^{*} G^{*} C \\
G^{*} C^{*} A^{*} C T C G C A C G C T C G C A C T^{*} C^{*} G^{*} C\end{array}$ \\
\hline
\end{tabular}

\subsection{Antibodies}

All antibodies used for protein detection are listed in Table 2.8. In the case of

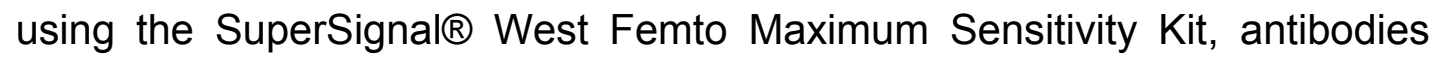
specifically for this kit were used according to the manufacturer's instructions.

Table 2.8 Antibodies used for protein dection

\begin{tabular}{|c|c|}
\hline Name & Source \\
\hline Zfm1 rabbit polycolonal & $\begin{array}{c}\text { Custom made by: Sigma-Genosys (Sigma- } \\
\text { Aldridge, Haverhill, UK). See results: } 4.1 .\end{array}$ \\
\hline $\begin{array}{c}\text { B-Actin mouse monoclonal } \\
\text { hTAF } 80 \text { mouse } \\
\text { monoclonal }\end{array}$ & Abcam plc. (Cambridge, UK) \\
\hline $\begin{array}{c}\text { hTAF } 68 \text { mouse } \\
\text { monoclonal }\end{array}$ & Prof. L. Tora (Strasbourg, France) \\
\hline Anti-Rabbit A6154 & Prof. L. Tora (Strasbourg, France) \\
\hline Anti-Mouse A5278 & $\begin{array}{c}\text { Santa Cruz Biotechnology Inc. (Heidelberg, } \\
\text { Germany) }\end{array}$ \\
\hline
\end{tabular}

\section{$2.9 \quad$ Kits}

All kits used are outlined in Table 2.9. 
Table 2.9 Kits used throughout this project

\begin{tabular}{|c|c|}
\hline \multicolumn{2}{|l|}{ A. Nucleic acid purification } \\
\hline Name & Source \\
\hline QIAQuick® Gel Extraction & Qiagen (Hilden, Germany) \\
\hline QIAPrep® Spin Miniprep Kit & Qiagen \\
\hline Endofree® Plasmid Maxi Kit & Qiagen \\
\hline RNeasy® Mini Kit & Qiagen \\
\hline
\end{tabular}

\begin{tabular}{|c|c|}
\hline \multicolumn{2}{|l|}{ B. PCR cloning kits } \\
\hline Name & Source \\
\hline Topo TA Cloning® Kit & Ínvitrogen (Karlsruhe, Germany) \\
\hline DNA Blunting and Ligation & Fermentas MBI (St. Leon-Rot, Germany) \\
\hline
\end{tabular}

\begin{tabular}{|c|c|}
\hline C. Cell biology \\
\hline Name & Source \\
\hline CyQuant $\circledast$ Cell Proliferation & Molecular Probes (Eugene, OR, USA) \\
\hline RNAifect $₫$ & Qiagen (Hilden, Germany) \\
\hline Human AoSMC & Amaxa GmbH (Cologne, Germany) \\
\hline Luciferase Assay Kit & Promega (Mannheim, Germany) \\
\hline
\end{tabular}

\begin{tabular}{|c|c|}
\hline \multicolumn{2}{|l|}{ D. Mutagenesis } \\
\hline Name & Source \\
\hline QuikChange Site-directed & $\begin{array}{c}\text { Stratagene (Amsterdam Zuidoost, The } \\
\text { Netherlands) }\end{array}$ \\
\hline
\end{tabular}

\begin{tabular}{|c|c|}
\hline \multicolumn{2}{|l|}{ E. Protein detection } \\
\hline Name & Source \\
\hline SuperSignal® West Femto & Pierce (Perbio Science GmbH, Bonn, Germany) \\
\hline SuperSignal $₫$ West Pico & Pierce \\
\hline
\end{tabular}

F. Chromosome immunoprecipitation

\begin{tabular}{|c|c|}
\hline Name & Source \\
\hline ChIP-IT ${ }^{\mathrm{TM}}$ Enzymatic & Active Motif (Active Motif, Rixensart, Belgium) \\
\hline
\end{tabular}




\subsection{Sequence analysis tools \& software}

Table 2.10 Software and sequence analysis tools

\begin{tabular}{|c|c|c|}
\hline \multicolumn{3}{|l|}{ A. Software } \\
\hline Program & Use & Reference \\
\hline GeneRunner & Primer design & Hastings Software Inc. \\
\hline InStat@ version 3.0 & Statistical analysis & Graph Pad Software Inc. \\
\hline One D Scan $®$ & $\begin{array}{c}\text { Densitometry } \\
\text { analysis }\end{array}$ & Scanalytics \\
\hline Photo Finish $®$ & Imaging system & Wordstar \\
\hline $\begin{array}{l}\text { SoftMax Pro® } \\
\text { version 1.3.1 }\end{array}$ & $\begin{array}{c}\text { Fluoro-imaging } \\
\text { analysis }\end{array}$ & Molecular Devices Corporation \\
\hline
\end{tabular}

\begin{tabular}{|c|c|c|}
\hline \multicolumn{3}{|c|}{ B. Online sequence analysis servers } \\
\hline Program & Use & Reference \\
\hline $\begin{array}{l}\text { SDS Biology } \\
\text { Workbench }\end{array}$ & $\begin{array}{c}\text { Multiple } \\
\text { sequence } \\
\text { alignments }\end{array}$ & http://www.workbench.sdsc.edu/ \\
\hline Webcutter & Restriction Maps & http://www.medkem.gu.se/cutter \\
\hline BLAST & $\begin{array}{c}\text { Finding similar } \\
\text { sequence }\end{array}$ & http://www.ncbi.nlm.nih.gov/BLAST/ \\
\hline ClustalW & $\begin{array}{c}\text { Multiple } \\
\text { sequence } \\
\text { alignments }\end{array}$ & http://www.ebi.ac.uk/clustalw/ \\
\hline Genomatix & $\begin{array}{l}\text { TF binding site } \\
\text { analysis }\end{array}$ & http://www.Genomatix.de/shop/index.html \\
\hline
\end{tabular}




\section{Methods}

\subsection{Cell biology methods}

\subsubsection{Culturing of human SMC from thymus veins}

Smooth muscle cells were obtained from the thymus of young children undergoing heart surgery. Parents of all young children had given their written and informed consent prior to the surgical procedure. The consent was approved by the Local Ethical Committee (Ethics document number 13/5/01). Small veins were excised from the organ, freed of adjacent fat and connective tissue and transferred to a $60 \mathrm{~mm}$ Petri dish containing $250 \mu \mathrm{l}$ of $1 \%$ collagenase solution and $1.4 \mathrm{ml}$ DMEM medium with $5 \%$ FCS. Petri dishes were placed in an incubator at $37^{\circ} \mathrm{C}$ with $5 \% \mathrm{CO}_{2}$ to allow hydrolysis of the extra cellular matrix overnight (14-16 h). Isolated cells were then centrifuged for $5 \mathrm{~min}$ at $1000 \mathrm{rpm}$ and ambient temperature; the cell sediment was re-suspended in 2-3 $\mathrm{ml}$ of SMC growth medium and allowed to adhere to a Petri dish previously coated with $2 \%$ gelatine. The medium was changed every 2 days thereafter.

\subsubsection{Plating and Passage of cells (enzymatic hydrolysis)}

After reaching 90-100 \% confluence (approximately after 5-6 days), cells were passaged or plated into a 24 well plate. Cells were washed with serum free DMEM medium, incubated with trypsin/EDTA ( $5 \mathrm{~min}, 37^{\circ} \mathrm{C}, 5 \% \mathrm{CO}_{2}$ ), re-suspended in $15 \%$ serum DMEM and spun at $1000 \mathrm{rpm}$ for $5 \mathrm{~min}$. Thereafter, the supernatant was carefully removed and cells were resuspended in $5 \mathrm{ml} 1 \%$ serum DMEM and counted using a haemocytometer. Calculation for cell counting proceeded as follows:

$$
\begin{array}{ll}
\mathrm{C}=\mathrm{N} \times 10^{4} \quad \text { where } \quad \mathrm{C} & =\text { cells per } \mathrm{ml} \\
\mathrm{N} & =\text { cells counted } \\
10^{4} & =\text { volume conversion factor for } 1 \mathrm{~mm}^{2}
\end{array}
$$

Total yield $=\mathrm{C} \times \mathrm{V}$ where $\quad \mathrm{V}=$ total volume of cells $(\mathrm{ml})$

For the experiments described, cells of passage 3 to 4 were used throughout. 


\subsubsection{Transfection with siRNA}

Two wells of a 6-well plate of hSMC 80-90\% confluence were transfected with siRNA as listed in Table 2.6 (the antisense sequence was annealed prior to use, see 3.2.5) and two wells with a mock transfection (no RNAi) using the RNAifect Kit according to the manufacturers instructions. Cells were kept in an incubator $\left(37^{\circ} \mathrm{C}, 5 \% \mathrm{CO}_{2}\right)$ for 2 days.

RNAifect transfection mix (for 1 well in a 6 -well plate. Concentration of RNAi used according to the manufacturers instructions)

$\begin{array}{lccccc} & \text { RNAi } & & \text { EC-Buffer } & \text { Transfection Reagent } \\ \text { siRNA } & 5 \mu \mathrm{g} & + & \text { up to } 100 \mu \mathrm{l} & + & 15 \mu \mathrm{l} \\ \text { Mock } & - & + & 100 \mu \mathrm{l} & + & 15 \mu \mathrm{l}\end{array}$

\subsubsection{Pre-stimulation of hSMC with cytokines and growth factors}

Cells were stimulated with cytokines (see 3.1 .5 ) of a $1: 1$ mix of IL-1 $\beta$ and TNFa $\left(6 \times 10^{3}\right.$ and $1 \times 10^{3}$ units/ $\mathrm{ml}$ respectively, both from R\&D systems) or with PDGF (60 units/ ml R\&D systems). For one well of a 6-well plate $2 \mu \mathrm{l}$ was added to a media volume of $2 \mathrm{ml}$. For one well of a 24-well plate, $0.5 \mu \mathrm{l}$ was added to a media volume of $500 \mu \mathrm{l}$. The plates were kept in an incubator $\left(37^{\circ} \mathrm{C}, 5 \% \mathrm{CO}_{2}\right)$ for up to 7 days and the medium was replaced with fresh DMEM containing $1 \%$ serum every two days.

\subsection{5 hSMC cell proliferation assay}

Cattaruzza et al. 2002 showed that transfection of siRNA into rSMC and stimulation with pro-inflammatory cytokines IL-1 $\beta / T N F \alpha$ or PDGF increased cell proliferation, along with up-regulation of adhesion molecules VCAM-1 and MCP-1. The following hSMC cell proliferation assays were performed to test the effect of siRNA on cell proliferation under PDGF or cytokine stimulation in hSMC.

15,000 cells per well were seeded in a 24 -well plate in $1 \%$ serum DMEM. Cells were incubated $\left(37^{\circ} \mathrm{C}, 5 \% \mathrm{CO}_{2}\right)$ for 6 hours before cells were 
transfected with siRNA. After 4 days, cell proliferation was measured using the CyQuant ${ }^{\circledR}$ cell proliferation assay kit according to the manufacturer's instructions. Thereafter, lysed cell samples were transferred to a 96-well microplate and the level of fluorescence was read using the Fmax Fluorescent Micro plate Reader ${ }^{\circledR}$ (Molecular Devices Corp.) and results were analysed using the Softmax Pro ${ }^{\circledR}$ version 1.3.1 program.

\subsubsection{Harvesting of cells}

Medium was removed from the wells and cells were washed twice with icecold PBS. One $\mathrm{ml}$ of PBS was added to the wells and the cells were scraped off with a cell scraper. They were then transferred to Eppendorf tubes and kept on ice. Cells were centrifuged for $5 \mathrm{~min}$ at $3000 \mathrm{rpm}$ and $4^{\circ} \mathrm{C}$. Thereafter the supernatant was removed and $50 \mu \mathrm{l}$ of lysis buffer (freshly made, see 3.4.1) was added, and the sample mixed. Samples were incubated on ice for $30 \mathrm{~min}$ and mixed every $5 \mathrm{~min}$. Thereafter, $2.5 \mu \mathrm{l}$ of 10 $\%$ Triton-X-100 was added to each sample and mixed for $30 \mathrm{sec}$. Samples were further incubated on ice for $15 \mathrm{~min}$ and mixed every minute. All samples were then centrifuged for $5 \mathrm{~min}$ at $2000 \mathrm{rpm}$ at $4^{\circ} \mathrm{C}$. The supernatant was transferred to fresh Eppendorf tubes (this sample was labelled as cytosol). Fifty $\mu$ l of Lysis Buffer was added to the remaining pellet and mixed until well dissolved. Protein concentrations of all cytosol samples were then determined by the Bradford Protein Assay (see 3.3.1).

\subsubsection{Antibody generation}

Zfm1 serum antibodies were generated by Sigma-Genosys. The following peptide was injected subcutaneously into two New Zealand white rabbits MATGAMATPLDFPSC (sequence obtained from Guth et.al, 2000). During a 77 day schedule the rabbits were immunised six times with the peptide and bled four times each. The serum antibodies from both rabbits were tested against several different cells types by western blot analysis (see 3.3.4). 


\subsection{Molecular biology methods}

\subsubsection{PCR}

The reagents for PCR amplification were premixed to ensure identical conditions in each reaction $[20 \mathrm{mM}$ Tris/ $\mathrm{HCl}(\mathrm{pH} 8.4), 1.5 \mathrm{mM} \mathrm{MgCl}, 0.2$ mM dNTP, $1 \cup$ Taq DNA polymerase (all from Genecraft, Lüdinghausen, Germany) and 20 pmol primers (both forward and reverse primers), in a total volume of $50 \mu \mathrm{l}$, each reaction containing $1 \mu \mathrm{g}$ of DNA]. The PCR was performed in an Eppendorf Thermal Mastercycler ${ }^{\circledR}$ (Eppendorf, Hamburg, Germany) programmed as follows:

Pre-denaturation:

Denaturation:

Annealing:

Extension:

Final extension:
2 min at $95^{\circ} \mathrm{C}$ $10 \mathrm{~s}$ at $94^{\circ} \mathrm{C}$ $30 \mathrm{~s}$ at temperatures shown in Table 2.3 2 min (depending on fragment size) at $72^{\circ} \mathrm{C}$ $10 \min$ at $72^{\circ} \mathrm{C}$

\subsubsection{Isolation of total RNA}

Messenger RNA from cultured hSMC was isolated using the RNeasy $\mathrm{Kit}^{\circledR}$ according to the manufacturer's instructions. An aliquot of $13 \mu \mathrm{l}$ of RNA was used to make single-stranded (ss) CDNA for RT-PCR analysis (see 3.2.3) and the remaining RNA stored at $-70^{\circ} \mathrm{C}$.

\subsubsection{Semi-quantitative RT-PCR}

For each sample, $13 \mu \mathrm{l}$ of RNA was mixed with $1 \mu \mathrm{l}$ of Oligo-dT (Promega, Mannheim, Germany) $(500 \mathrm{ng} / \mathrm{\mu l})$ and denatured by incubation at $70^{\circ} \mathrm{C}$ for $10 \mathrm{~min}$. After brief centrifugation, $6 \mu \mathrm{l}$ of cDNA synthesis mix [50 mM Tris/ $\mathrm{HCl}(\mathrm{pH}$ 8.3), $75 \mathrm{mM} \mathrm{KCl}, 3 \mathrm{mM} \mathrm{MgCl}, 10 \mathrm{mM} \mathrm{DTT}, 2.5 \mathrm{mM}$ dNTP (all from Genecraft, Lüdinghausen, Germany), and $200 \mathrm{U}$ MMLV reverse transcriptase (Promega, Mannheim, Germany)] was added and cDNA synthesis was continued for $50 \mathrm{~min}$ at $42^{\circ} \mathrm{C}$. The reaction was stopped by a further incubation for $10 \mathrm{~min}$ at $70^{\circ} \mathrm{C}$. Each cDNA sample was diluted with $180 \mu \mathrm{l}$ of $\mathrm{dH}_{2} \mathrm{O}$ and stored at $-20^{\circ} \mathrm{C}$. 
Semi-quantitative PCR was performed by normalising the relative amount of cDNA of a house-keeping gene. For this purpose, glyceraldehyde phosphate dehydrogenase (GAPDH) was chosen as an internal standard. The reagents for PCR were premixed as in 3.2.1. The PCR reaction was performed in an Eppendorf Thermal Mastercycler (Eppendorf, Hamburg, Germany) programmed as follows:

$\begin{array}{ll}\text { Pre-denaturation: } & 2 \mathrm{~min} \text { at } 94^{\circ} \mathrm{C} \\ \text { Denaturation: } & 30 \mathrm{~s} \text { at } 94^{\circ} \mathrm{C} \\ \text { Annealing: } & 40 \mathrm{~s} \text { at the temperatures shown in Table } 2.3 \\ \text { Extension: } & 1 \mathrm{~min} \text { at } 72^{\circ} \mathrm{C} \\ \text { Final extension: } & 5 \mathrm{~min} \text { at } 72^{\circ} \mathrm{C}\end{array}$

After amplification, PCR products were separated on 1-1.5\% agarose gels (depending on fragment size) with ethidium bromide staining. The densities of the detected bands were determined by using the PhotoFinish ${ }^{\circledR}$ imaging system and the One-Dscan ${ }^{\circledR}$ software. These results permitted adjustments for the volume of cDNA administered in order to obtain (in a PCR reaction of 20 cycles) the identical quantity of the product for the housekeeping gene (GAPDH). With that amount of cDNA fixed, the PCR reactions were performed with specific primers for the genes of interest.

\subsubsection{Sequencing of the PCR product}

A $10 \mu$ sequencing reaction was setup by mixing $5 \mu$ of purified PCR product (100 ng), $3 \mu$ of BigDye Terminator DNA-sequencing-mix (Applied Biosystems, Damstadt, Germany); $1 \mu \mathrm{l}$ of primer (see Table 2.3 for primers) and $1 \mu \mathrm{l}$ of sterilised water. The sequencing PCR was performed as follows: denaturation at $94^{\circ} \mathrm{C}$ for $30 \mathrm{sec}$; annealing temperature was primer specific as shown in Table 1 for $15 \mathrm{sec}$; and extension at $60^{\circ} \mathrm{C}$ for $4 \mathrm{~min}$.

After the sequencing PCR, the products were precipitated by adding $50 \mu \mathrm{l}$ $100 \%$ ethanol and $1.5 \mu \mathrm{l}$ of $2 \mathrm{M} \mathrm{NaAc}(\mathrm{pH} 4.0)$. The samples were left overnight at $-20^{\circ} \mathrm{C}$. Thereafter, the samples were centrifuged at $4^{\circ} \mathrm{C}, 13,000$ rpm for $20 \mathrm{~min}$. The supernatant was carefully removed, and washed with $250 \mu \mathrm{l} 70 \%$ ethanol. The pellet was then dissolved in $25 \mu \mathrm{l}$ of $\mathrm{dH}_{2} \mathrm{O}$. The 
products were sequenced by using a model 3100 Genetic Analyser (Applied Biosystems, Damstadt, Germany).

\subsubsection{SiRNA technique}

Double-stranded (ds) RNAi were prepared from the complementary singlestranded 2'-OH RNAi (Dharmacon, RNA Technologies, Lafayette, CO, USA) according to the manufacturer's instructions. The single stranded sequences of the RNAi are listed in Table 2.6

\subsubsection{Cloning}

\subsubsection{Topo-cloning}

Large and small fragments of the promotor region were cloned into the pCR® Topo 2.1 vector $(3.9 \mathrm{~Kb})$ using the Topo TA Cloning ${ }^{\circledR}$ Kit according to the manufacturer's instructions. Plasmids containing the inserts were further amplified as in 3.2.6.3. The plasmids were sequenced as in 3.2 .4 to check for the correct insert.

\subsubsection{Cloning into pGL3}

Empty pGL3 vector containing the luciferase reporter gene, was digested with restriction enzyme Smal. The hydrolysed vector was then dephosphorylated using calf alkaline phosphatase in order to minimise the chances of the vector re-annealing on itself during the ligation procedure. Both large and small fragments of the Zfm1 promotor were excised from the pCR® Topo 2.1 vector with EcoRI, which produced 'sticky ends' on the insert. The 'sticky ends' of the promotor insert were 'polished' to produce 'blunt ends' using the DNA Blunting and Ligation Kit. The blunt ended promotor insert and Smal digested pGL3 vector were ligated in a reaction mixture [ $\sim 80 \mathrm{ng}$ of plasmid DNA; $\sim 300 \mathrm{ng}$ of insert DNA; $2 \mu$ l of $10 \mathrm{X}$ ligation buffer; $2 \mu \mathrm{PEG} 4000 ; \mathrm{dH}_{2} \mathrm{O}$ up to $20 \mu \mathrm{l}$ and $2 \mu \mathrm{l} \mathrm{T4}$ DNA ligase] at $14^{\circ} \mathrm{C}$ overnight. Transformation of Top $10^{\mathrm{TM}}$ competent cells were carried out as stated in 3.2.6.3.1. Colonies containing the insert of interest were screened via mini-culture; plasmid DNA analysis (see 3.2.6.3-4) and restriction digest 
with $\mathrm{Kpnl}$ and HindlII restriction enzymes. The orientation of the insert was confirmed via sequencing (see 3.2.4) with primers specific for the pGL3 multiple cloning site (MCS) (see Table 2.3).

\subsubsection{Amplification of plasmid \\ 3.2.6.3.1 Transformation of competent cells}

One $\mu l$ of $p G L 3$ vector with insert or $p C R \circledast$ Topo vector with insert was mixed with $20 \mu$ of Top $10^{\mathrm{TM}}$ competent cells in a $1.5 \mathrm{ml}$ Eppendorf tube. The mix was then incubated on ice for $30 \mathrm{~min}$. Thereafter, the cells were subjected to a heat shock at $42^{\circ} \mathrm{C}$ for $20 \mathrm{~s}$, and placed on ice for a further 2 min. Two hundred and fifty $\mu \mathrm{l}$ of SOC Medium was added and cells were incubated for $1 \mathrm{~h}$ at $37^{\circ} \mathrm{C}$ with shaking. Sterile LB-agar (see 3.4.3) was melted and cooled until 'warm to the touch'. Ampicillin was then added to give a final working concentration of $20 \mu \mathrm{g} / \mathrm{ml}$. While still warm, the LB-agar ampicillin solution was poured equally into $100 \mathrm{~mm}$ petri dishes and left to set at room temperature. Before evenly plating transformed competent cells, the LB-agar plates were pre-warmed to $37^{\circ} \mathrm{C}$. Thereafter, up to $200 \mu \mathrm{l}$ of transformed competent cells were plated on pre-prepared LB-agar plates. Plates were then incubated at $37^{\circ} \mathrm{C}$ overnight to allow bacterial colonies to grow.

\subsubsection{Plasmid mini-cultures}

Plasmid mini-cultures were set up in $15 \mathrm{ml}$ falcon tubes. One transformed colony of Top10 cells was added to $5 \mathrm{ml}$ of LB Broth (with appropriate antibiotic) via sterile technique. Holes were perforated on the cap of the falcon tubes to allow air to circulate through the tube. These cultures were then incubated at $37^{\circ} \mathrm{C}$ with shaking overnight.

\subsubsection{Plasmid purification}

Plasmids grown in mini-cultures were purified using the Qiagen Plasmid Mini Spin Kit according to the manufacturer's instructions. 


\subsubsection{Nucleofection}

Nucleofection is a new technique for transfecting plasmids into cells produced by Amaxa ${ }^{\mathrm{TM}}$ Biosystems (Köln, Germany). To transfect hSMC with our reporter plasmid, $2 \mu \mathrm{g}$ of the plasmid of interest was mixed with $100 \mu \mathrm{l}$ containing approximately $0.5-1 \times 10^{6}$ cells of hSMC harvested (as in 3.1.2) suspended in Nucleofector ${ }^{\mathrm{TM}}$ Solution optimised for human aortic smooth muscle cells. The cells were then transferred to a cuvette especially manufactured for the Nucleofector ${ }^{\mathrm{TM}}$ apparatus and transfected under the optimised transfection program A-33. The transfection program was optimised according to the manufacturer. After transfection, $500 \mu \mathrm{l}$ of prewarmed $15 \%$ FCS DMEM was added to the cuvette and transferred to an appropriate well in a 6 -well plate containing $1.5 \mathrm{ml}$ of $15 \%$ FCS DMEM prewarmed to $37^{\circ} \mathrm{C}$. The cells were then kept at $37^{\circ} \mathrm{C}$ with $5 \% \mathrm{CO}_{2}$.

\subsubsection{Preparation of decoy oligonucleotides}

\subsubsection{Rehydration of decoy oligonucleotides}

Decoy ODN (dODN) were manufactured by Eurogentec, Seraign, Belgium and each dODN had a specific molecular weight, stated on the accompanying information sheet. An appropriate volume of TEN Buffer (see 3.4.1) was added to give a final concentration of $2 \mu \mathrm{M}$ per dODN oligonucleotide. Each oligonucleotide was then mixed and incubated at ambient for 40 min. mixing every 2 min.

\subsubsection{Hybridisation of decoy oligonucleotides}

Equal volumes of forward and reverse decoy oligonucleotides were mixed carefully in an Eppendorf tube. The mix was placed in a boiling $\left(100^{\circ} \mathrm{C}\right)$ waterbath for 2-4 $\mathrm{min}$. The waterbath was then switched off and the decoy oligonculeotides were left in the waterbath until the temperature reached approximately $30^{\circ} \mathrm{C}$. Decoy ODN were then confirmed for hybridisation by running single stranded and hybridised decoys on a $2.5 \%$ agarose gel (if hybridised the dODN should be a higher molecular weight compared to its single stranded counterpart) and stored at $-20^{\circ} \mathrm{C}$. 
In order to test whether the dODNs were successfully hybridised, singlestranded oligonucleotides and hybridised dODN were run on a $2.5 \%$ agarose gel. Figure 5 confirms that our single-stranded oligonucleotides were successfully hybridised.

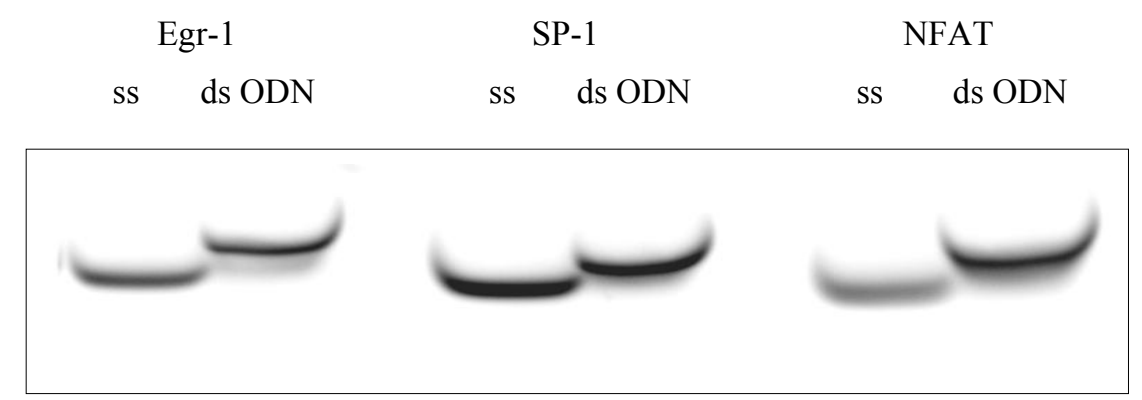

Figure 5. Hybridisation of dODNs. Exemplary agarose gel depicting single stranded (ss oligonucleotide) vs Hybridised dODN. Less than $500 \mathrm{ng}$ of DNA was loaded on the gel.

\subsubsection{Decoy oligonucleotide experiments}

All experiments containing decoy oligonucleotides had a final experimental concentration of $10 \mu \mathrm{M}$. All dODN stock solutions used were at 100 fold concentration.

\subsubsection{Site-directed mutagenesis}

The short promotor fragment cloned into the pGL3 vector was mutated at two transcription factor (TF) binding sites of interest. Primers for mutagenesis (Table 2.3) were designed and manufactured by IBA nucleic acids research (Göttingen, Germany). Site-directed mutagenesis was carried out using the QuikChange ${ }^{\circledR}$ Site-Directed Mutagenesis Kit according to the manafacturer's instructions. Mutations were confirmed by mini-culture, plasmid purification and sequencing as outlined in 3.2.4, 3.2.6 and 3.2.6.3 respectively. 


\subsubsection{0 luciferase reporter gene analysis}

Transfected cells to be analysed for luciferase gene activity were lysed and prepared according to the Luciferase Assay Kit instructions. The luminescence was recorded from an average of 15 readings using the MicroLumat LB 96P EG \& G luminometer EG \& G Berthold Winglow( software version 1.22 (1992-1997) both from Berthold Technologies $\mathrm{GmbH}$ \& Co KG (Bad Wildbad, Germany). And luciferase activity was calculated against the protein concentration of each sample and represented as level of fluorescence per $\mu \mathrm{g}$ protein.

\subsection{Protein biochemistry methods}

\subsubsection{Bradford protein assay}

hSMC samples harvested as in 3.1.6 were diluted $1: 100$ with $\mathrm{dH}_{2} \mathrm{O}$. In a 96well micro-plate, $200 \mu \mathrm{l}$ of Bradford Protein Assay solution (BioRad, München, Germany) was added. Eighty $\mu$ of each diluted sample along with pre-prepared protein standards $(10,20,30$ and $40 \mu \mathrm{g} / \mathrm{ml}$ protein) were added and mixed with the assay solution. The samples were left for $10 \mathrm{~min}$ at room temperature. Samples were analysed using the ELX808 micro-plate reader (Bio-Tek Instruments, Inc.) and the MikroWin version 3.0 program (Mikrotek Laborsysteme GmbH, Germany).

\subsubsection{Ethanol prepcipitation of protein samples}

$100 \%$ ice-cold ethanol was added nine times the volume of the protein sample to be precipitated. Samples were mixed and incubated at $-20^{\circ} \mathrm{C}$ overnight. Thereafter, samples were centrifuged at 10,000 rpm for $10 \mathrm{~min}$. Ethanol was removed and samples were left to air dry and resuspended in $\mathrm{dH}_{2} \mathrm{O} .3 \mathrm{X}$ sample loading buffer (see 3.4.2.3) was added, and the samples incubated at $95^{\circ} \mathrm{C}$ for $5 \mathrm{~min}$. 


\subsubsection{Protein analysis by SDS-PAGE}

SDS-polyacrylamide gels were made according to the Laemmli method (Laemmli, 1977). Gels from $10-15 \%$ SDS were used. For recipies and buffers see chapter 3.4. Proteins were denatured by the addition of $3 \times$ sample loading buffer (see 3.4.2.3) and heated for $5 \mathrm{~min}$ at $95^{\circ} \mathrm{C}$. Thereafter, proteins were separated by electrophoresis at $100 \mathrm{~V}$ through the stacking gel, and $200 \mathrm{~V}$ through the separating gel.

\subsubsection{Western blot analysis}

Proteins were separated by SDS-PAGE (see 3.3.3) and transferred onto a hydrated PVDF membrane (5 min in $100 \%$ methanol and 45 min $\mathrm{ddH}_{2} \mathrm{O}$ ) at $350 \mathrm{~mA}$ for $45 \mathrm{~min}$ with transfer buffer (see 3.4.2.3). The membrane was then dried for $2 \mathrm{~h}$ at $50^{\circ} \mathrm{C}$ or directly blocked overnight (or for $2 \mathrm{~h}$ ) with blocking buffer (see 3.4.2.3).

The primary antibody (diluted 1:1000 in Washing Buffer) was added to the membrane and incubated at ambient temperature for $2 \mathrm{~h}$. Thereafter the membrane was washed 3 times for $10 \mathrm{~min}$. with washing buffer. The appropriate secondary antibody conjugated to peroxidase (see Table 2.8, diluted 1:10,000 in Washing Buffer) was added and the membrane was further incubated at ambient temperature for $1 \mathrm{~h}$. After $1 \mathrm{~h}$, the membrane was washed 3 times for 10 min with Washing Buffer.

\subsubsection{Development of membrane}

The membrane was developed using ECL solution (Amersham Pharmacia Biotech, Freiburg, Germany), according to the manufacturer's instructions.

\subsubsection{Immuno-precipitation (IP) of hSMC}

Human SMC were harvested as in 3.1.6. Cells were then resuspended in 1 $\mathrm{ml}$ of IP buffer (see 3.4.2.1) and divided into two Eppendorf tubes, $500 \mu \mathrm{l} \mathrm{per}$ tube (each tube containing between approximately 350 - $400 \mu \mathrm{g}$ of protein). Five hundred $\mu \mathrm{l}$ of antibody was added to each tube and samples were incubated at ambient temperature with rotation for $1 \mathrm{~h}$. Thereafter, $25 \mu \mathrm{l}$ of 
protein-A sepharose beads (Sigma-Aldridge, München, Germany, preprepared according to manufacturer's instructions) was added and the samples further incubated at ambient temperature with rotation for $2 \mathrm{~h}$.

Samples were then centrifuged for $1 \mathrm{~min}$ at $1000 \mathrm{rpm}$ at $4^{\circ} \mathrm{C}$ and a $90 \mu \mathrm{l}$ aliquot of the supernatant was kept for analysis. All samples were then washed consecutively with $100 \mu \mathrm{l}$ of washing buffer I, washing buffer II and washing buffer III (see 3.4.2.1), for $10 \mathrm{~min}$ at ambient temperature with rotation and centrifuged for $1 \mathrm{~min}$ at $1000 \mathrm{rpm}$ and $4{ }^{\circ} \mathrm{C}$. Ninety $\mu \mathrm{l}$ from each supernatant was kept for analysis, along with the pellet samples, respectively.

\subsection{Chromosome immuno-precipitation (ChIP)}

ChIP was performed on different batches of hSMC, using the ChIP IT ${ }^{\mathrm{TM}}$ Enzymatic Kit (Active Motif, Rixensart, Belgium) according to the manufacturer's instructions.

\subsection{Statistical analysis}

Results are expressed as the mean \pm SEM of ' $n$ ' independent observations (i.e samples from different batches of cells), unless otherwise stated. Statistical evaluation was performed by employing a One-way nonparametric ANOVA with the appropriate student $t$-test using the Instat ${ }^{\mathrm{TM}}$ version 3.00 for Windows 95 statistics software package (Graph Pad Software, San Diego, CA, USA). A ' $p$ ' value $<0.05$ was considered statistically significant.

\subsection{Buffers and stock solutions}

3.6.1 Cell biology buffers and stock solutions

\section{CyQUANT Cell Lysis mix}

$19 \mu \mathrm{R}$ RNAse-free water

$1 \mathrm{ml} 20$ X CyQuant Lysis buffer

$50 \mu \mathrm{l}$ CyQuant dye 
TEN Buffer

$100 \mathrm{mM} \mathrm{NaCl}$

$10 \mathrm{mM}$ Tris $\mathrm{pH} 7.5$

$1 \mathrm{mM}$ EDTA

\section{Cell Lysis Buffer}

$905 \mu$ S Solution A buffer

$20 \mu \mathrm{l}$ of DTT

$25 \mu \mathrm{l}$ of Protease Inhibitor Mix

$50 \mu$ of Pefabloc

Solution A Buffer (in a final volume of $10 \mathrm{ml}$ )

$0.1 \mathrm{mM}$ EDTA

$0.1 \mathrm{mM}$ EGTA

$10 \mathrm{mM} \mathrm{KCl}$

10 mM HEPES pH 7.5

3.6.2 Protein biochemistry buffers and stock solutions

3.6.2.1 Immuno-precipitation buffers

IP Lysis buffer

20 mM TRIS pH 7.5

$100 \mathrm{mM} \mathrm{NaCl}$

$0.5 \%$ Triton-X-100

$0.5 \mathrm{mM}$ EDTA

$0.5 \mathrm{mM}$ Pefabloc

$0.5 \%$ Protease inhibitor mix

Washing buffer I

$100 \mathrm{mM}$ TRIS pH 7.5

$150 \mathrm{mM} \mathrm{NaCl}$

2 mM EDTA

$0.2 \%$ Triton-X-100

Washing buffer II

40 mM TRIS pH 8.5

$50 \mathrm{mM} \mathrm{NaCl}$

5 mM EDTA

$1.25 \%$ Triton-X-100 
Washing buffer III

$40 \mathrm{mM}$ TRIS pH 8.5

$300 \mathrm{mM} \mathrm{NaCl}$

$10 \mathrm{mM}$ EDTA

$1.25 \%$ Triton-X-100

$0.2 \%$ SDS

3.6.2.2 SDS-PAGE buffers and recipies

$10 \%$ SDS-PAG $\quad 4 \%$ Stacking Gel

$\begin{array}{lll}\text { Acrylamide stock }(30 \%) & 3.3 \mathrm{ml} & 0.65 \mathrm{ml} \\ 1.5 \mathrm{M} \text { Tris. } \mathrm{HCl} \mathrm{pH} 8.8 & 2.5 \mathrm{ml} & - \\ 0.5 \mathrm{M} \text { Tris. } \mathrm{HCl} \mathrm{pH} 6.8 & - & 1.25 \mathrm{ml} \\ \mathrm{dH}_{2} \mathrm{O} & 4.1 \mathrm{ml} & 3.05 \mathrm{ml} \\ 20 \% \text { SDS } & 50 \mu \mathrm{l} & 50 \mu \mathrm{l} \\ 10 \% \text { APS } & 50 \mu \mathrm{l} & 25 \mu \mathrm{l} \\ \text { TEMED } & 10 \mu \mathrm{l} & 10 \mu \mathrm{l}\end{array}$

\subsubsection{Buffers for western blot}

Transfer buffer

Tris

$25 \mathrm{mM}$

Glycine

$0.192 \mathrm{M}$

Methanol AR

$20 \%$

Wash Buffer

Triton X 100

PBS $1 X$

$2.5 \mathrm{~g}$

$1 \mathrm{~L}$

\section{Blocking Buffer}

Milk powder

$2.5 \mathrm{~g}$

Wash buffer

$50 \mathrm{ml}$

3 X Loading Buffer

$\begin{array}{ll}\text { Tris. HCl pH } 6.8 & 150 \mathrm{mM} \\ \text { DTT } & 300 \mathrm{mM} \\ \text { SDS } & 6 \% \\ \text { Bromophenol blue } & 0.3 \% \\ \text { Glycerol } & 30 \%\end{array}$




\subsection{3}

Molecular biology recipies

\section{LB (Luria-Bertani) Medium}

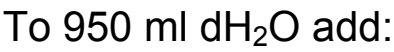

$\begin{array}{ll}\text { Bacto-tryptone } & 10 \mathrm{~g} \\ \text { Bacto yeast extract } & 5 \mathrm{~g} \\ \mathrm{NaCl} & 10 \mathrm{~g}\end{array}$

Dissolved solutes and adjust $\mathrm{pH}$ to 7.0 with $5 \mathrm{M} \mathrm{NaOH}$. Adjust the volume to $1 \mathrm{~L}$ with $\mathrm{dH}_{2} \mathrm{O}$. Sterilise by autoclaving for $20 \mathrm{~min}$ at $15 \mathrm{lb} / \mathrm{square}$ inch or liquid cycler.

\section{LB agar}

Add $15 \mathrm{~g}$ of agarose to $1 \mathrm{~L}$ of LB-medium.

Sterilise as above. 


\section{Results}

\subsection{Production of the $\mathrm{Zfm} 1$ antibody}

In order to analyse Zfm1 protein expression, first antibodies against the human protein has to be generated as they were not available. Thus, suitable peptides were selected and antibodies against Zfm1 were produced in two different rabbits (numbered 1675 and 1676 respectively) by SigmaGenosys (Sigma-Aldridge, Haverhill, UK) using the following sequence: MATGAMATPLDFPSC (obtained from Guth et al. 2000). Approximately 6 months after the peptides were injected, the rabbits were bled for a maximum of five times and the blood sera were analysed and tested for antibody quality with protein samples derived from several different species. Western blot analysis revealed that Zfm1 antibody number 1676 detects two isoforms, Zfm1 A and Zfm1 E, with a molecular mass of approximately 55 and $70 \mathrm{kDa}$ respectively, in hSMC and HUVECs. The Zfm1 antibody number 1675 only detected the $55 \mathrm{kDa}$ isoform (Fig. 6). From this point, the Zfm1 antibody number 1676 was used for all further protein expression analyses.

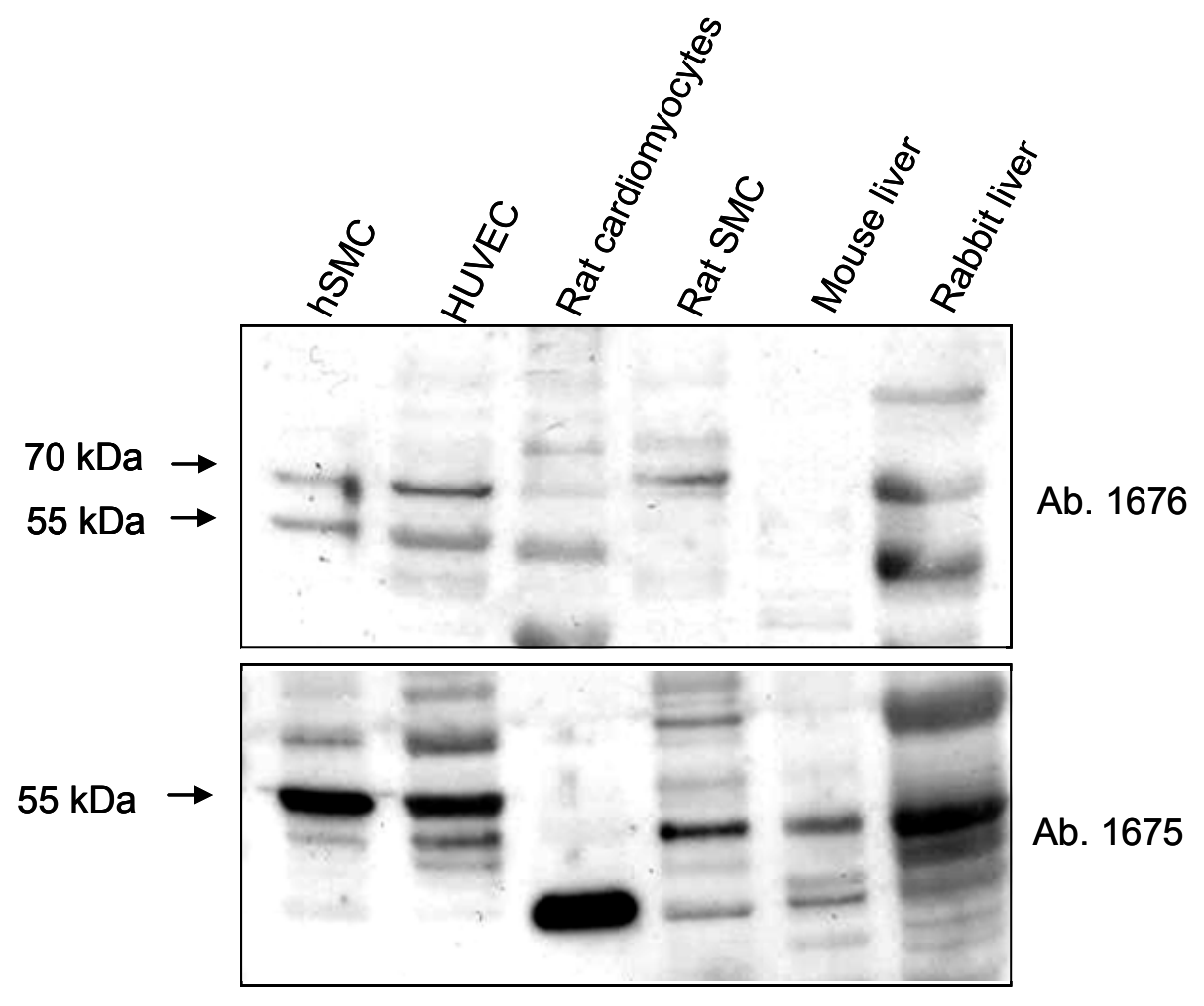

Figure 6. Zfm1 serum antibody test. Expression of Zfm1 was tested using custom made serum antibodies in several different species; rat, human and mouse. The figure depicts a representative Western blot analysis. The expected band sizes of Zfm1 are approximately 55 and $70 \mathrm{kDa}$ which corresponds to $\mathrm{Zfm} 1$ isoforms $E$ and $A$, respectively. 


\subsection{Zfm1 siRNA}

The siRNA technique was chosen in order to analyse the role of $Z \mathrm{fm} 1$ in cell proliferation. Expression of $\mathrm{Zfm} 1$ was monitored from 24 to $72 \mathrm{~h}$ post transfection of Zfm1 siRNA. Subsequent analysis confirmed that the expression of Zfm1 RNA (Fig. 7) and protein (Fig. 8) was decreased effectively following Zfm1 siRNA transfection.

A
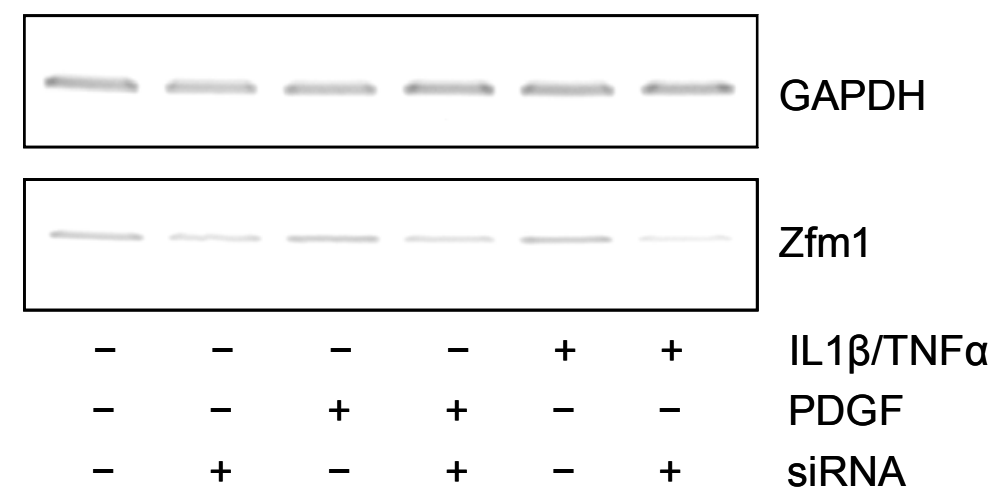

B

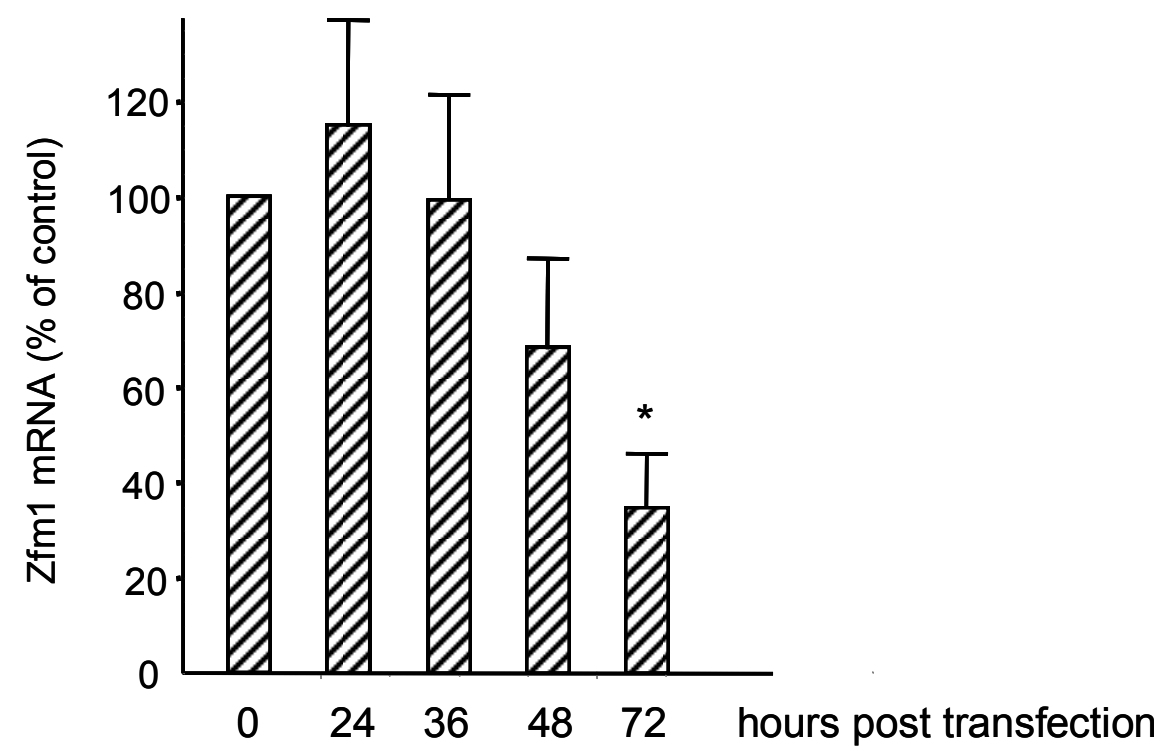

Figure 7. Analysis of Zfm1 siRNA effects in hSMC. A) Representative RTPCR analysis result. Primers against GAPDH were used as an internal control. B) Statistical analysis of RT-PCR timecourse of Zfm1 siRNA in hSMC. ( ${ }^{*} P<0.05$, control vs. $\left.72 \mathrm{~h} ; \mathrm{n}=5\right)$. 


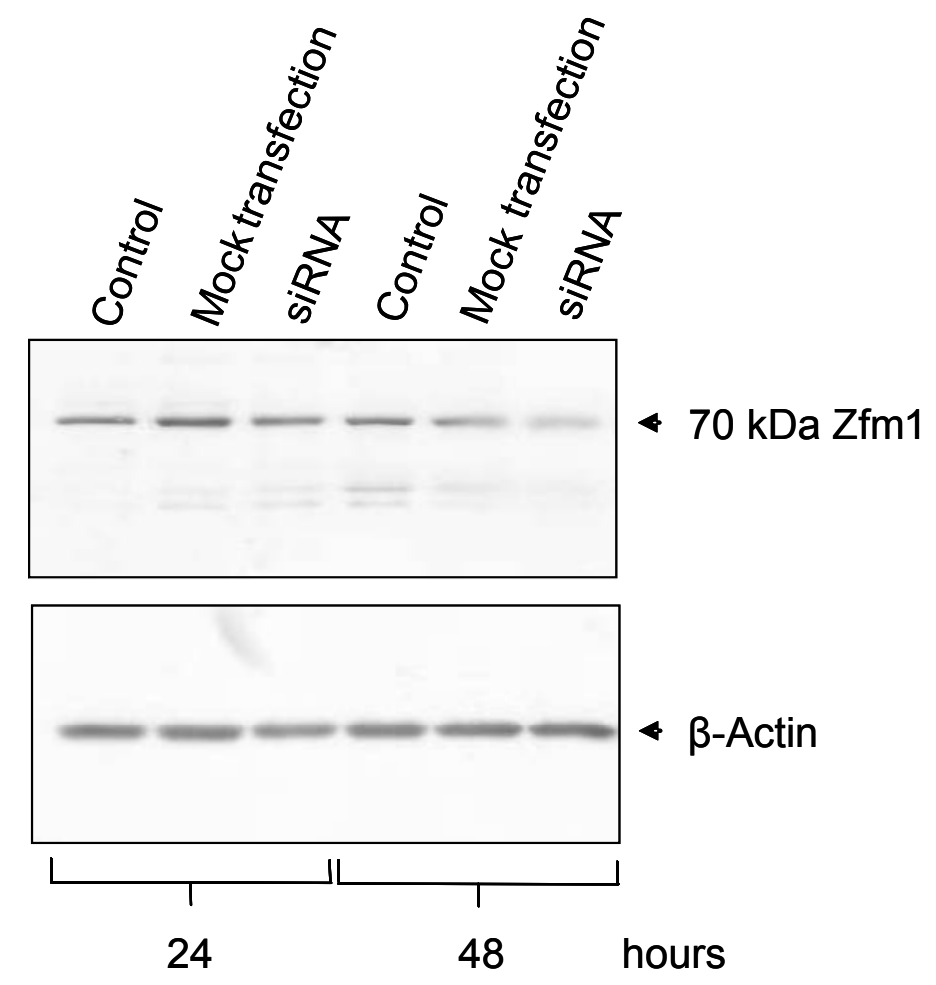

Figure 8. Western blot analysis of Zfm1 siRNA effects on Zfm1 protein expression. Representative Western blot analysis, similar experiments were obtained in 3 different batches of hSMC. B-actin was used to verify equal loading of each lane

\subsection{Proliferation of human vascular smooth muscle cells}

Proliferation of hSMC pre-treated with Zfm1 siRNA was analysed following stimulation with PDGF or IL-1 $/$ TNFa. This analysis confirmed that stimulation of hSMC with pro-inflammatory cytokines IL-1 $\beta / T N F \alpha$ alone is not sufficient to induce cell proliferation. However, an approximate $25 \%$ increase in cell proliferation was observed in response to IL-1 $\beta / T N F \alpha$ stimulation in cells treated with Zfm1 siRNA (Fig. 9). This result is different from previously published data obtained with rat SMC ( $\mathrm{rSMC}$ ) showing that both exposure to IL-1 $\beta / T N F \alpha$ and decreasing Zfm1 abundance alone stimulates proliferation. 


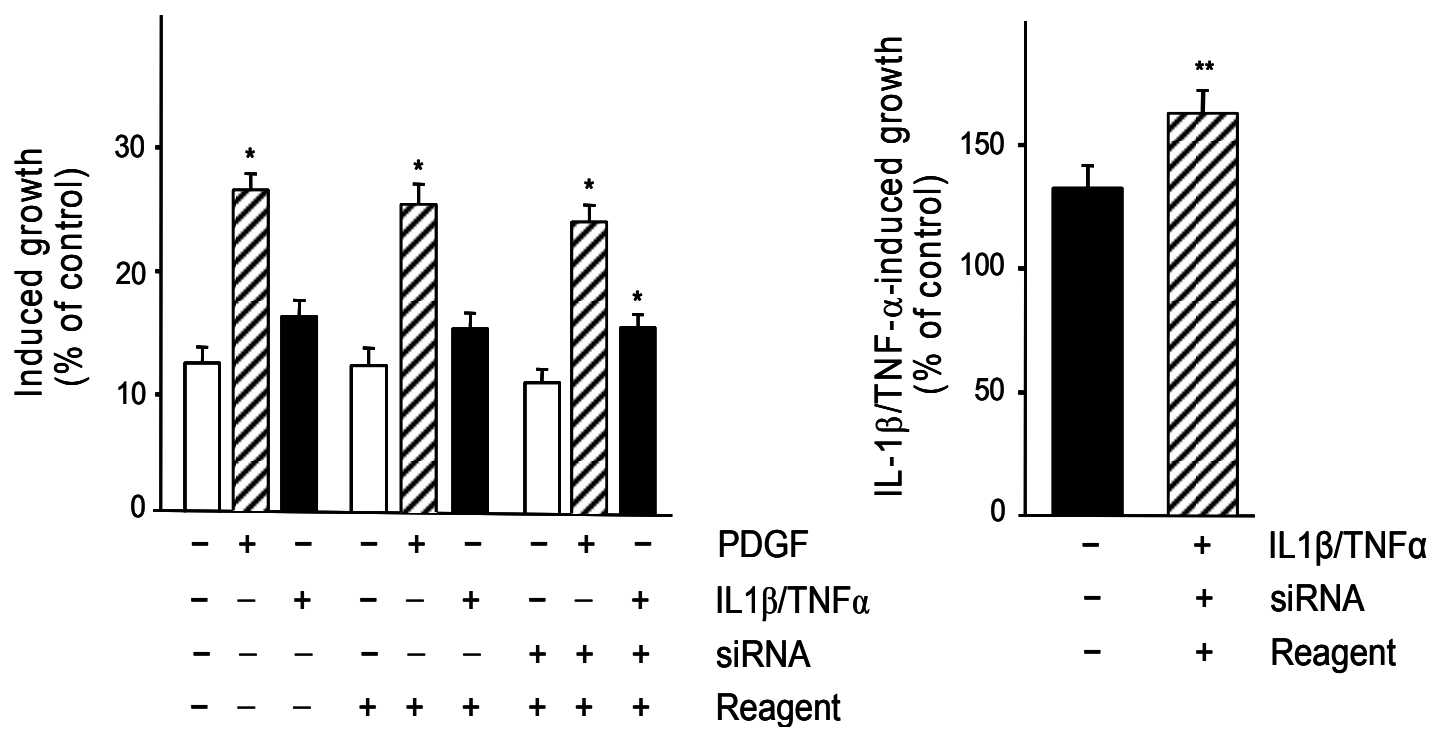

Figure 9. Proliferation of human vascular smooth muscle cells pretreated with Zfm1 siRNA stimulated with either PDGF $(60 \mathrm{u} / \mathrm{ml})$ or IL$1 \beta / T N F \alpha(1000 \mathrm{u} / \mathrm{ml})$ for $72 \mathrm{~h}$. Cell proliferation was measured in hSMC using the CyQuant ${ }^{\mathrm{TM}}$ method, which determines cell number by the amount of fluorescent DNA. A mock transfection (transfection reagent only) was performed as a control for potential cell cytotoxicity. ( ${ }^{*} P<0.05$ vs. respective controls;** $P<0.01$ vs. mock-transfected cells; $n=14$ ).

Besides proliferation, Zfm1 also inhibits pro-inflammatory gene expression in rSMC (Cattaruzza et al., 2002). VCAM-1 is such a pro-inflammatory gene product which was shown to be up-regulated by Zfm1 knock down alone and in the presence of pro-inflammatory cytokines. Therefore, endogenous VCAM-1 expression in hSMC pre-treated with Zfm1 siRNA following stimulation with PDGF or IL-1 $\beta / T N F \alpha$ was analysed. In contrast to rSMC, knock down of Zfm1 with or without exposure to PDGF had no effect on VCAM-1 expression. Only after stimulation with IL-1 $\beta / T N F \alpha$ is VCAM-1 expression was significantly increased and this effect was independent of the abundance of $\mathrm{Zfm} 1$ (Fig. 10). Thus Zfm1 does not play a role in modulating pro-inflammatory gene expression in human SMC. 


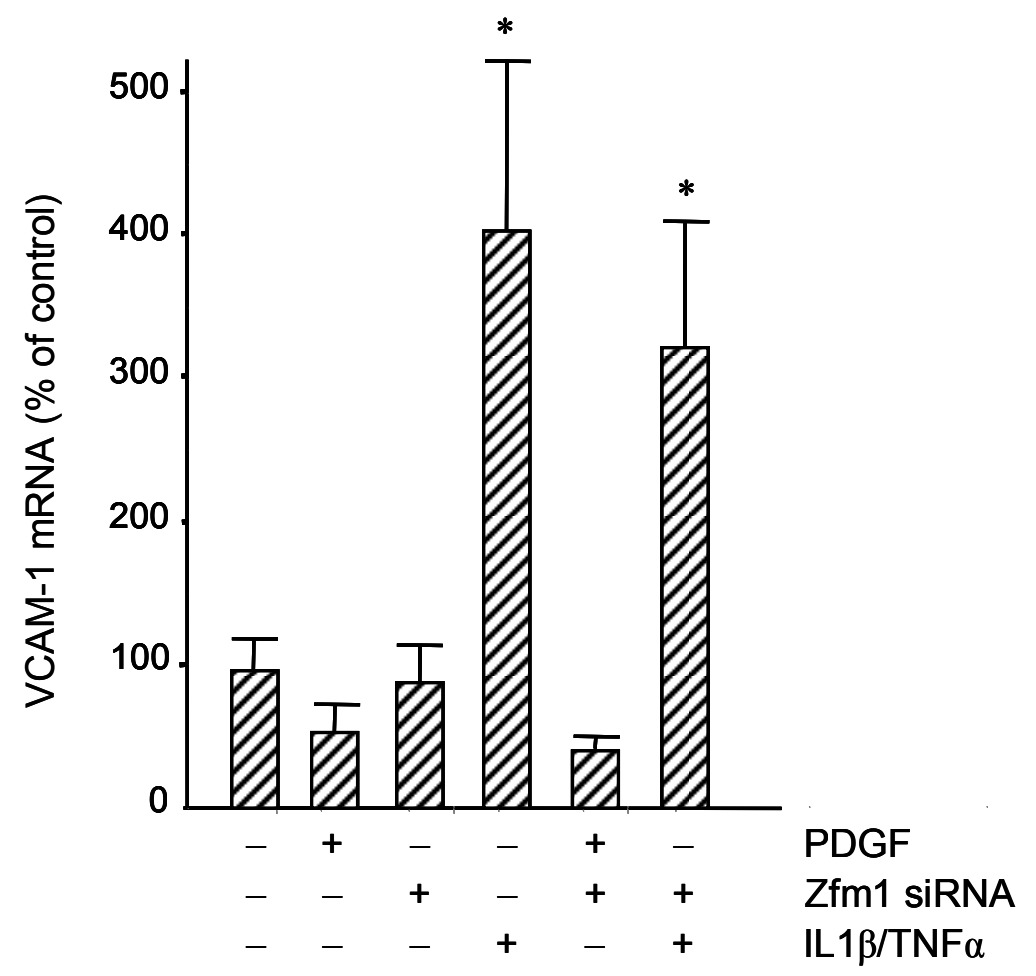

Figure 10. RT-PCR analysis of VCAM-1 expression in hSMC pre-treated with Zfm1 siRNA and stimulated with PDGF $(60 \mathrm{u} / \mathrm{ml})$ or IL-1 $\beta / T N F \alpha(1000$ $\mathrm{u} / \mathrm{ml}$ ) for $48 \mathrm{~h}$ post treatment with siRNA, ( ${ }^{*} P<0.01$ vs. control; $\left.n=5\right)$.

\subsection{Effects of PDGF and IL-1 $\beta / T N F a$ on Zfm1 protein expression}

Cell proliferation assays revealed that stimulating hSMC with IL-1 $1 / T N F \alpha$ alone is not sufficient to induce proliferation, while a growth promoting effect of these cytokines was observed following knock down of Zfm1. On the other hand, PDGF induced cell proliferation to a maximum extent, and this effect was not dependent on Zfm1 abundance. Because of this, it was hypothesised that PDGF itself down-regulates endogenous Zfm1 gene expression, and in order to test this, Western blot and RT-PCR analyses were performed. IL-1ß/TNFa effects (Fig. 11) on endogenous Zfm1 gene expression were analysed as well to support their lack of effect in the cell proliferation assay. 
A

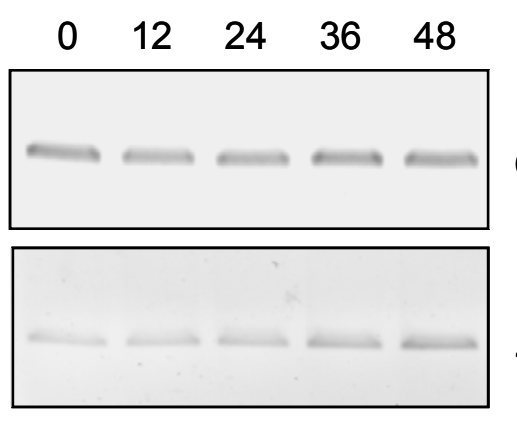

hours

GAPDH

$\mathrm{Zfm} 1$

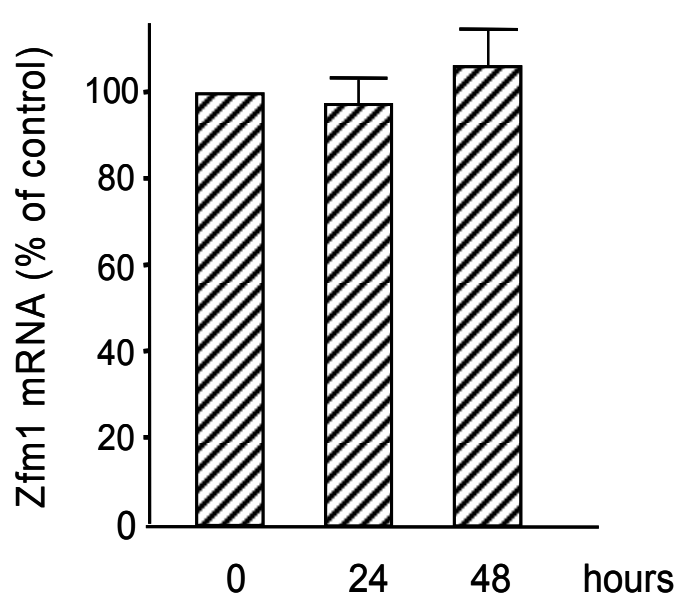

B
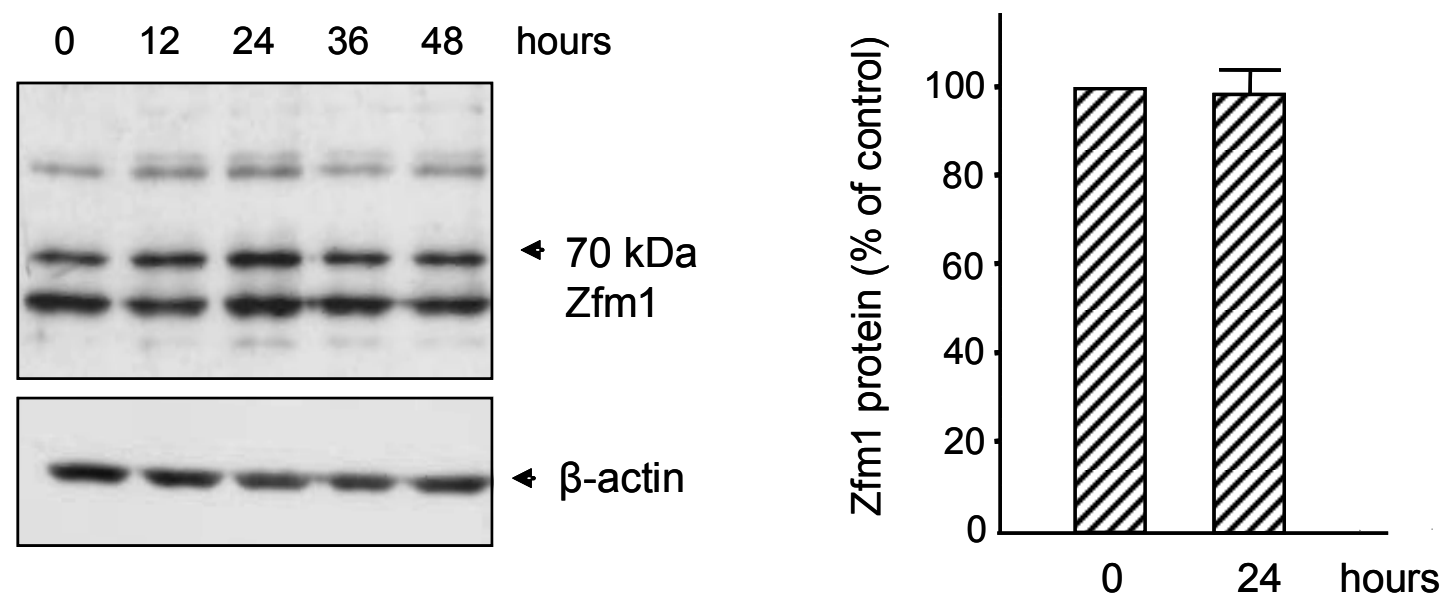

Figure 11. Effects of IL-1- $\beta / T N F \alpha$ on endogenous $\mathrm{Zfm} 1$ expression at the RNA and protein level in hSMC. A) IL-1 $\beta / T N F \alpha(1000 \mathrm{u} / \mu \mathrm{l})$ has no effect on Zfm1 mRNA levels after 24 and $48 \mathrm{~h}$ exposure. GAPDH served as an internal control. B) IL-1 $\beta / T N F \alpha$ has no effect on Zfm1 mRNA and protein abundance. Actin was used as a loading control. Figures depict the result of one representative experiment (left panel) and the statistical summary of five independent experiments (right panel).

Messenger RNA and protein time course analyses confirmed that IL$1 \beta / T N F a$ alone does not down regulate endogenous Zfm1 in hSMC. In contrast, hSMC stimulated with PDGF revealed a significant decrease in Zfm1 expression, both at the mRNA and protein levels (Fig. 12). 
A
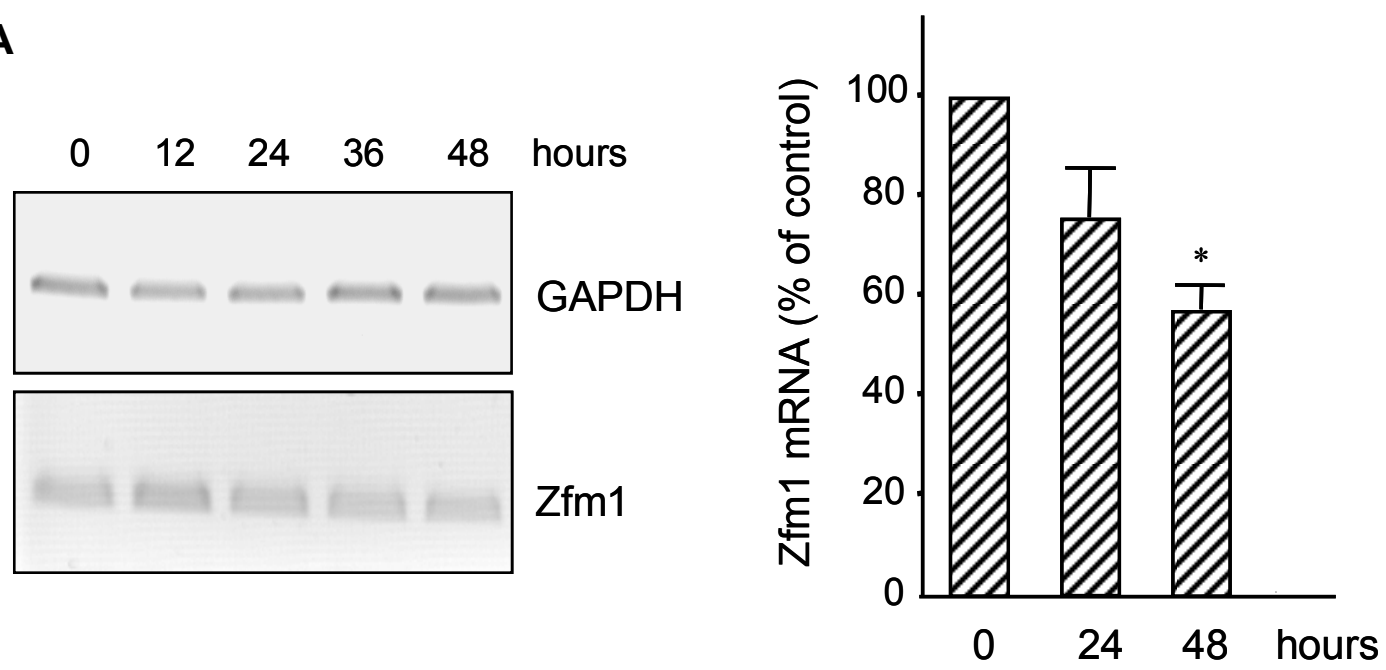

B
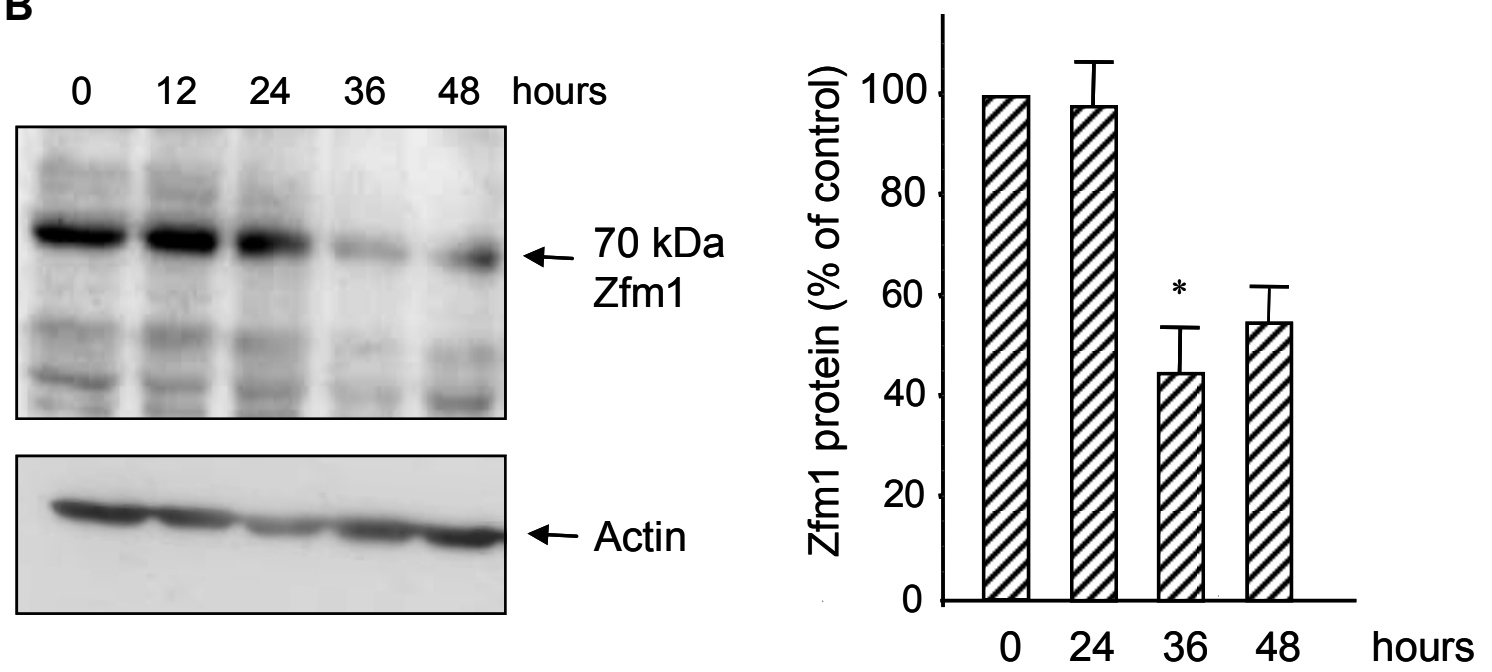

Figure 12. Time-dependent PDGF-induced knockdown of endogenous Zfm1 expression at the RNA and protein level in hSMC. A) PDGF $(60 \mathrm{u} / \mathrm{ml})$ down regulates $\mathrm{Zfm} 1$ at the RNA level approximately after 24 and $48 \mathrm{~h}$ exposure. GAPDH served as an internal control $\left({ }^{*} P<0.05\right.$ vs. control;n=5). B) PDGF down regulates $\mathrm{Zfm} 1$ at the protein level at approximately 36 and $48 \mathrm{~h}$ after stimulation. Actin was used as a loading control. Figures depict results of one representative experiment $\left({ }^{*} P<0.05\right.$ vs. control; $\left.n=5\right)$.

As Zfm1 down-regulation was likely to be important for PDGF-induced hSMC cell proliferation, we set out to analyse the mechanisms of this PDGF effect. A first step in this analysis was to clone the human $\mathrm{Zfm} 1$ promotor and to create a Zfm1 promotor reporter-gene construct. 


\subsection{Cloning of the Zfm1 promotor}

The Zfm1 promotor was cloned as two fragments (large and small) into the pGL3 basic luciferase reporter gene vector (see Annex Fig. 1 for full Sf1/Zfm1 sequence as published in GenBank, Accession no. AJ000051). During our attempt to amplify the Zfm1 promotor directly from a genomic DNA template, numerous PCR products whose sizes were approximately within the right range were obtained. These products were sequenced and came back negative for Zfm1 and were labelled as 'false positives'. Thus, a second approach to cloning the promoter was employed (outlined in Fig. 13) and involved screening of the human chromosome 11 clone library no. LANL-LA11NCO1 (obtained from the Deutsche Resourcenzentrum für Genomforschung $\mathrm{GmbH}$ (DRG, Berlin, Germany). The chromosome 11 library is organised in hierarchical clone pools. In a first step of the search for a single clone therefore primary pools (up to a total of 4608 single clones) were screened by PCR for the sequence of interest (Fig. 13).

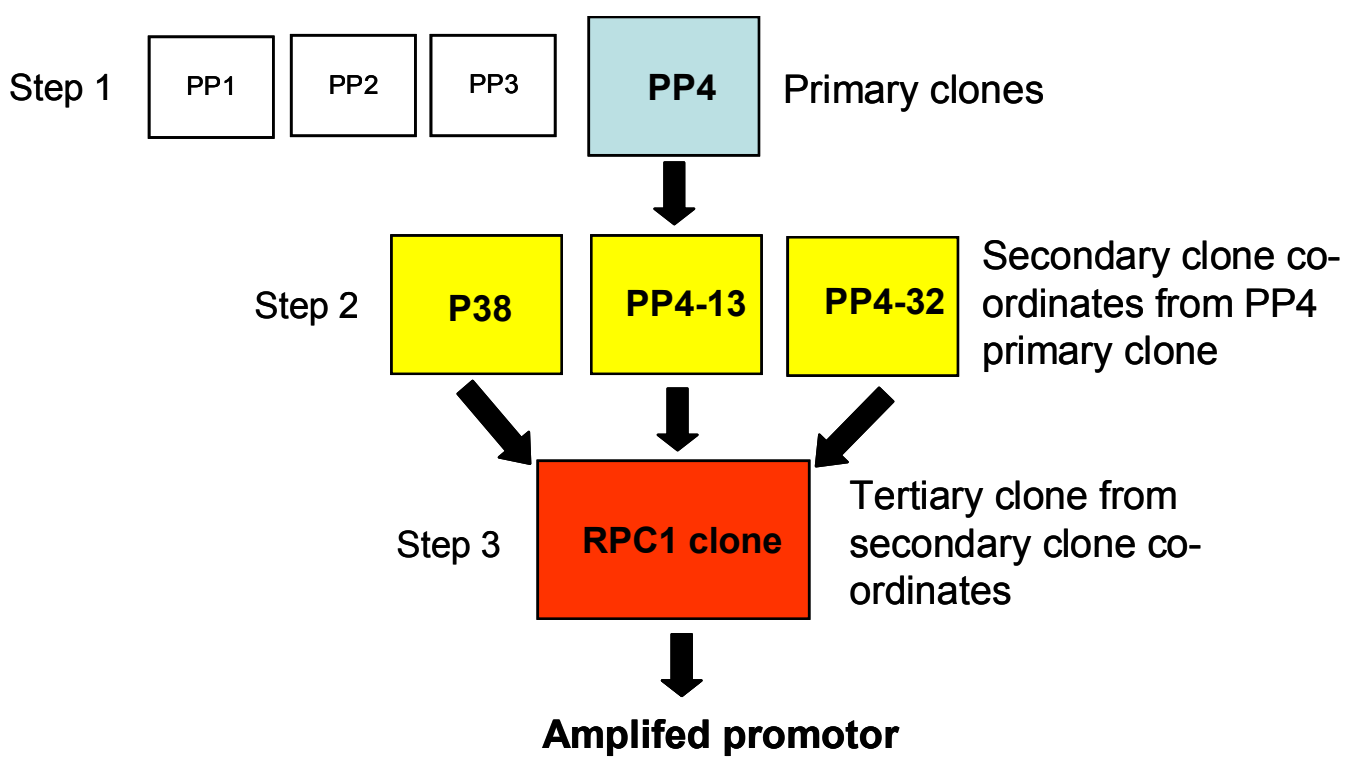

Figure 13. Outline of the $\mathrm{Zfm} 1$ promotor amplification from a chromosome 11 BAC clone library. Secondary clone co-ordinates p38, PP413 and PP4-32 (in bold) were used to elect the tertiary clone (RPC1-11) for further analysis by PCR. Coloured boxes represent the clones that gave positive products for Zfm1. 
A 96-well plate of primary pool 4 containing redundant pools of secondary clones (up to 54 single clones per well) was then obtained and screened (see Annex Fig. 10 for the PP4-secondary clone map). As these pools are redundant and every single clone is obtained by a unique ('co-ordinate') combination of secondary clone pools, with this step, a single clone can be unambiguously identified. In this case, the 'co-ordinate' combination P38, PP4-13 and PP4-32 pointed towards the single clone RPC1 of chromosome 11 (Fig. 15). Details of the screening procedure are outlined in chapter 4.5.1.

\subsubsection{Screening the chromosome 11 BAC clone library}

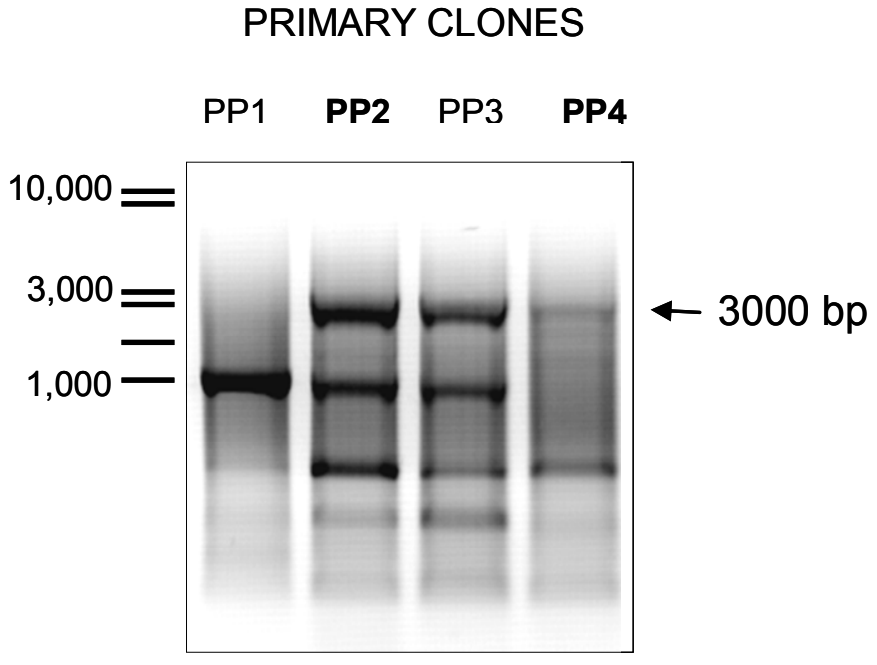

Figure 14. Screening of primary clones. The bands indicated from clones PP2 and PP4 (in bold) were excised and purified. The DNA was sequenced and BLAST (http://www.ncbi.nlm.nih.gov/BLAST/) results were positive for Zfm1. Co-ordinate numbers PP2 and PP4 were then used to order the secondary clones of human chromosome 11.

Both plates of secondary clones named PP2 and PP4 were then screened. Screening of the PP4 plate was successful and three co-ordinates from the secondary clones were matched (Fig. 15). In the next step, the secondary clone pools 'PP-4' were screened for Zfm1-specific sequences (as outlined above). 
A

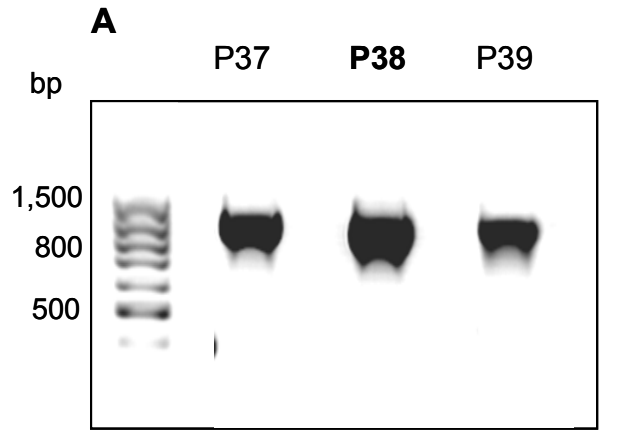

B

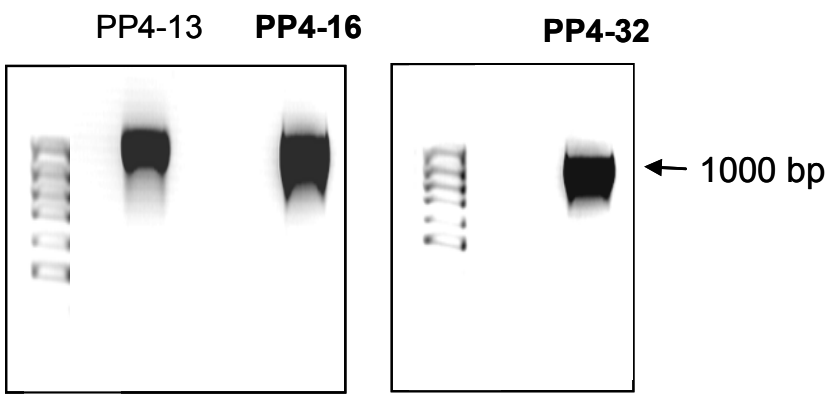

Figure 15. Screening of 13 plate pools, 16 pooled rows and 24 pooled columns in the PP4 secondary clone. A) 13 plate pools. B) 16 pooled rows. C) 24 pooled columns. The candidate fragments (in bold) were excised, purified and sequenced. BLAST results indicated that the fragments were positive for human Sf1/Zfm1. These were then chosen as co-ordinates to obtain the tertiary clone.

\subsubsection{Amplification of $\mathrm{Zfm} 1$ promotor fragments}

A large fragment approximately $870 \mathrm{bp}$ long, of the $\mathrm{hZfm} 1$ promotor was amplified (Fig. 16) using primer pair 3 (Table 2.3).

\section{TERTIARY BAC CLONE}

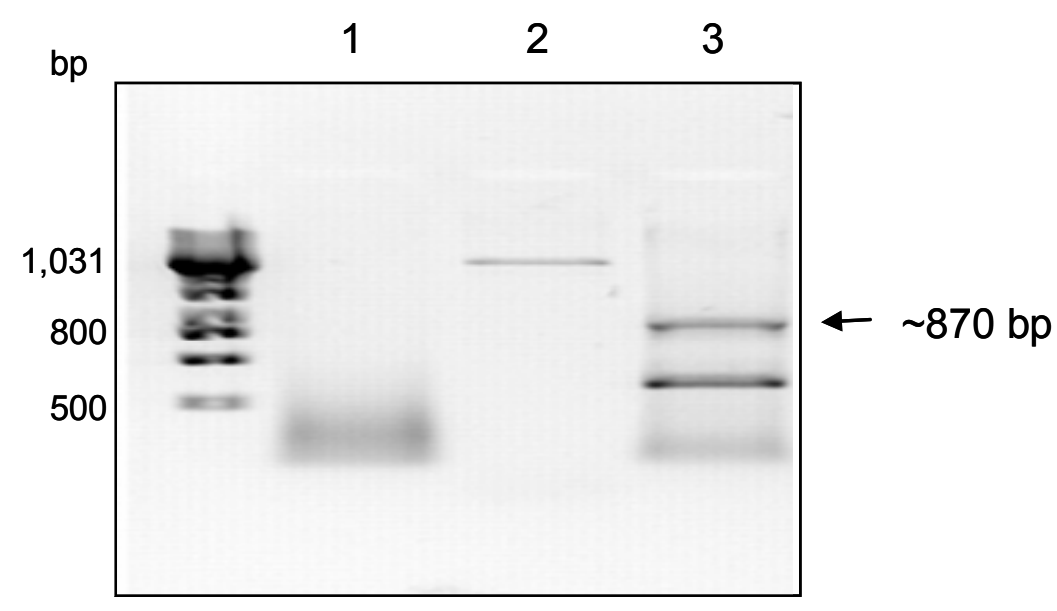

Figure 16. PCR and amplification of the large Zfm1 promotor fragment. The upper band (marked by the arrow), was excised, purified and sequenced. 
Because the large fragment amplified fell $672 \mathrm{bp}$ upstream of the transcriptional start site, new primers had to be designed in order to amplify the missing $672 \mathrm{bp}$. Primer pair 4 (Table 2.3) was used to amplify the missing $672 \mathrm{bp}$ romoter fragment from the same human chromosome 11 BAC clone RPC1-11 (Fig. 17).

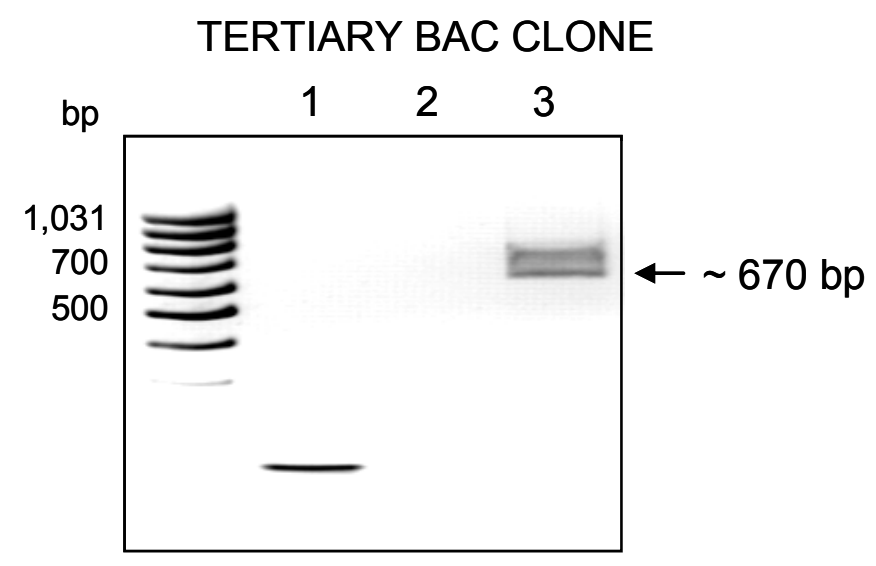

Figure 17. PCR and amplification of small $\mathrm{Zfm} 1$ promotor fragment. The fragment amplified was approximately $670 \mathrm{bp}$ long, and termed 'small romoter fragment'.

Of the $672 \mathrm{bp}, 629 \mathrm{bp}$ belonged to the romoter while the remaining $43 \mathrm{bp}$ corresponded to the coding region of the hZfm1 gene.

\subsection{Generation of the Zfm1 promotor reporter gene construct}

The Zfm1 promoter sequence cloned into pGL3 was 629 bp long and had no sequence mismatches in any known transcription factor binding sites (Fig.18). Details of the full amplified sequence are provided in the Annex (Fig. 5). 
-629 tcccccgccg taaatctcgt tccggctggg cctttcccgc cgcgactctc

-579 gcttaatccc ggagaaactg ccccctgggg gaggggagta gaaaaaggct

-529 ggaaccagcg acagccaatc ccgcgacact acaacgcagg cgagattgat

-479 tgagtccacc accgcagcca atgagagagc tcgccgtcgc tccgtcatag

-429 agttcgcccc accccatccc ctcctttctg gactcggagc tcagttcacg

-379 cagtaacaaa tgaagtgcgc gctgcgacac ctcccagccc accgaactcc

-329 gccgccattt cctcgcttgg cctaacggtt cggccaatcc cagcgcgcat

-279 caagaaggac tgaggctccg ccaatcggag gccgccgatt tcgacccttc

-229 gcctcggccc ggcccaatcc aggccccggt cccgccgccc ccggcccgcc

-179 cccgcggtgc cctctctcct ccctctttgt gcgtctcgcg ccgccgccgc

-129 ccgccgcgtg agaggacggg ctccgcgcgc tccggcagcg cattcgggtc

-79 ccctcccccc gggaggcttg cgaaggagaa gccgccgcag aggaaaagca

-29 ggtgccggtg cctgtccccg ggggcgccat g

Figure 18. Sequence of the $\mathrm{Zfm} 1 / \mathrm{Sf1}$ short promotor fragment. The fragment cloned into pGL3 basic was sequenced using the GL2 reverse sequencing primer. And the orientation and confirmation of the fragments cloned were confirmed using BLAST (http://www.ncbi.nlm.nih.gov/BLAST/). The transcription startsite is highlighted in yellow. When compared to the wild-type Zfm1 promotor sequence deposited in GenBank (Acc. No. AJ000051), two base differences were detected which are depicted in red (see Annex Fig. 5 for the alignment sequence).

In order to amplify the promoter by PCR a reverse primer was chosen well within the coding region of the Zfm1 gene resulting in a reporter gene construct containing the $14 \mathrm{~N}$-terminal amino acids of Zfm1. This fragment was blunt cloned via the Smal restriction enzyme into the MCS of the pGL3 basic vector (Fig. 19). The sequence of the short Zfm1 promotor and a map of the pGL3-basic reporter gene vector can seen in Annex Fig. 2 and Fig. 9, respectively.

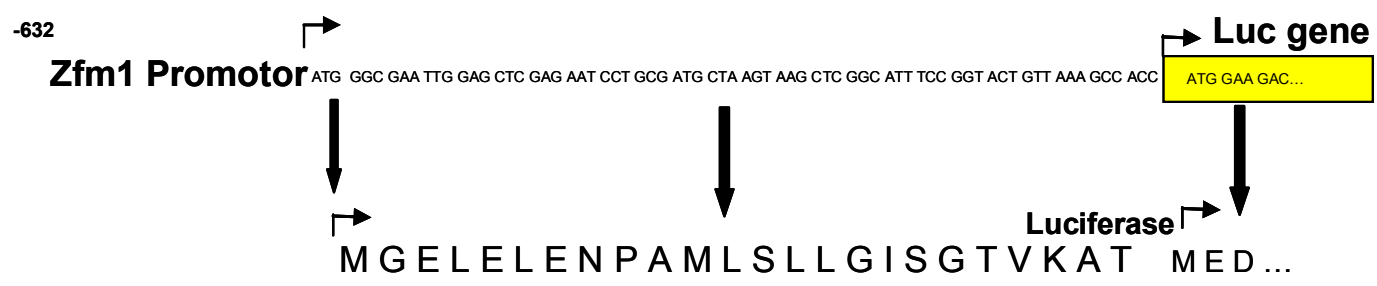

Figure 19. Map of the Zfm1 small promotor construct in pGL3. The amino acid sequence derived from the $\mathrm{N}$-terminal sequence of the Zfm1 gene, along with some sequences of the multiple cloning site (MCS) is emphasised. 


\subsection{Analysis of the Zfm1 promotor}

\subsubsection{PDGF down-regulates Zfm1 promotor activity}

In order to analyse how PDGF down-regulates Zfm1 expression, the Zfm1 promotor luciferase reporter-gene construct was transfected into hSMC. The transfected hSMC were stimulated for $48 \mathrm{~h}$ with PDGF and Zfm1 promotor activity was measured by chemiluminesence analysis. This, revealed that PDGF decreases Zfm1 promotor activity $48 \mathrm{~h}$ after PDGF stimulation (Fig. 20) confirming that the construct, similar to the endogenous gene, is PDGFsensitive.

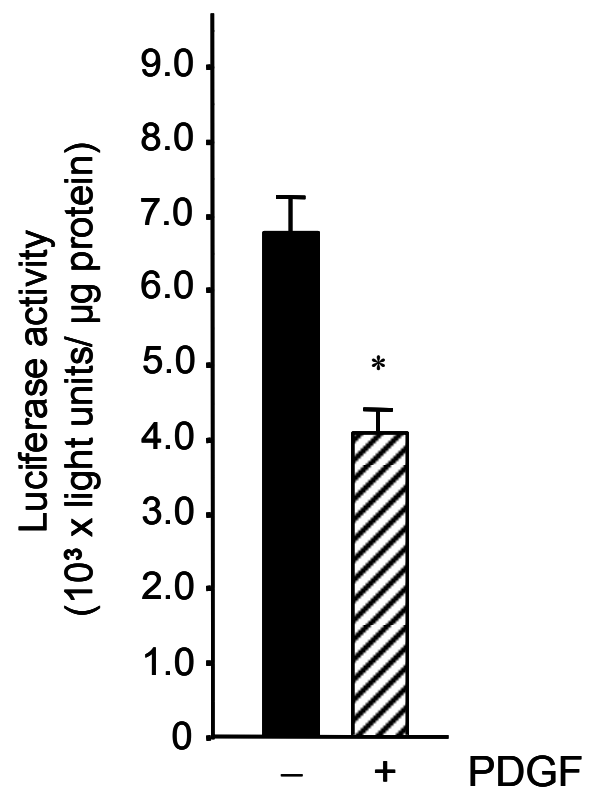

Figure 20. Exposure to PDGF decreases Zfm1 promotor activity in hSMC. Plasmid was transfected into hSMC via nucleofection and the transfected hSMC were stimulated with PDGF $(60 \mathrm{u} / \mathrm{ml})$ for $48 \mathrm{~h}$, ( ${ }^{*} P<0.01$ control vs. PDGF; n=16)

\subsubsection{TRANSFAC analysis of the hZfm1 short promotor}

TRANSFAC analysis was performed in order to identify candidate transcription factors that may bind to the short promotor sequence of the hZfm1 gene. Several transcription factor binding sites for transcription factors (TFs) known to be activated by PDGF were identified (Fig. 21). 
-629 tcccccgccg taaatctcgt tccggctggg ccttttccgc cgcgactctc

-579 gcttaatccc ggagaaactg ccccctgggg gaggggagta gaaaaaggct

-529 ggaaccagcg acagccaatc ccgcgacact acaacgcagg cgagattgat

-479 tgagtccacc accgcagcca atgagagagc tcgccgtcgc tccgtcatag

-429 agttcgcccc accccatccc ctcctttctg gactcggagc tcagttcacg

-379 cagtaacaaa tgaagtgcgc gctgcgacac ctcccagcc accgaactcc

-329 gccgccattt cctcgcttgg cctaacggtt cggccaatcc cagcgcgcat

-279 caagaaggac tgaggctccg ccaatcggag gccgccgatt tcgacccttc

-229 gcctcggcc ggcccaatcc aggccccggc cccgccgccc ccggccegcc

-179 cccgcggtgc cctctctcct ecetetttgt gegtetegeg eegeegeege

-129 ccgccgcgtg agaggacggg ctccgcgcgc tccggcagcg cattcgggtc

-79 ccctcccccc gggaggcttg cgaaggagaa gccgccgcag aggaaaagca

-29 ggtgccggtg cctgtccccg ggggcgccat g

\section{AP-1, CREB, ATF-2 SP-1 EGR-1 NFAT}

Figure 21. Putative TF binding site analysis of the $\mathrm{hZfm} 1$ short promotor by TRANSFAC. All binding sites for transcription factors known to be activated by PDGF are highlighted (http://www.Genomatix.de/shop/index.html). Three overlapping SP-1/ Egr-1 consensus sequences were revealed. The transcription start site is highlighted in yellow. Only conserved binding sites indicated in this figure were considered for further analysis (parameters: core and matrix similarities equaling 1.00 and 0.90 , respectively).

\subsection{Analysis of the Zfm1 promotor with decoy ODN}

The transcription factors Egr-1, SP-1 and NFAT were chosen for further analysis. The following experiment was designed to identify which of these TFs is involved in PDGF inhibition of Zfm1 gene expression. Decoy oligonucleotides ((dODN) for a short discussion on the mechanism of dODN actions on target-TFs, see 5.4) against Egr-1, SP-1 and NFAT were designed and hybridised (see 3.2.8). AP-1 and ATF-2/CREB dODNs had been previously tested without significant effects (not shown). The hSMC were again transfected with the reporter gene construct. The respective dODNs $(10 \mu \mathrm{mol} / \mathrm{L})$ were added $12 \mathrm{~h}$ later. After another $4 \mathrm{~h}$, the cells were stimulated with PDGF $(60 \mathrm{u} / \mathrm{ml})$ and luciferase activity analysed $48 \mathrm{~h}$ post PDGF exposure (Fig. 22). 


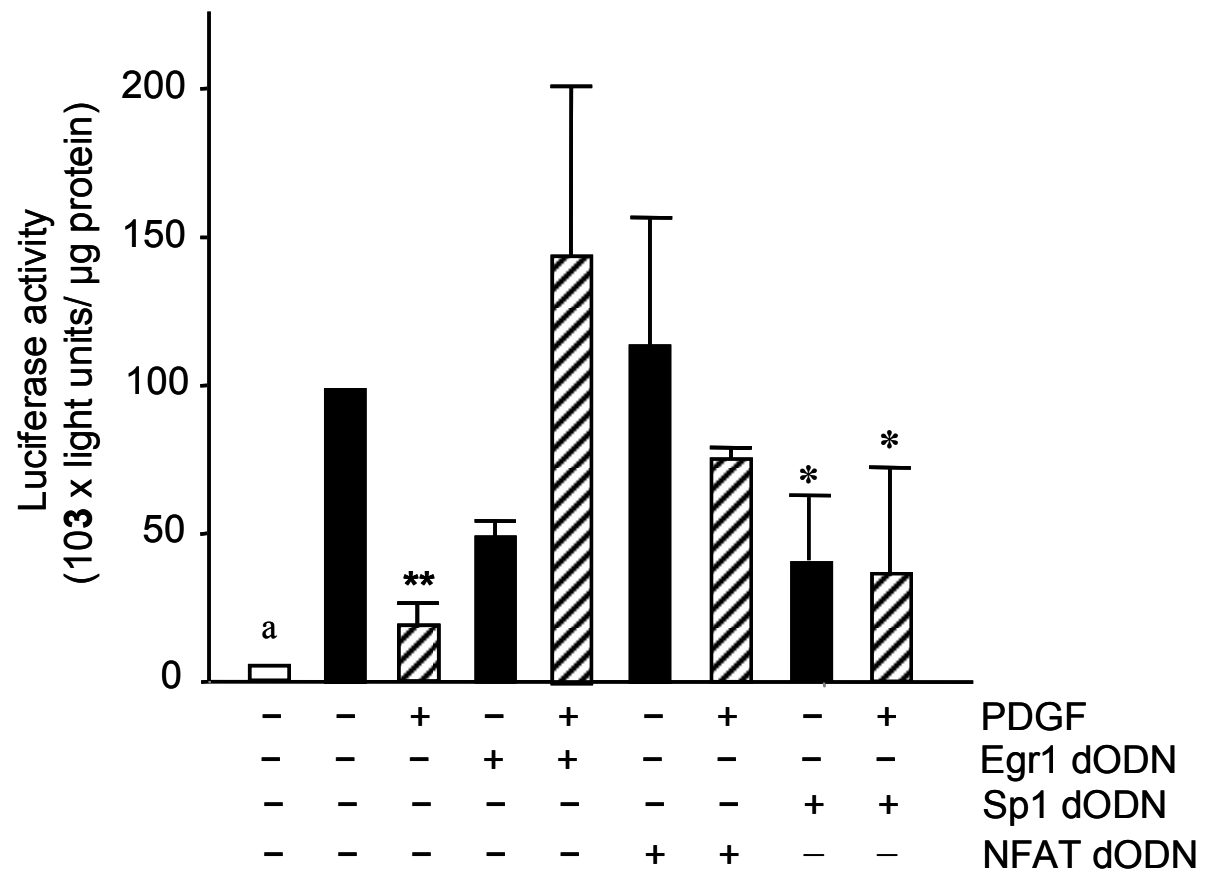

Figure 22. Effects of different dODNs on $\mathrm{hZfm} 1$ reporter gene activity in $\mathrm{hSMC}$, in the absence and presence of PDGF $(60 \mathrm{u} / \mathrm{ml})$ over a period of $48 \mathrm{~h}$. $\left({ }^{* *} P<0.005\right.$ vs. control, ${ }^{*} P<0.05$ vs. control; $\mathrm{n}=5$; a: non-transfected negative control).

Data derived from these experiments suggested that SP-1 may be responsible for basal expression of Zfm1, while Egr-1 may be responsible for PDGF induced down-regulation of Zfm1 gene expression. In order to confirm whether dODNs targeting these two TFs exert similar effects on endogenous (i.e. genomic) Zfm1 gene expression, these were added to nontransfected hSMC, followed by PDGF stimulation for $48 \mathrm{~h}$. Subsequent RTPCR analyses (Fig. 23) revealed that addition of either dODN resulted in an increase in basal Zfm1 expression. This finding seems to contradict those obtained in the Zfm1 reporter gene assays (Fig. 22). Several reasons exist as to why apparently opposing results were obtained at the genomic level and these will be further discussed in chapter 5.4. 
A

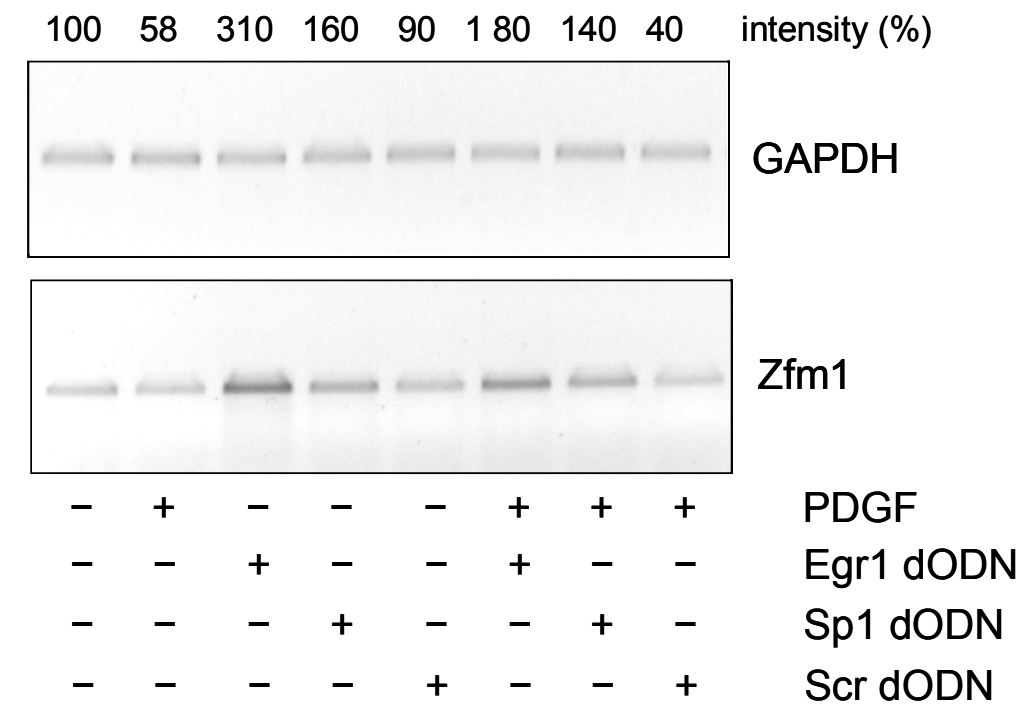

B

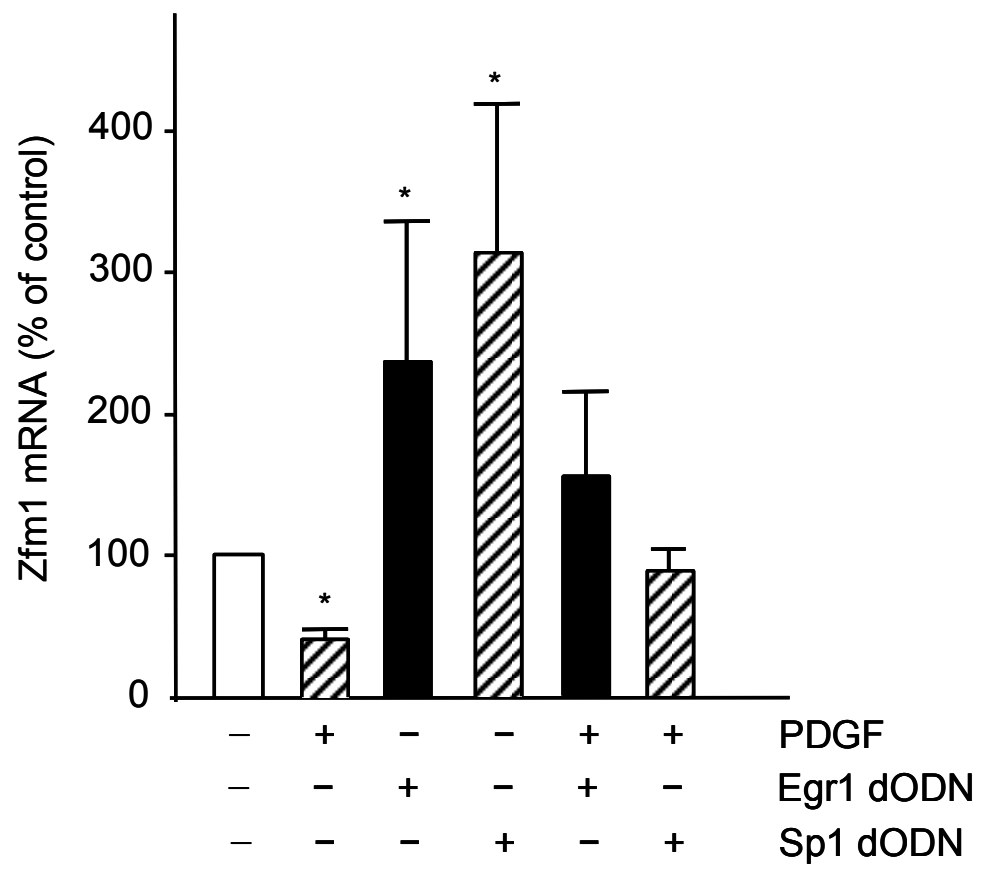

Figure 23. RT-PCR analysis of the effects of Egr-1 and SP-1 dODN on the expression of the endogenous $\mathrm{Zfm} 1$ gene. A) Exemplary RT-PCR analysis. B) Statistical summary ). ( ${ }^{\star} P<0.05$ vs. control; $n=8$.). A scrambled dODN (ScODN), as seen in $A, 10 \mu \mathrm{mol} / \mathrm{L}$ ) was used as a control and had no effect on Zfm1 expression (not shown 


\subsubsection{Deletion constructs of the Zfm1 reporter gene}

In an attempt to characterise the role of Egr-1 and SP-1 in Zfm1 gene expression, Zfm1 reporter gene deletion constructs were generated using the Quik Change site-directed mutagenesis kit (Stratagene). The deletion constructs (Fig. 24) targeting the most probable putative Egr-1/SP-1 binding sites were labelled $\Delta 1$ and $\Delta 2$ respectively. For further details refer to Figs 3 , 4 and 6 in the Annex.

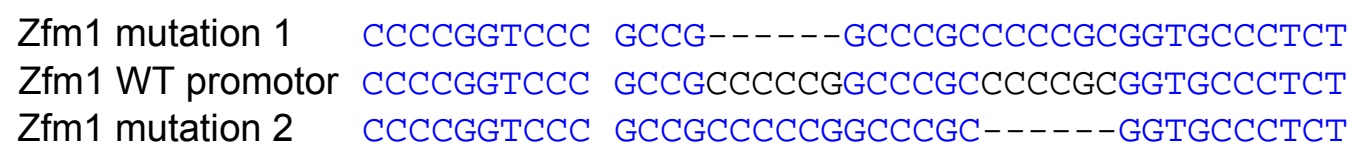

( $\Delta 1-191$ to $-186 \mathrm{bp}$ and $\Delta 2-179$ to $-174 \mathrm{bp}$ from the start site)

Figure 24. Sequence of the $\mathrm{Zfm} 1$ promotor with the missing $\Delta 1$ and $\Delta 2$ binding sites (missing basepairs are represented by dashes). The mutation was achieved by using the QuikChange Site Directed-Mutagenesis Kit using the $\Delta 1$ and $\Delta 2$ primers shown in Table 2.3 (WT: wild-type).

The deletion constructs were then transfected into hSMC which were stimulated for $48 \mathrm{~h}$ with PDGF $4 \mathrm{~h}$ post transfection (Fig. 25). The results indicate that both the $\Delta 1$ and the $\Delta 2$ sites are responsible for basal expression of Zfm1. After stimulation with PDGF, no further effect was seen with the $\Delta 1$ construct, suggesting that sensitivity to PDGF had been lost. On the other hand, this PDGF sensitivity seems to have been preserved in the $\Delta 2$ construct. 


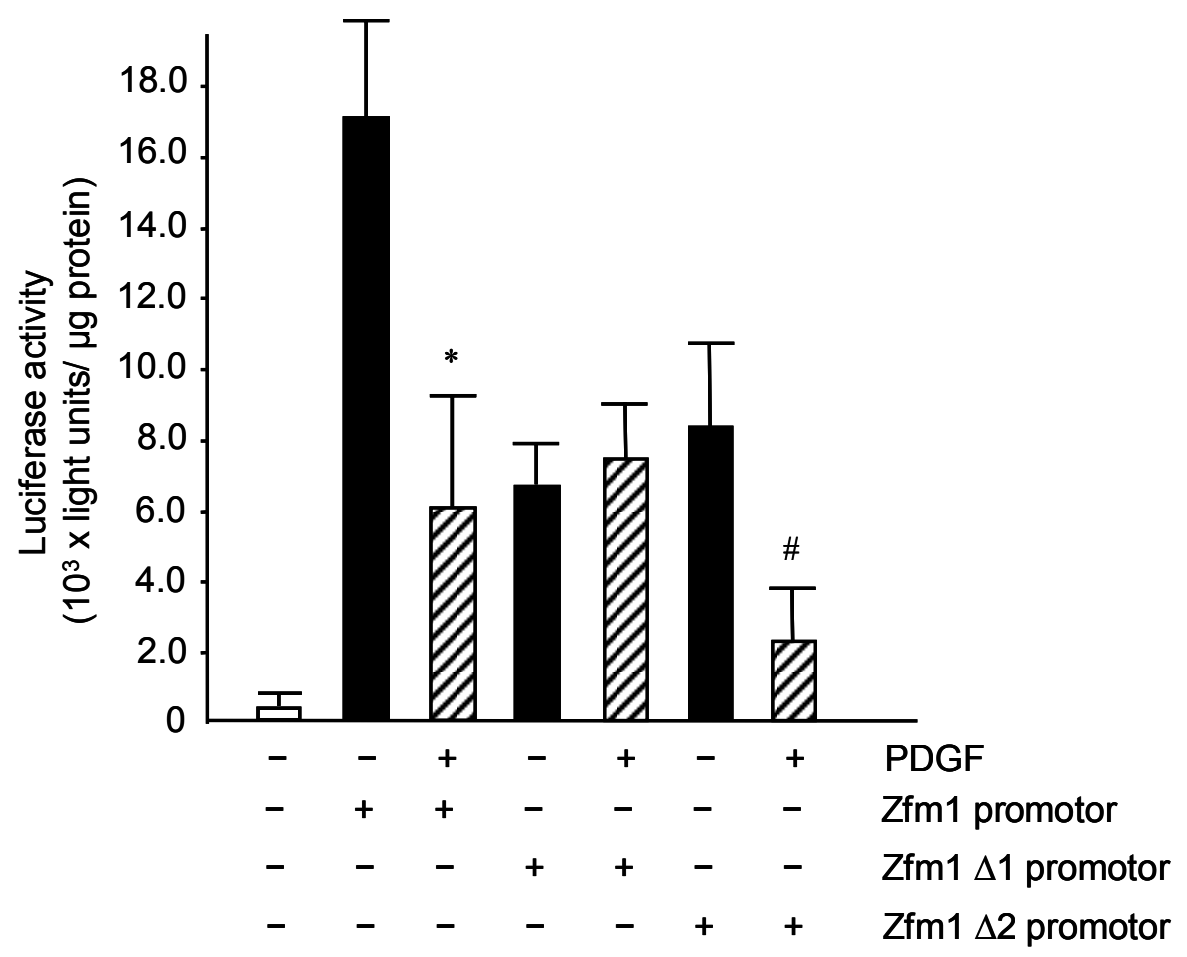

Figure 25. Effects of the $\Delta 1$ and $\Delta 2$ deletion on $\mathrm{Zfm} 1$ reporter gene activity in hSMC in the absence and presence of PDGF (60 u/ml, $48 \mathrm{~h})$. ( ${ }^{*} P<0.01$ vs. control; $n=9 .{ }^{\#} P<0.05$ vs. $\Delta 2$-control; $n=12$ ).

In order to confirm the data obtained with the single deletion constructs, a double mutant Zfm1 promotor construct was generated, which lacks both the $\Delta 1$ and the $\Delta 2$ motif (Fig. 26). The double mutant construct was created using the double mutant primers as outlined in Table 2.3 and the Quik Change $^{\mathrm{TM}}$ site-directed mutagenesis kit (see Annex Fig. 8 for the full double deletion and wild-type sequence alignment). As before, the mutant constructs were then transfected into hSMC which were stimulated with PDGF for $48 \mathrm{~h}$.

\subsubsection{Zfm1 double deletion construct}

Zfm1 double mutant CCCGGTCCCGCCG - - - -GGCCCGC - - - - - GGTGCCCTCTCTC Zfm1 WT promoter CCCGGTCCCGCCGCCCCCGGCCCGCCCCCGCGGTGCCCTCTCTC

Figure 26. Sequence of the double mutant $\mathrm{Zfm} 1$ promotor luciferase reporter gene construct. The remaining base (highlighted in red) was unexpected from the mutagenesis strategy. Missing base pairs are represented as dashes. 
Deleting both $\Delta 1$ and the $\Delta 2$ sites resulted in a similar basal reporter gene activity as seen in the wild-type construct (Fig. 27). This result is in contrast to what was expected, i.e that with the double mutant, both basal reporter gene activity and PDGF sensitivity are lost. Possible reasons for this rather curious finding are discussed in chapter 5.6.

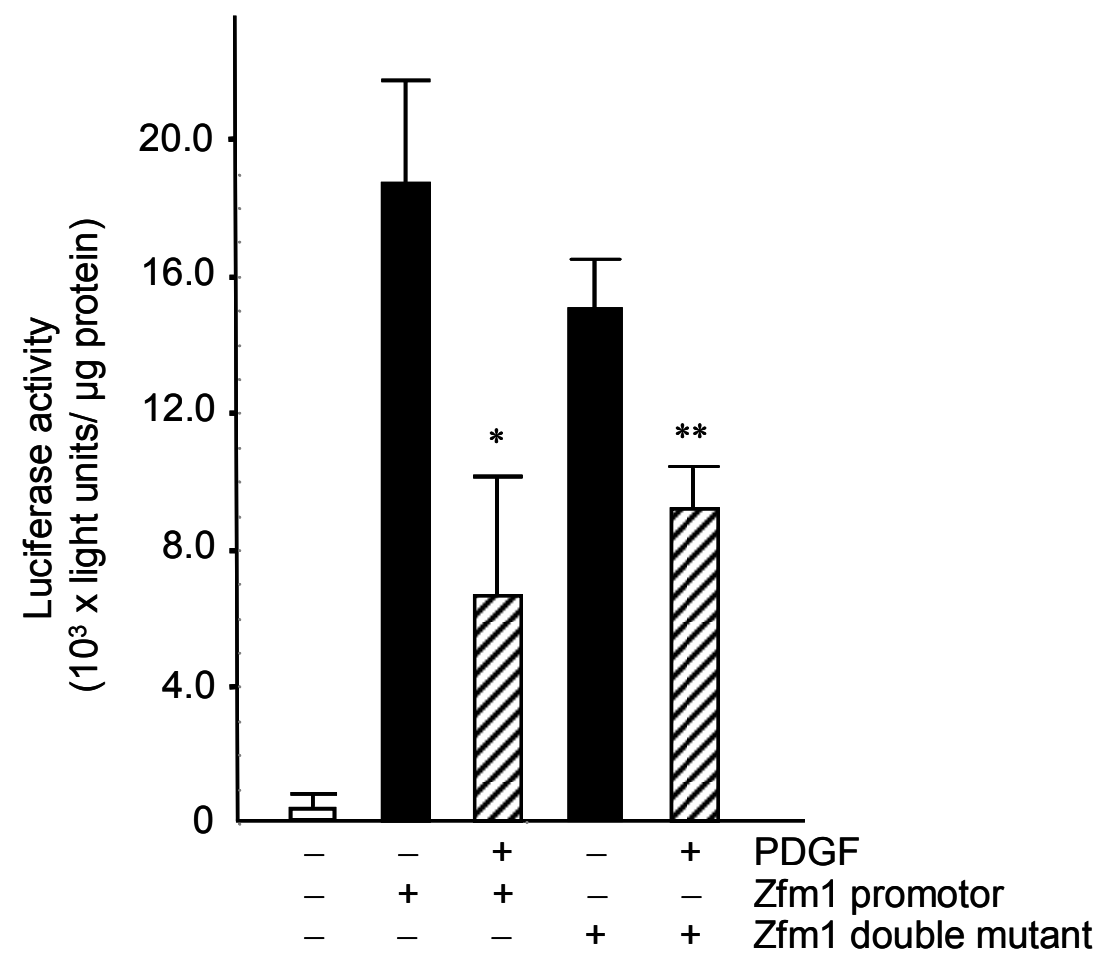

Figure 27. Luciferase reporter-gene analysis of the Zfm1 promotor double mutant construct. Cells were stimulated for $48 \mathrm{~h}$ with PDGF $(60 \mathrm{u} / \mathrm{ml})$ posttransfection. ( ${ }^{*} P \leq 0.01$ control vs. PDGF ; $n=12 ;{ }^{* *} P \leq 0.01$ control vs. Double mutant + PDGF ; $n=6)$.

\subsection{Chromosome immuno-precipitation (ChIP) analysis}

In order to define the TFs regulating basal expression and PDGFinduced down-regulation of the endogenous Zfm1 gene expression, ChIP analysis was performed with hSMC in the absence and presence of PDGF. ChIP analysis revealed that the combined Egr-1/SP-1 binding site at position approximately at -190 to -170 bp of the Zfm1 gene promotor (Fig. 21) was predominantly associated with SP-1 under basal conditions. In contrast, in response to PDGF stimulation SP-1 was effectively replaced by Egr-1 for this site (Fig. 28). This confirms that SP-1 maintains basal expression of Zfm1, whereas in the presence 
of PDGF, Egr-1 is responsible for repressing Zfm1 gene expression.

This will be further discussed in 5.7.

Std IP: NC Pol II SP-1 Egr-1 Pol II SP-1 Egr-1 PC

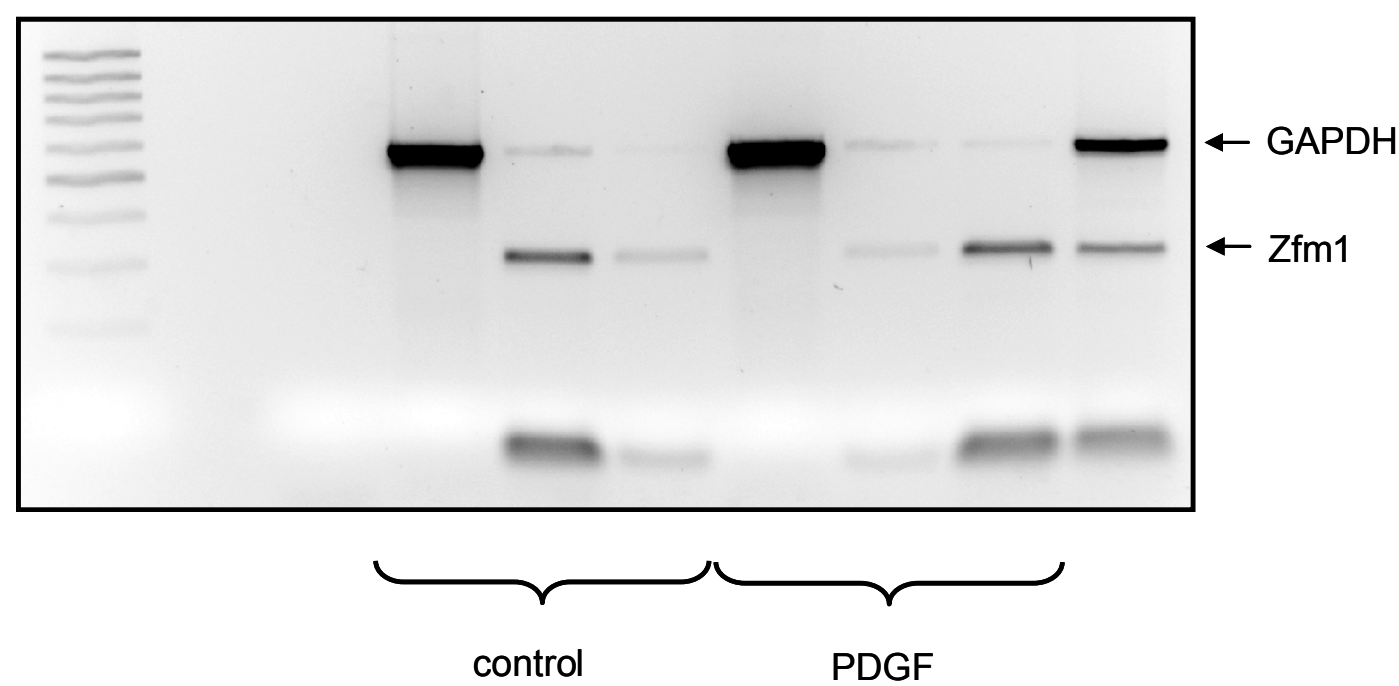

Figure 28. ChIP analysis of the Zfm1 gene promoter. Human SMC were incubated for $4 \mathrm{~h}$ in the presence or absence of PDGF $(60 \mathrm{u} / \mathrm{ml})$. RNApolymerase II was immuno-precipitated and part of the gapdh gene promoter was amplified as a positive control for the ChIP procedure itself. Egr-1: Egr-1 precipitation with amplification of the Zfm1 gene promoter. IP: immunoprecipitation; NC: control without DNA load. PC: positive PCR control. Pol II: RNA-polymerase precipitation with amplification of the gapdh gene promoter. SP-1: SP-1 precipitation with amplification of the Zfm1 gene promoter; Std: DNA length standard.

\subsection{Co-immunoprecipitation of $\mathrm{Zfm} 1$}

Co-immunoprecipitation assays are employed to characterise protein-protein interactions of a specific protein of interest. In order to characterise new Zfm1-binding proteins and to deduce a functional role for Zfm1 in hSMC; coimmunoprecipitation of Zfm1 followed by immuno-blots using different antibodies was performed with cell lysates from hSMC. The Zfm1 antibody (No. 1676) that is able to detect both isoforms of Zfm1 was used for the assay, and Western blot analysis revealed that co-immunoprecipitation of Zfm1 from hSMC was successful (Fig. 29). 


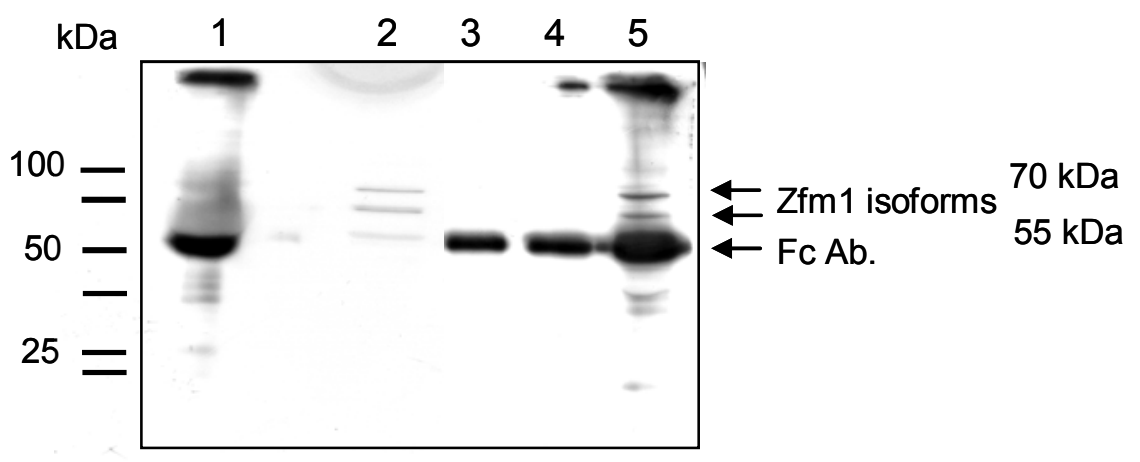

Figure 29. Western Blot analysis of the $\mathrm{Zfm} 1$ protein after coimmunoprecipitation. Lane 1 - Zfm1 serum antibody; lane 2 - hSMC cell lysate; lanes 3 and 4 - supertantants from the immunoprecipitation washes; lane 5 - co-immunoprecipitated pellet

Western blot analysis was also performed on Zfm1 co-immunoprecipitated samples, using antibodies against protein components of the basal transcription factor TFIID (Fig. 30), namely $\mathrm{hTAF}_{\|} 68$ and $\mathrm{hTAF}_{\|} 80$ (a kind gift from Prof. Tora, Strasbourg, France). The data obtained confirm that hTAF ${ }_{\| 68}$ does interact with Zfm1, as previously published (Zhang et al.,1998 (b)). The results presented also reveal that $Z \mathrm{fm} 1$ interacts with $\mathrm{hTAF}_{\|} 80$.

A

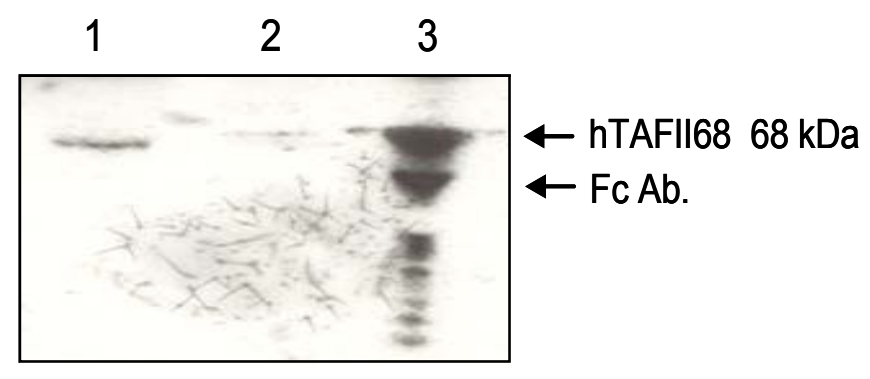

Figure 30. $h T A F_{\|} 68$ and $h T A F_{\| 1} 80$ interact with $\mathbf{Z f m} 1$, representative coimmunoprecipitation analyses. A) Lane 1- hSMC cell lysate; lanes 2 and 3 supernatants from the immuno-precipitation washes; lane 4 -immuno-pellet. 
B

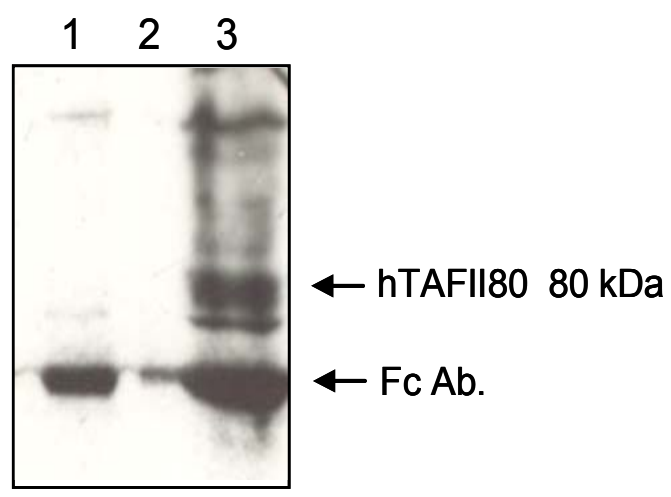

Figure 30. $h T A F_{\| \mid} 68$ and $h T A F_{\|} 80$ interact with $Z f m 1$, representative coimmunoprecipitation analyses. B) Lane 1- hSMC cell lysate with antibody; lane 2 - supernatant from the immuno-precipitation wash; Lane 3 - Coimmunoprecipitated pellet. 


\section{Discussion}

During the last decade there has been increasing evidence ranging from in vitro experiments to pathological evidence that pro-inflammatory cytokines and growth factors such as IL-1 $\beta /$ TNFa and PDGF play major roles in the pathogenesis of atherosclerosis (Plutzky, 2001). Smooth muscle cell (SMC) proliferation induced by these factors is one of the major hallmarks in the pathophysiology of atherosclerosis whereby the SMC phenotype changes from a contractile phenotype, predominantly located in the media to a proliferative synthetic phenotype, present in the neo-intima. In rat, one gene important for preventing the development of a synthetic SMC phenotype might be Zfm1/Sf1. Thus, it has been shown that stimulation of rat SMC with pro-inflammatory cytokines leads to an increase in cell proliferation and an up-regulation of pro-inflammatory gene products such as VCAM-1 and MCP1 that is paralleled by a decrease in Zfm1 gene expression (Cattaruzza et al., 2002). Interestingly, even Zfm1 down-regulation alone without cytokine or growth factor stimulation led to an increase in cell proliferation and expression of VCAM-1. Thus, it seems that Zfm1/Sf1 plays an important role in maintaining the phenotype in non-proliferating rat SMC by acting as a 'repressor' of pro-inflammatory and growth-promoting gene products.

As outlined above, a better understanding of the regulatory mechanisms that govern the remodeling process is crucial for developing new strategies to prevent atherosclerosis and hence the majority of cardiovascular disease. One purpose of this present work thereafter was to investigate whether Zfm1/Sf1 plays a role (if any) also in human SMC proliferation. Moreover, the human Zfm1 promotor was cloned for the first time in order to understand how pro-inflammatory cytokines and growth factors affect Zfm1 gene expression.

\subsection{Zfm1 antibodies and Zfm1 siRNA - the development of experimental tools.}

Antibodies against Zfm1 were not available, and thus had to be generated in two New Zealand white rabbits by using the peptide MATGAMATPLDFPSC (previously published by Guth et al., 2000). The Zfm1 anti-sera were required for Zfm1 protein expression analysis. The quality of each anti- 
serum was tested and confirmed that anti-serum 1676 is able to detect both Zfm1 isoforms $A(70 \mathrm{kDa})$ and $E(55 \mathrm{kDa})$, whilst anti-serum 1675 only detected isoform E. Thus, only anti-serum 1676 was chosen for all subsequent analysis.

RNA interference (RNAi) is an evolutionary conserved cellular defense mechanism for controlling the gene expression of foreign (e.g., viral) genes, occurring in most eukaryotes including humans (Tuschl et al., 2002; Hammond, 2005). The Zfm1 siRNA was tested for its efficiency to knock down the Zfm1 gene at the protein and mRNA level. Although basal Zfm1 expression was not completely suppressed (approximately to 35\% of control), this was sufficient to analyse the function of Zfm1 e.g in SMC proliferation.

\subsection{Zfm1 is involved in the repression of cell proliferation in hSMC}

Stimulating rat SMC with pro-inflammatory cytokines and PDGF led to an increase in cell proliferation and an up-regulation of pro-inflammatory gene products (Cattaruzza et al., 2002), and this effect was partially dependent o a down-regulation of Zfm1 gene expression. Whether or not Zfm1 plays a similar role in human SMC, and if Zfm1 could be a potential target for maintaining the SMC contractile phenotype under pro-atherosclerotic conditions, was elucidated by the analysis of pro-inflammatory gene expression and cell proliferation assays.

Whereas pro-inflammatory gene expression (the cell adhesion molecule VCAM-1 was chosen as a read out) was not dependent on Zfm1 expression, cell proliferation assays revealed that in contrast to rat SMC, in human SMC IL-1 $\beta /$ TNF $\alpha$ alone is not sufficient to induce cell proliferation but requires the knock down of Zfm1 expression by pretreatment with a Zfm1-specific siRNA. Thus, Zfm1 appears to be a repressor of IL-1 $\beta / T N F \alpha$ mediated proliferation also in human SMC. Stimulation of these cells with PDGF on the other hand, induced a maximum increase in cell growth, paralleled by a PDGF-induced down-regulation of Zfm1 expression. This suggests that suppression of Zfm1 in fact is crucial for the growth-promoting effects of PDGF in hSMC as will be discussed below. 
One logical approach to confirm this role of $\mathrm{Zfm} 1$ would be to over-express the protein by transfecting a gene construct with a strong and PDGFindependent gene promoter into primary hSMC. One anticipated result of such an experiment may be a decreased proliferative response to PDGF in transfected hSMC. Regrettably, it was not feasible to perform such an experiment, since primary cells are highly sensitive to culture conditions and the harsh transfection conditions would most probably spoil all consecutive analyses on hSMC proliferation. The use of stable cell lines for such an assay also proves to be unfavourable, because of their stable proliferation rate, possibly leading to invalid growth effects. But how could Zfm1 potentially inhibit PDGF-induced proliferation as suggested by the data? Besides playing a role in mRNA splicing, Zfm1 is known to act as a transcriptional repressor by interacting with $\mathrm{hTAF}_{\| 68 / E W S / T L S}$ TFIID complexes (Zhang et al,. 1998 (b)).

It is important to consider that PDGF induces proliferation via de novo expression of growth-promoting gene products, e.g., the up-regulation of amino acid transporters in order to fulfill the metabolic requirements of cell growth (Durante et al., 1996). Taking into account that the association of Zfm1 with $\mathrm{hTAF}_{\|} 68$ and homologous factors in active transcriptional complexes has been implicated in cell proliferation (Zhang et al., 1998 (b)) and cancer progression (Ranallo et al., 1999), it is conceivable that PDGFinduced cell proliferation may require the down-regulation of $\mathrm{Zfm} 1$. Zfm1 may act as a repressor of growth-promoting gene transcription by sustaining the transcriptome architecture, thus preserving the non-proliferative hSMC phenotype. As previously stated, Zhang et al. also revealed that Zfm1 repression of the SSAP transcription factor occurs through its Gal4-GQC interaction region, which recognizes sequences rich in glutamine-glycine/ serine-threonine. Interestingly, $\mathrm{hTAF}_{\| 68 / E W S / T L S}$ binds RNA polymerase ॥ via sequences rich in glycine, arginine and proline repeats. Thus, the GQCinteraction domain of Zfm1 may repress $\mathrm{hTAF}_{\|} 68 / \mathrm{EWS} / \mathrm{TLS}$ mediated gene transcription by interacting with the glycine repeats in RNA polymerase II. This possibility has however not been tested here. Nonetheless, taking into account these ideas as to how Zfm1 may maintain the non-proliferative hSMC phenotype at the level of transcriptional, and the fact that PDGF effectively represses Zfm1 gene expression, it became of interest to deduce 
the mechanism underlying the latter effect. To this end, the Zfm1 gene promoter was cloned and different promoter-reporter gene constructs were generated.

\subsection{Cloning of the human Zfm1 promotor}

Luciferase reporter gene analysis proves to be a useful method in studying how a specific romoter of interest is regulated. The romoter of interest is cloned and situated in front of a gene encoding a reporter protein. Here the gene encoding the light-generating enzyme luciferase was used (Wood et al., 1984). Activation of the romoter induces luciferase gene expression and translation into the active enzyme. Thus, in this assay system romoter activity is proportional to the level of light generated from luciferin. Therefore, in order to understand PDGF induced down regulation of the Zfm1 gene, parts of the human Zfm1 promotor were cloned into a luciferase reporter gene construct.

However, no detailed information was available on the sequence of the human Zfm1 gene romoter. Our literature analysis revealed that approximately $90 \%$ of the romoter contains CpG islands. CpG islands are target motifs for DNA methylation and represent approximately $1 \%$ of the human genomic DNA. Generally they are found in the romoter region of house keeping genes (Caiafa et al., 2005). Cloning of the hZfm1 promotor reported here posed a number of problems. Addition of organic additives such as dimethyl sulfoxide (DMSO) to the reaction mixture has been previously used to optimize amplification, but results can be unpredictable (Hube et al., 2005). More than 30 different primer pairs, along with differing concentrations, annealing temperatures and cycles were used in a futile attempt to directly amplify the romoter from a human genomic DNA template, but only random annealing of the primers and random amplification was achieved.

Therefore, the alternative selective strategy of isolating the romoter from a chromosome 11 BAC clone was elected. For this purpose, a special screening procedure was employed starting from a primary BAC clone pool containing 4,608 single clones. This approach proved successful, and the 
Zfm1 promotor was cloned into two separate fragments of approximately 860 and $670 \mathrm{bp}$ in length. Although it was hoped to amplify a longer 1500-bp fragment of the romoter, this was impossible due to the high redundancy of the GC-rich romoter sequence.

Both large and short romoter fragments of the Zfm1 gene were cloned separately into the pGL3 basic vector. The short fragment composing of approximately 670 bps was chosen for analysis since important transcription factors are more likely to bind within this region downstream of the start site. Moreover, the Zfm1 gene is situated close to the locus of the MEN-1 gene, which is associated with an inherited form of endocrine neoplasia (Toda et al., 1994). The start sites of both genes are approximately 1500 bp apart. Choosing to analyse a larger promoter fragment (spanning -670 up to -1530 bp from the start site, cloned alternatively) may have posed problems due to overlapping promoter sequences with the MEN 1 gene. Thus, it made sense to analyse the short Zfm1 promotor fragment first.

\subsection{Analysis of the human Zfm1 promotor}

As anticipated, the $670 \mathrm{bp} Z \mathrm{fm} 1$ promotor reporter gene construct worked well with a clearly detectable enzyme activity in hSMC. Moreover, exposure of the transfected hSMC with PDGF resulted in a decrease in luciferase activity, further confirming that the Zfm1 promotor reporter-gene construct is fully operational. Therefore, in order to deduce which transcription factors might be involved in PDGF-induced down-regulation of Zfm1 expression, two strategies were employed: The decoy ODN approach and the generation of Zfm1 promotor deletion constructs.

Decoy ODN (dODN) provide a powerful experimental tool to target transcription factors. These short double-stranded DNA molecules usually mimic the consensus binding site of their target transcription factor, thereby effectively neutralising the protein following uptake into the target cell. As a consequence, gene expression controlled by this transcription factor is effectively blocked. Therefore, the dODN technique can also be considered as a gene silencing approach (or in the case of the Zfm1 gene, maintaining gene expression), which is less specific than the siRNA or anti-sense ODN 
approach. However, dODN are highly specific for their target transcription factor.

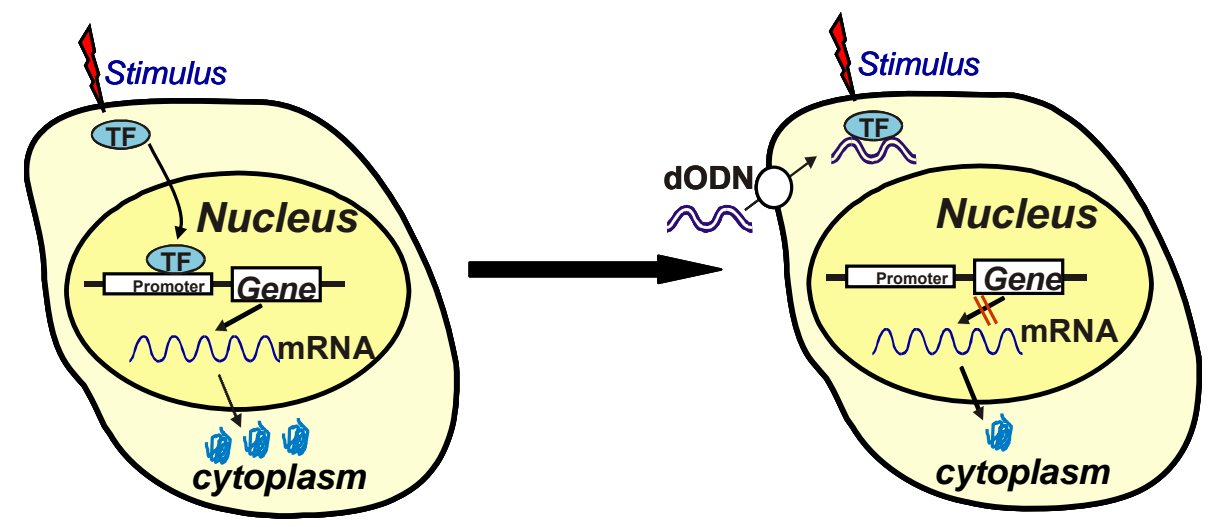

Figure 31. The gene silencing action of dODN. (adopted from Prof. M. Hecker, 2006). Decoy ODN bind to a specific transcription factor (TF), preventing the TF to interact with its regulatory binding site in the genome, thereby silencing gene expression.

\subsection{Decoy ODN characterization of the $\mathrm{Zfm} 1$ promotor}

First a TRANSFAC analysis of the Zfm1 short promoter was performed in order to identify possible transcription factors that could be involved in PDGF down-regulation of the Zfm1 gene. TFs known to be activated by PDGF are Egr-1, SP-1, NFAT, ATF-2, and AP-1 (Fos/ Jun heterodimers), and binding sites for all these transcription factors were found in the $630 \mathrm{bp}$ promoter construct.

Egr-1 binds to the promoters of many genes involved in pro-artherogenic processes such as SMC proliferation and migration, and target genes activated by Egr-1 include PDGF-A and B (Kamimura et al., 2004). Moreover, Zfm1 contains a region homologous to the WT1 gene, and WT1 is known to function as a repressor when bound by Egr-1 (Wang et al., 1992). SP-1 on the other hand is a member of a family of zinc finger transcription factors that have highly conserved DNA binding domains which recognise GC boxes (GGGGCGGGC) and GT motifs (GGTTGTGGC) (Hagen et al., 1994). Finally, NFAT is a transcription factor initially identified in T-cells, but has been shown to regulate other genes related to cell cycle progression, differentiation and apoptosis (Viola, et al., 2005). 
Since in previous experiments, dODN against AP-1 and ATF-2 were without effect on Zfm1 gene expression (data not shown), Egr-1, SP-1 and NFAT as the remaining candidates, were chosen for further analysis. Zfm1 promotor reporter-gene construct analysis in hSMC pre-treated with Egr-1, SP-1 or NFAT dODNs without PDGF stimulation revealed that Egr-1 and SP-1, but not NFAT may be important in maintaining basal expression of Zfm1. Furthermore, after stimulation with PDGF, it was confirmed that Egr-1 is the transcription factor responsible for PDGF induced down-regulation of Zfm1, whilst SP-1 is the transcription factor responsible for maintaining basal Zfm1 expression.

Interestingly, it has been shown that PDGF induces Egr-1 expression in bovine aortic SMC (BASMC), and that increased activity of Egr-1 leads to the displacement of SP-1 at a site 55 and $71 \mathrm{bp}$ upstream of the PDGF-A chain promotor start site (Silverman et al., 1997). It was also confirmed that $\mathrm{SP}-1$ is the transcription factor responsible for maintaining basal expression of the PDGF-A chain gene. Since PDGF is known to activate Egr-1, the question arose as to whether a similar mechanism could operate with respect to PDGF induced down-regulation of the Zfm1 gene. This was the more suggestive as the combined Egr-1/SP-1 binding site found approximately at position -191 to -174 in the $\mathrm{Zfm} 1$ gene promotor was virtually identical to the binding site functionally characterised by Silverman et al. in the PDGF-A gene promotor (Fig. 32). Therefore these binding sites were chosen for further analysis in the Zfm1 promotor reporter-gene construct.

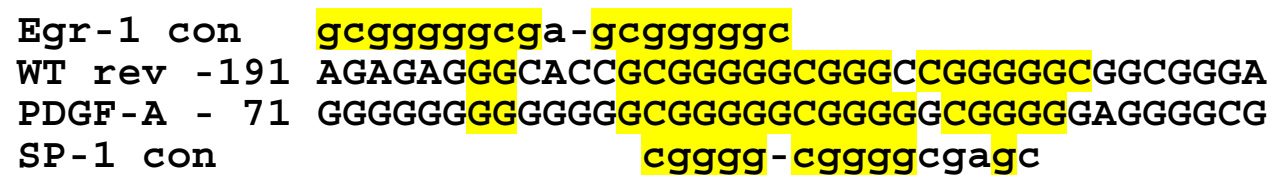

Figure 32. Alignment of the Zfm1 wild type promotor with the PDGF-A Egr1/SP-1 responsive promotor element (derived from Silverman et al., 1997) and Egr1/SP1 consensus sites. The highlighted bases in yellow represent homologous bases between the sequences. 


\subsection{Transcription factor binding site characterisation using Zfm1 promotor deletion construct.}

In order to define the binding sites responsible for basal and PDGF-induced down-regulation of Zfm1 expression, the homologous putatitive Egr-1/SP-1 binding sites (shown in Fig. 32) were deleted in the Zfm1 promotor reportergene construct. These were labelled $\Delta 1$ and $\Delta 2$, respectively. Stimulation of hSMC transfected with the $\Delta 1$ or $\Delta 2$ construct with PDGF revealed that both sites are important for maintaining basal Zfm1 expression. However, loss of sensitivity to PDGF-induced down-regulation was observed only with the $\Delta 1$ construct. Thus, the $\Delta 1$ site seems to be important for the effects of PDGF on Zfm1 gene expression.

Considering that both $\Delta 1$ and $\Delta 2$ sites are important for maintaining the basal expression of Zfm1, it was speculated as to whether deleting both sites would result in almost complete knock-down of Zfm1 expression. In order to test this hypothesis, a double deletion Zfm1 promotor construct was created. Human SMC transfected with the double deletion construct and stimulated with PDGF revealed a restoration of basal Zfm1 promotor activity. This result was opposite to what was anticipated since both sites seemed to be important for maintaining basal Zfm1 promotor activity.

Taking into consideration the GC-rich promoter sequence, it is possible that a new artificial Egr1/SP1 binding site was created during the mutagenesis procedure. In order to assess the likelihood of this to have occurred, an alignment between the combined Egr-1/SP-1 consensus site, and the Zfm1 double deletion construct was made (Fig. 33).

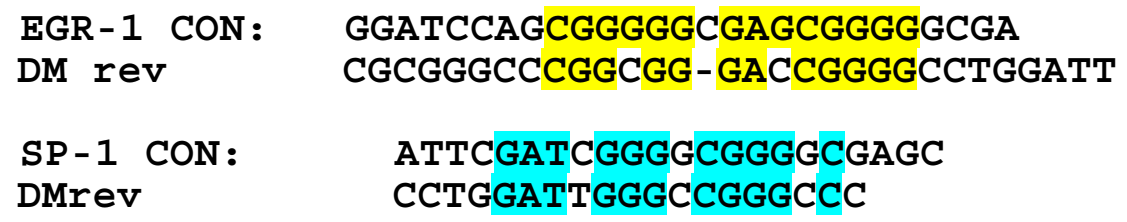

Figure 33. Alignment between the $\mathrm{Zfm} 1$ double mutant construct and recognition sites for Egr-1 and SP-1. Yellow highlighted bases represent homologous sites between the double mutant and the Egr-1 consensus site. Blue highlighted bases represent homologous sites between the SP-1 consensus sites. 
The alignment revealed that a GC-rich motif highly homologous to both the Egr-1 and SP-1 consensus sites is present in the double mutant of Zfm1 promotor, suggesting that a new artificial and overlapping binding motif for Egr-1 and SP-1 was created. It is therefore feasible that indeed by chance a functionally similar binding motif was created by the double deletion.

\subsection{Analysis of genomic Zfm1 gene expression}

As previously stated, the Egr-1 and SP-1 dODNs down-regulate Zfm1 promotor reporter gene activity at the basal level. In order to test whether these dODNshave a similar effect at the genomic level, hSMC pre-treated with Egr-1 or SP-1 dODN were incubated in the absence and presence of PDGF. The genomic Zfm1 expression was then analysed by RT-PCR.

In contrast to the Zfm1 promotor construct, genomic Zfm1 expression analysis revealed that addition of either Egr-1 or SP-1 dODN leads to an increase in basal Zfm1 expression. The apparent discrepancy between genomic and plasmid gene expression data is conceivable since dODNs are not fully selective for transcription factors that recognise similar or almost identical binding sites. Moreover, since Egr-1 and SP-1 recognise highly homologous motifs, this suggests that overlapping effects between the Egr-1 and SP-1 dODN were observed, evidently leading to effective inactivation of SP-1 at the basal level.

Another reason to consider is the fact that only the $670 \mathrm{bp}$ long Zfm1 promotor fragment was used for analysis. The endogenous gene would be regulated by a full length romoter that may contain additional regulatory elements, which could account for the increase in basal expression of the endogenous gene. As previously stated, analysis with the 860 bp long romoter fragment was not feasible, as this most likely contains nucleotides overlapping with the MEN 1 gene romoter. However as discussed above, the construct was fully sensitive to PDGF, suggesting that the romoter construct analysed was indeed fully functional.

A comparison between the amplified romoter sequence and the wild-type sequence deposited in GenBank (see Annex Fig. 1) revealed two nucleotide mismatches not present in any known binding sites. The GC-rich sequence of the romoter may account for the minor sequence mismatches that exist 
which also posed problems in the PCR amplification. However, these mismatches are unlikely to be responsible for the differences in basal expression between the genomic Zfm1 gene and the plasmid construct as they do not affect any known transcription factor binding site.

The most likely reason for this experimental discrepancy is that previously published electro-mobility shift assay (EMSA) data by Silverman et al. revealed that Egr-1 is present and active in the nucleus of SMC also under basal conditions. Considering that SP-1 apparently maintains basal expression of Zfm1, and that Egr-1 and SP-1 recognise overlapping binding sites, it is tempting to speculate that the low basal activity of Egr-1 is in balance with the higher basal activity of SP-1, resulting in a relatively high, but not maximal endogenous Zfm1 expression. Inhibiting the low Egr-1 activity with a dODN may be sufficient to fully shift the balance towards SP1 , so that SP-1 is able to mediate maximal $\mathrm{Zfm} 1$ expression under such experimental conditions. In the case of the reporter gene assay, however, a significantly increased number of nuclear Zfm1 promotor-like binding sites are present relative to the endogenous sites. Therefore, the low basal activity of Egr-1 may not suffice to decrease SP-1-mediated basal luciferase expression. In this situation a dODN (not fully selective for SP-1 and Egr-1 as both factors have similar binding sites, see above), will not lead to a noticeable Egr-1 inhibition, but rather a significant inhibition of SP-1, thereby in fact decreasing the activity of the multiple constructs in the transfected cell. In conclusion, although the romoter construct is probably fully functional, the copy number of Egr-1/SP-1 binding sites per cell may result in such a mere discrepancy between the genomic and plasmid-driven gene expression.

Although suggestive, the data discussed so far do not show a real binding of SP-1 or Egr-1 to the Zfm1 gene romoter. One method to confirm such specific protein-DNA interactions is through chromosome immunoprecipitation (ChIP). In order to verify that Egr-1 and SP-1 are the transcription factors involved in regulation of the $\mathrm{Zfm} 1 \mathrm{gene}$, and that the same mechanism of gene-regulation proposed by Silverman et al. holds true for the Zfm1 promotor, with ChIP analyses were performed on hSMC in the absence or presence of PDGF. 
The analysis revealed that in the absence of PDGF, SP-1 predominantly binds to the Zfm1 promotor at an Egr-1/SP-1 recognition motif situated approximately $200 \mathrm{bp}$ upstream of the start site. In the presence of PDGF however, Egr-1 is predominantly bound to the same motif whilst SP-1 interaction is lost. The ChIP analysis thus confirmed our model of how PDGF induces down-regulation of Zfm1 expression through Egr-1 displacement of SP-1 (Fig. 34).

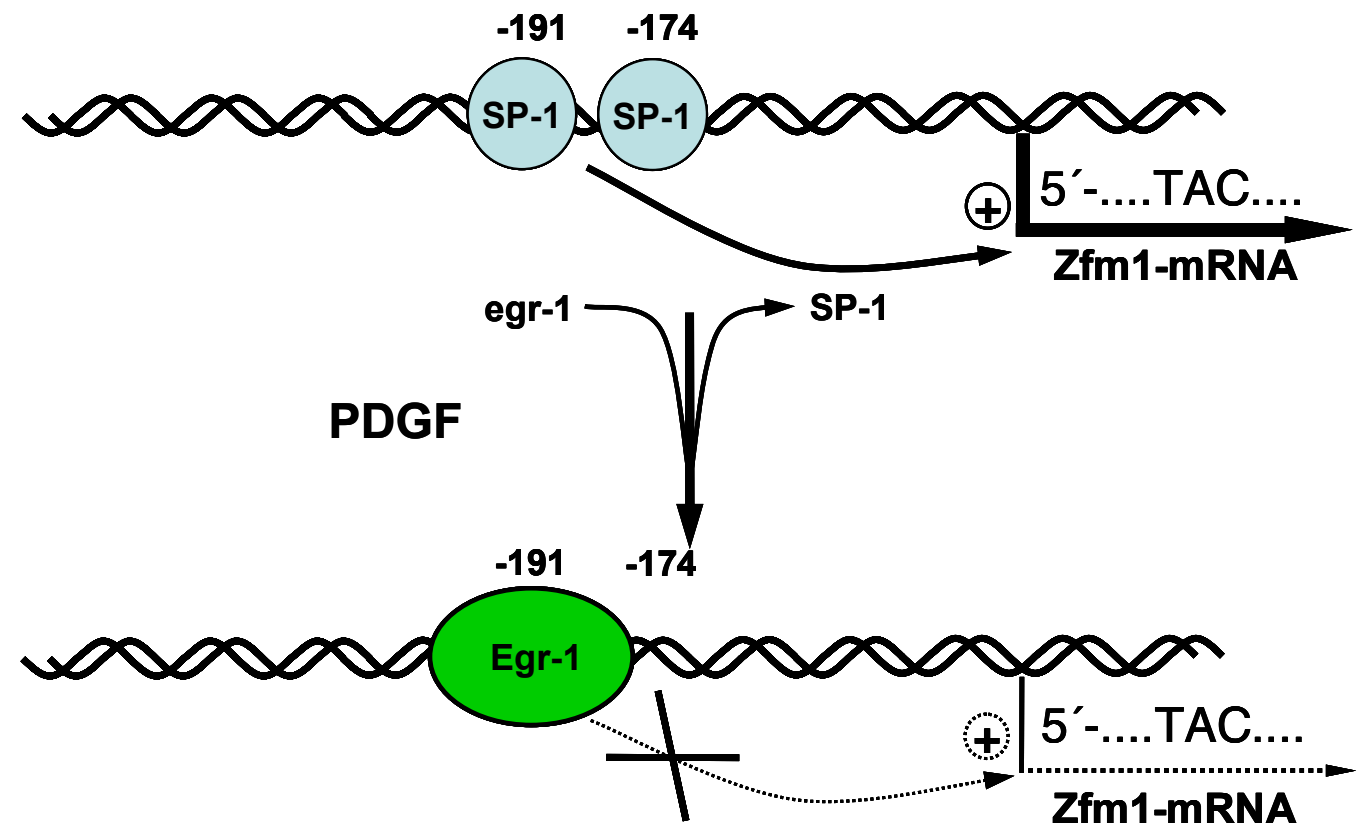

Figure 34. Model mechanism of PDGF induced down-regulation of the human Zfm1 gene. Under basal conditions SP-1 is the transcription factor maintaining Zfm1 gene expression. In the presence of PDGF, Egr-1 activity is up-regulated, and displaces SP-1 from its binding site, thereby inhibiting Zfm1 gene transcription.

In conclusion, Egr-1 induces transcription of growth-promoting genes (Santiago et al., 1999) and also plays a role in repressing Zfm1 gene expression. Silverman et al. have suggested a similar mechanism to induce PDGF-A expression. This is the first experimental proof that PDGF, through the displacement of SP-1 by Egr-1, elicits down-regulation of the human Zfm1 gene, hence relieving its repressing effects on the expression. 


\subsection{Possible functional roles of Zfm1}

As stated in the aims, it was hoped to elucidate Zfm1 protein-protein interactions by investigating whether $Z \mathrm{fm} 1$ interacts with other distinct $\mathrm{TAF}_{\| S}$ known to play a role in directing the formation of a functional phenotypic 'transcriptome'/TFIID complex. Due to time constraints however, only experiments to analyse Zfm1-TAF interactions could be performed revealing that $\mathrm{Zfm} 1$ interacts with $\mathrm{hTAF}_{\|} 80$. As previously demonstrated by Zhang et al., Zfm1 interacts with $\mathrm{hTAF}_{\|} 68 / \mathrm{EWS} / \mathrm{TLS}$, suggesting that Zfm1 plays a regulatory role in the expression of genes controlled by these factors. Interaction with $\mathrm{hTAF}_{\|} 68$ was also confirmed. Taking into account this finding, it may be feasible to conclude that Zfm1 possibly acts as a repressor of $h T_{A F} 68 / E W S / T L S$ TFIID complexes.

A new isoform of $h T A F_{\|} 80$ termed ' $h T A F_{\|} 80 \delta$ ' was recently reported by Bell et al. to form a specific TFIID complex that lacks $h T_{A F} 31$ and is sufficient to trigger induction of its target genes gadd45 and p21, both of which are proapoptotic. Thus, both a growth-promoting $\left(\mathrm{hTAF}_{\| 68)}\right.$ and a pro-apoptotic TAF $\left(\mathrm{hTAF}_{\|} 80\right)$ may interact with $\mathrm{Zfm} 1$; indeed suggesting that $\mathrm{Zfm} 1$ can repress both processes alike and therefore, is a key factor in regulating the cellular response to PDGF.

\subsection{A role of $\mathrm{Zfm} 1$ in atherosclerosis? An outlook.}

Taking into account the findings presented here, the role of $\mathrm{Zfm} 1$ in atherosclerosis still remains incompletely understood, though the data strongly suggest that one main function of Zfm1 lies in maintaining SMC in an anti-proliferative state. Considering the pathogenesis of atherosclerosis, it may be an attractive concept to prolong Zfm1 gene expression during the early stages of disease progression, where SMC proliferation and migration contributes greatly to the formation of the neo-intima. SMC at this stage are in the synthetic proliferative state, and are highly susceptible to respond to pro-inflammatory cytokines and growth factors. Therapeutically maintaining the expression of Zfm1 at this stage may efficiently inhibit SMC cell proliferation, evidently slowing down the progression of plaque and neointima formation, and preserving the contractile, non-proliferative SMC phenotype. Nevertheless, the late stages of atherosclerosis are 
characterised by vulnerable fibrous plaques, where matrix metalloproteinase's (MMPs) derived from SMC and various leukocytes, are naturally up-regulated by pro-inflammatory cytokines and growth factors. Eventually these MMPs degrade the ECM components of the fibrous cap in advanced lesions, causing the cap to thin and rupture, resulting in thrombosis and most often ischemia. At this point, it may be favourable to decrease $\mathrm{Zfm} 1$ expression in vascular SMC to promote a synthetic proliferative phenotype, in order to induce an increase in ECM formation and thus, to protect the vulnerable fibrous cap from degradation and rupture.

At this stage, it is important to increase our understanding of Zfm1 at the functional level in order to acquire an appreciation of its role in the phenotypic regulation of hSMC. To enhance our understanding of the functional role that Zfm1 plays in SMC, it would be important to clearly define proteins that interact directly with $\mathrm{Zfm} 1$ in the absence or presence of pro-inflammatory or growth promoting stimuli and to analyse their function in the course of atherogenic SMC proliferation. 


\section{Summary}

The first aim of the present study was to elucidate whether IL-1 $\beta / T N F \alpha$ and/or PDGF down-regulate Zfm1 gene expression and induce proliferation also in human SMC. The results revealed that IL-1 $1 / T N F \alpha$ alone is not sufficient to induce cell proliferation, but only after down-regulation of the Zfm1 gene through siRNA treatment proliferation was increased. In contrast, PDGF alone maximally induced cell proliferation. Thus, it was investigated whether PDGF directly down-regulates the endogenous Zfm1 gene in order to induce cell proliferation. The findings presented here revealed that PDGF does down-regulate endogenous $\mathrm{Zfm} 1$ gene expression, suggesting that this decrease in Zfm1 abundance may be important to allow PDGF induced growth-promoting gene transcription.

In order to understand the mechanism of PDGF induced down-regulation of $\mathrm{Zfm} 1$ expression in hSMC, the promotor of the human gene was cloned for the first time. Zfm1 promotor reporter gene analysis confirmed that PDGF down-regulates $\mathrm{Zfm} 1$ gene expression in hSMC.

Experiments employing decoy ODN directed against the transcription factors Egr-1 and SP-1 revealed that both factors are involved in the regulation of the Zfm1 gene; while Egr-1 is the transcription factor responsible for PDGFinduced down-regulation of $\mathrm{Zfm} 1, \mathrm{SP}-1$ is important for maintaining basal expression of Zfm1. In order to define the exact binding sites and transcription factors important for basal expression and PDGF-induced down-regulation of the Zfm1 gene, deletion constructs of a combined Egr1/SP-1 consensus site (situated approximately $200 \mathrm{bp}$ upstream of the transcriptional start site) of the Zfm1 promotor were generated. Together with a paralleled chromosome immunoprecipitation analysis, data obtained confirmed that under basal conditions, SP-1 predominantly interacts with the complex binding site located at position -191 to -174 of the Zfm1 gene and maintains the basal expression of Zfm1. Interestingly, under PDGF stimulation, Egr-1 activity was up-regulated, whilst SP-1 activity was decreased, confirming that under PDGF stimulation, Egr-1 displaces SP-1 from the binding site.

Finally, analysis of $\mathrm{Zfm} 1$ protein-protein interactions through coimmunoprecipitation confirmed that $\mathrm{Zfm} 1$ interacts with both $\mathrm{hTAF}_{\|} 68$ and 
$\mathrm{hTAF}_{\|} 80$, suggesting that $\mathrm{Zfm} 1$ plays a role as a regulator of SMC phenotype at the transcriptional level.

In summary, these findings reveal that Zfm1 is a repressor of growth promoting gene transcription possibly through modulating the 'transcriptome' architecture via specific Zfm1-TAF interactions. Zfm1 expression is downregulated by PDGF through the displacement of SP-1 by Egr-1. A deepened understanding of SMC proliferation in atherosclerosis and the role of $\mathrm{Zfm} 1$ therein, may lead to new therapeutic strategies involving the stabilization of a contractile and non-proliferating SMC phenotype, in order to prevent or slow down neo-intima formation in the course of the disease. 


\section{References}

Albright, S.R. and Tjian, R.: TAFs revisited: more data reveal new twists and confirm old ideas. Gene 242 (2000) 1-13.

Arning, S., Gruter, P., Bilbe, G. and Kramer, A.: Mammalian splicing factor SF1 is encoded by variant cDNAs and binds to RNA. Rna 2 (1996) 794-810.

Bell, B., Scheer, E. and Tora, L.: Identification of hTAF(II)80 delta links apoptotic signaling pathways to transcription factor TFIID function. Mol Cell 8 (2001) 591-600.

Berglund, J.A., Fleming, M.L. and Rosbash, M.: The KH domain of the branchpoint sequence binding protein determines specificity for the premRNA branchpoint sequence. Rna 4 (1998) 998-1006.

Bertolotti, A., Lutz, Y., Heard, D.J., Chambon, P. and Tora, L.: hTAF(II)68, a novel RNA/ssDNA-binding protein with homology to the pro-oncoproteins TLS/FUS and EWS is associated with both TFIID and RNA polymerase II. Embo J 15 (1996) 5022-31.

Caiafa, P. and Zampieri, M.: DNA methylation and chromatin structure: the puzzling CpG islands. J Cell Biochem 94 (2005) 257-65.

Cattaruzza, M., Schafer, K. and Hecker, M.: Cytokine-induced downregulation of $\mathrm{zfm} 1 / \mathrm{splicing}$ factor-1 promotes smooth muscle cell proliferation. J Biol Chem 277 (2002) 6582-9.

Durante, W., Liao, L., Iftikhar, I., Cheng, K., Schafer, A.I.: Platelet-derived growth factor regulates vascular smooth muscle cell proliferation by inducing cationic amino acid transporter gene expression. J. Biol. Chem 271 (1996) 11838-43.

Covini, N., Tamburin, M., Consalez, G., Salvati, P. and Benatti, L.: ZFM1/SF1 mRNA in rat and gerbil brain after global ischaemia. Eur $\mathrm{J}$ Neurosci 11 (1999) 781-7.

Gashler, A.L., Swaminathan, S., and Sukhatme, V.: A novel repression module, an extensive activation domain, and a bipartite nuclear localization signal defined in the immediate-early transcription factor Egr-1. Mol. Cell. Biol. 8 (1993) 4556-4571.

Gaston, K. and Jayaraman, P.S.: Transcriptional repression in eukaryotes: repressors and repression mechanisms. Cell Mol Life Sci 60 (2003) 721-41.

Guth, S. and Valcarcel, J.: Kinetic role for mammalian SF1/BBP in spliceosome assembly and function after polypyrimidine tract recognition by U2AF. J Biol Chem 275 (2000) 38059-66. 
Hagen, G., Müller, S., Beato, M., and Suske, G.: Sp1-mediated transcriptional activation is repressed by Sp3. EMBO 13 (1994) 3843-3851.

Hagen, G., Muller, S., Beato, M. and Suske, G.: Cloning by recognition site screening of two novel GT box binding proteins: a family of Sp1 related genes. Nucleic Acids Res 20 (1992) 5519-25.

Hammond, S.M.: Dicing and slicing: the core machinery of the RNA interference pathway. FEBS Lett 579 (2005) 5822-9.

Heldin, C.H. and Westermark, B.: Mechanism of action and in vivo role of platelet-derived growth factor. Physiol Rev 79 (1999) 1283-316.

Hube, F., Reverdiau, P., lochmann, S. and Gruel, Y.: Improved PCR method for amplification of GC-rich DNA sequences. Mol Biotechnol 31 (2005) 81-4.

Kamimura, M., Bea, F., Akizawa, T., Katus, H.A., Kreuzer, J. and Viedt, C.: Platelet-derived growth factor induces tissue factor expression in vascular smooth muscle cells via activation of Egr-1. Hypertension 44 (2004) 944-51.

Kramer, A.: Purification of splicing factor SF1, a heat-stable protein that functions in the assembly of a presplicing complex. Mol Cell Biol 12 (1992) 4545-52.

Kramer, A., Quentin, M. and Mulhauser, F.: Diverse modes of alternative splicing of human splicing factor SF1 deduced from the exon-intron structure of the gene. Gene 211 (1998) 29-37.

Kramer, A. and Utans, U.: Three protein factors (SF1, SF3 and U2AF) function in pre-splicing complex formation in addition to snRNPs. Embo $\mathrm{J} 10$ (1991) 1503-9.

Ladomery, M. and Dellaire, G.: Multifunctional zinc finger proteins in development and disease. Ann Hum Genet 66 (2002) 331-42.

Lavezzi, A.M., Ottaviani, G., and Matuturri, G.: Biology of the smooth muscle cells in human atherosclerosis. APMIS 113 (2005) 112-121.

Lee, H.J., Kim, S., Pelletier, J., and Kim, J.: Stimulation of hTAFII68 (NTD)mediated transactivation by v-Src. FEBS lett. 564 (2004) 188-198.

Liu, Z., Luyten, I., Bottomley, M.J., Messias, A.C., Houngninou-Molango, S., Sprangers, R., Zanier, K., Kramer, A., Sattler, M.: Structural basis for recognition of the intron branch site RNA by splicing factor 1 . Science 294 (2001) 1098-1102.

Morishita, R., Aoki, M. and Kaneda, Y.: Decoy oligodeoxynucleotides as novel cardiovascular drugs for cardiovascular disease. Ann N Y Acad Sci 947 (2001) 294-301; discussion 301-2.

Owens, G.K.: Regulation of differentiation of vascular smooth muscle cells. 
Physiol Rev 75 (1995) 487-517.

Pintucci, G., Yu, P.J., Saponara, F., Kadian-Dodov, D.L., Galloway, A.C. and Mignatti, P.: PDGF-BB induces vascular smooth muscle cell expression of high molecular weight FGF-2, which accumulates in the nucleus. J Cell Biochem 95 (2005) 1292-300.

Plutzky, J.: Inflammatory pathways in atherosclerosis and acute coronary syndromes. Am J Cardiol 88 (2001) 10K-15K.

Raines, E.W.: PDGF and cardiovascular disease. Cytokine Growth Factor Rev 15 (2004) 237-54.

Ross, R.: The pathogenesis of atherosclerosis: a perspective for the 1990s. Nature 362 (1993) 801-9.

Ross, R.: Atherosclerosis is an inflammatory disease. Am Heart J 138 (1999) S419-20. (a)

Ross, R.: Atherosclerosis--an inflammatory disease. N Engl J Med 340 (1999) 115-26. (b)

Santiago, T.S., Atkins, D.G. and Khachigian, L.M.: Vascular smooth muscle cell proliferation and regrowth after mechanical injury in vitro are Egr1/NGFI-A-dependent. Am. J. Pathol. 155 (1999) 897-905.

Silverman, E.S., Khachigian, L.M., Lindner, V., Williams, A.J. and Collins, T.: Inducible PDGF A-chain transcription in smooth muscle cells is mediated by Egr-1 displacement of Sp1 and Sp3. Am J Physiol 273 (1997) H1415-26.

Sullivan, G.W., Sarembock, I.J., and Linden, J.: The role of inflammation in vascular disease. J. Leukoc. Biol. 67 (2000) 591-602.

Toda, T., lida, A., Miwa, T., Nakamura, Y. and Imai, T.: Isolation and characterization of a novel gene encoding nuclear protein at a locus (D11S636) tightly linked to multiple endocrine neoplasia type 1 (MEN1). Hum Mol Genet 3 (1994) 465-70.

Tuschl, T. and Borkhardt, A.: Small interfering RNAs: a revolutionary tool for the analysis of gene function and gene therapy. Mol Interv 2 (2002) 158-67.

Verrijzer, C.P. and Tjian, R.: TAFs mediate transcriptional activation and promoter selectivity. TIBS 21 (1996) 338-342.

Viola, J.P., Carvalho, L.D., Fonseca, B.P. and Teixeira, L.K.: NFAT transcription factors: from cell cycle to tumor development. Braz J Med Biol Res 38 (2005) 335-44.

Wang, Z.Y. and Deuel, T.F.: An S1 nuclease-sensitive homopurine/homopyrimidine domain in the PDGF A-chain promoter contains a novel binding site for the growth factor-inducible protein EGR-1. Biochem Biophys Res Commun 188 (1992) 433-9. 
Wood, K.V., de Wet, J.R., Dewji, N. and DeLuca, M.: Synthesis of active firefly luciferase by in vitro translation of RNA obtained from adult lanterns. Biochem Biophys Res Commun 124 (1984) 592-6.

Zhang, D. and Childs, G.: Human ZFM1 protein is a transcriptional repressor that interacts with the transcription activation domain of stage-specific activator protein. J Biol Chem 273 (1998) 6868-77 (a).

Zhang, D., Paley, A.J. and Childs, G.: The transcriptional repressor ZFM1 interacts with and modulates the ability of EWS to activate transcription. J Biol Chem 273 (1998) 18086-91 (b). 


\title{
Appendix
}

\author{
Figure A1. \\ Sequence of Homo sapiens gene encoding splicing factor $1 / \mathrm{Zfm} 1$, exon 1 , as \\ published in GenBank. Accession number AJ000051.
}

1 agatgcaggc gggccaggct ggtctcgaac tcctgacctc aggtgatcca cccacctcgg 61 cctcccaaag tgttggagcc accgcgcctg gatggagatt aagtttctaa cacatgagct 121 ttgggggaca cattcaaacc tgtccaccta aagtaatcaa aagggtcaga atctaatttc 181 aatagtttat tcaagcacaa aacatgaggg tggactacct ggaaacaccg actccaaatg 241 aatggagtca gtgtttcgaa gtagagaagt taaggtttca tttacacaca caaaggcaga 301 ggagttttag gattacattc ttcatatatg gtcagtgcgt acttacagta atttggttat 361 aggccgagtg cagtggtcca ctcctgtaat cccagcactt tgggaggccg aggcgggcag 421 atcacctgag gtcaggagtt caagaccagc ctggccaaca tggtgaaatt ccatctttac 481 aaaatgtaa caattagctg ggcatgatgg caggtggctg taatcccggc tactcaggag 541 gctgaggtgg gagaatcgct tgaatctggg aggcagaggg tgcagtgagc cgagattgtg 601 ccattgcact ccagcctggg cgacagagcc agactctgtc tcaaattgaa ataataataa 661 taaataattt ggttgtaagc agtgtttctt tttgggaggc atacatttaa catttttac 721 agagggtgta atagtcatgg gtttgctgtc atctggtcta agtaaagcag gacaacaaaa 781 gggaagttat ctataagaag ggtcattaag aaggcagcag gtttttgtcc catgtttaat 841 tctctccaat aattgtacag aacaagaaaa acaagcaggt ctaatttatt atctcagaaa 901 aaattataac catacatggc tgagatcaca gtcacctctc tctccaggtt tcaagtgttg 961 tgggggttcc aacatctttt ctatttatt taaaaacca cagcagaggg gttgtgcacc 1021 cttcatatt tcttggctat ttggatttgt tcttctgaga catgtccatt cctattttt 1081 gctcatttc tattgtttt gcctttttc taattagtt ttaagatgta ttg tatatt 1141 acaggtattg gctctttatc atgtatggca aatattttt cctcatctat cattgtctct 1201 tgacttttat cagtgttaat tttcggggta atcaagtata tcttttaca gtttgaggtt 1261 cctgtctttg cagtctctca acccctagaa tacccttata gtctcctaaa ttatattcta 1321 aatgttttgt tgtttaaatt taagattcta cgccatttat caacgaaatc atctttcct 1381 gattgaaata aaatactaca tttgtggtat ttccggattc tgttgcacta atgtgtcttt 1441 cctaccaaca atatcatatt gttttattat tgtggtttt tgtttttgag acggagtctc 1501 atgctgttgc ccaggctgga gtacagtggt gcgatctcag ctcactacac ctccgcctcc 1561 tgggttcaag caattctcct gcctcagcct cctgagaagc tgggattata ggcgtctgcc 1621 accacgctcg gctaatttt gtacttttag tagagacggg ggtttcaccg tgttggtcag 1681 gttggtctcg aactcctgac ctcaggtgat cccccogcct tggcctccca gtgccttggc 1741 actggcctat tgtgttttat atactatgtt tgtcatctgg aaaggcaagc tcctgctccg 1801 tcttgtaaag ttttcccagt actgtagtag ttattttat ttttatttt gacagtctcg 1861 ctctgtcacc caggctgaag tgcagtggcc ccatctcggc tcactgcaac ctccgcctcc 1921 cgggttcaag cgattctctt gcctcatcct cctgggaagc tgggattgca ggagtgcacc 1981 actacaccca actaatttt gtattttcg tagagacggg gtttcgccat gttggtcagg 2041 ctggtctcga ccttctgacc ttgtgattcg cccgcctcgg cctgtcaaag tgctgggatt 2101 acaggcgtga gccaccgcgc ccggccgtag ttattgttt atacgattt aagatcatt 2161 aattaaatcc tctgaactcc gtggagattc caatagaagt gtgtatttgt aattttgaa 2221 ctgacaacct tctgttacct ttcatctaat atgttgttgc atcagttcaa atactgtttt 2281 aaatccttcg ataagtcgtc tctattcgta gctttttggg tcacttttt tttttttt 2341 tttttccaaa aaaacaggaa gtctttttac ctgcagcgtc aactgagccg gttttccggc 2401 gcgcgccagc ccctcccctg ctcccgcccc aaggttctgc gttaccatgg gaacaaaggt 2461 tgacgtcact tagggcttcc ttgctggacc caagggtcga tggtgaaggg agacgggtgg 2521 agaggcggtt ttgctccatc tacgcatgcg cacttcctgc tccaggactc ccccgccgta 2581 aatctcgttc cggctgggcc ttttccgccg cgactctcgc ttaatcccgg agaaactgcc 2641 ccctggggga ggggagtaga aaaaggctgg aaccagcgac agccaatccc gcgacactac 2701 aacgcaggcg agattgattg agtccaccac cgcagccaat gagagagctc gccgtcgctc 2761 cgtcatagag ttcgccccac cccatcccct cctttctgga ctcggagctc agttcacgca 2821 gtaacaaatg aagtgcgcgc tgcgacacct cccagcccac cgaactccgc cgccatttcc 2881 tcgcttggcc taacggttcg gccaatccca gcgcgcatca agaaggactg aggctccgcc 2941 aatcggaggc cgccgatttc gacccttcgc ctcggccogg cccaatccag gccccggccc 3001 cgccgccccc ggcccgcccc cgcggtgccc tctctcctcc ctctttgtgc gtctcgcgcc 3061 gccgccgccc gccgcgtgag aggacgggct ccgcgcgctc cggcagcgca ttcgggtccc 3121 ctccccccgg gaggcttgcg aaggagaagc cgccgcagag gaaaagcagg tgccggtgcc 3181 tgtcccoggg ggcgccatgg cgaccggagc gaacgccacg ccgttgggta agctgggccc cccogggctg ccccogctcc ccgggcccaa aggaggcttc gagccgggcc ctccgcctgc accogggcet ggggcggggc tgctggctcc cgggcegccg ccgccccogc ccgtgggetc gatgggggcc ctgaccgcgg cettcccett cgcggcgctg cetccgccgc ctccgccgcc gccecctccg cctccccagc agccgecgcc gcctccaccg ccaccgtccc coggegectc gtacccgccg ccgcagccgc cCCCTCCGCC GCCGCTCTAC CAGCGCGTGT CGCCGCCGCA GCCGCCGCCA CCCCAGCCGC CGCGTAAGGA CCAGCAGCCG GGCCCGGCCG GCGGCGGAGG AGGTGAGTCG GGCCGAGAGA GCGCGAGAGG CGTCGCGCGG ACGGGCCCGG CCGCCTGAGG GGCGCGCGGC GGCGGCGACG GCGGCTGCAC GCGGCAGGGG CGCGCGTGCG CGCACGGGGA 
GGCCCGGGCG GAGGCGCCCC TGGGCGCGCG CGGCCTGGTT CTAGGGCCTC GAGTGCGCAC GCGCGCTGTG GGGGGAGGGC TGGGCGGGCG GGAGGCGCTC TGTGCGCAGA CGCAGTGAGG TGGCCGGGCT GTGCGGCGCA ACTGTATAGA CTGGGGGCCC ACTATTGCTG TCCAGTCCGC TGGTGTCGGG AACAGGGGTG GCGGGTGTTC AGCGCTGGAC GGGGTGCTAG CTGTGAATGC CAGCAGGGCG TGAAAGCCTC ACCTGATGAC GTGCAGCGAC TCCCTTCTGG TCTTGAGGAA CCAGAATGGG AACCGTACCA AGGATAGCTC CTCTGCTTCT ACAGCAAGGC AGGGTTTTCA TCCGGGAGAG GTTG

Yellow: (major) atg-site

Blue: defined zfm1-sequence (2463197); capitalized letters: chromosomal clone (4755212)

\section{Figure A2.}

\section{Zfm1 short promoter cloned into pGL3-basic}

-629 tcccccgccg taaatctcgt tccggctggg ccttttccgc cgcgactctc gcttaatccc

-569 ggagaaactg ccccctgggg gaggggagta gaaaaaggct ggaaccagcg acagccaatc

-509 ccgcgacact acaacgcagg cgagattgat tgagtccacc accgcagcca atgagagagc

-449 tcgccgtcgc tccgtcatag agttcgcccc accccatccc ctcctttctg gactcggagc

-389 tcagttcacg cagtaacaaa tgaagtgcgc gctgcgacac ctcccagccc accgaactcc

-329 gccgccattt cctcgcttgg cctaacggtt cggccaatcc cagcgcgcat caagaaggac

-269 tgaggctccg ccaatcggag gccgccgatt tcgacccttc gcctcggccc ggcccaatcc

-209 aggccccggc cccgccgccc ccggcccgcc cccgcggtgc cctctctcct ccctctttgt

-149 gcgtctcgcg ccgccgccgc ccgccgcgtg agaggacggg ctccgcgcgc tccggcagcg

-89 cattcgggtc ccctcccccc gggaggcttg cgaaggagaa gccgccgcag aggaaaagca

-29 ggtgccggtg cctgtccccg ggggcgccat g

\section{Figure A3.}

\section{Zfm1 promotor with Delta 1 mutation}

-629 tcccccgccg taaatctcgt tccggctggg ccttttccgc cgcgactctc gcttaatccc -569 ggagaaactg ccccctgggg gaggggagta gaaaaaggct ggaaccagcg acagccaatc

-509 ccgcgacact acaacgcagg cgagattgat tgagtccacc accgcagcca atgagagagc

-449 tcgccgtcgc tccgtcatag agttcgcccc accccatccc ctcctttctg gactcggagc

-389 tcagttcacg cagtaacaaa tgaagtgcgc gctgcgacac ctcccagccc accgaactcc

-329 gccgccattt cctcgcttgg cctaacggtt cggccaatcc cagcgcgcat caagaaggac

-269 tgaggctccg ccaatcggag gccgccgatt tcgacccttc gcctcggccc ggcccaatcc

-209 aggccccggc cccgccgcce ccggcccgcc cccgcggtgc cctctctcct ccctctttgt

-149 gcgtctcgcg ccgccgccgc ccgccgcgtg agaggacggg ctccgcgcgc tccggcagcg

-89 cattcgggtc ccctcccccc gggaggcttg cgaaggagaa gccgccgcag aggaaaagca

-29 ggtgccggtg cctgtcccog ggggcgccat $g$

Pink highlighted sequences represent missing bp. Start site is highlighted yellow

\section{Figure A4.}

\section{Zfm1 promotor with Delta 2 Mutation}

-629 tcccccgccg taaatctcgt tccggctggg ccttttccgc cgcgactctc gcttaatccc

-569 ggagaaactg ccccctgggg gaggggagta gaaaaaggct ggaaccagcg acagccaatc

-509 ccgcgacact acaacgcagg cgagattgat tgagtccacc accgcagcca atgagagagc

-449 tcgccgtcgc tccgtcatag agttcgcccc accccatccc ctcctttctg gactcggagc

-389 tcagttcacg cagtaacaaa tgaagtgcgc gctgcgacac ctcccagccc accgaactcc

-329 gccgccattt cctcgcttgg cctaacggtt cggccaatcc cagcgcgcat caagaaggac

-269 tgaggctccg ccaatcggag gccgccgatt tcgacccttc gcctcggccc ggcccaatcc

-209 aggccccggc cccgccgcce ccggcccgcc cccgcggtgc cctctctcct ccctctttgt

-149 gcgtctcgcg ccgccgccgc ccgccgcgtg agaggacggg ctccgcgcgc tccggcagcg

-89 cattcgggtc ccctcccccc gggaggcttg cgaaggagaa gccgccgcag aggaaaagca

-29 ggtgccggtg cctgtcccog ggggegccat g

Pink highlighted sequences represent missing bp. Start site is highlighted yellow 
Figure A5.

Zfm1 short promotor alignment with Wildtype sequence (from BLAST)

THE_672_PROMOTOR

SF1_original_from_Blast

THE_672_PROMOTOR

SF1_original_from_Blast

THE 672 PROMOTOR

SF1_original_from_Blast

THE 672 PROMOTOR

SF1_original_from_Blast

THE_672_PROMOTOR

SF1_original_from_Blast

THE_672_PROMOTOR

SF1_original_from_Blast

THE_672_PROMOTOR

SF1_original_from_Blast

THE 672 PROMOTOR

SF1_original_from_Blast

THE 672_PROMOTOR

SF1_original_from_Blast

THE_672_PROMOTOR

SF1_original_from_Blast

THE_672_PROMOTOR

SF1_original_from_Blast

THE_672_PROMOTOR

SF1_original_from_Blast

THE_672_PROMOTOR

SF1_original_from_Blast

THE_672_PROMOTOR

SF1_original_from_Blast

THE_672_PROMOTOR

SF1_original_from_Blast

THE 672 PROMOTOR

SF1_original_from_Blast

THE 672 PROMOTOR

SF1_original_from_Blast
GAACAAAGGTTGACGTCACTTAGGGCTTCCTTGCTGGACCCAAGGGTCGA

TGGTGAAGGGAGACGGGTGGAGAGGCGGTTTTGCTCCATCTACGCATGCG

CACTTCCTGCTCCAGGACTCCCCCGCCGTAAATCTCGTTCCGGCTGGGCC
$* * * * * * * * * * * * * * * * * * * * * * * * * *$

TTTCCCGCCGCGACTCTCGGCTTAATCCCGGAGAAACTGCCCCCTGGGG TTTTCCGCCGCGACTCTCG - CTTAATCCCGGAGAAACTGCCCCCTGGGG

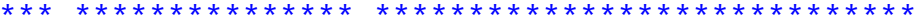

GAGGGGAGTAGAAAAAGGCTGGAACCAGCGACAGCCAATCCCCGCGACA GAGGGGAGTAGAAAAAGGCTGGAACCAGCGACAGCCAATCCC - GCGACA $* * * * * * * * * * * * * * * * * * * * * * * * * * * * * * * * * * * * * * * * * * * * * * * *$

CTACAACGCAGGCGAGATTGATTGAGTCCACCACCGCAGCCAATGAGAGA CTACAACGCAGGCGAGATTGATTGAGTCCACCACCGCAGCCAATGAGAGA

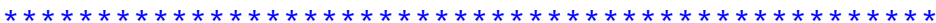

GCTCGCCGTCGCTCCGTCATAGAGTTCGCCCCACCCCATCCCCTCCTTT GCTCGCCGTCGCTCCGTCATAGAGTTCGCCCCACCCCATCCCCTCCTTT

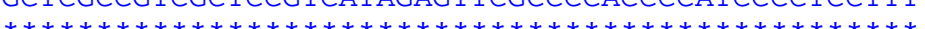

TGGACTCGGAGCTCAGTTCACGCAGTAACAAATGAAGTGCGCGCTGCGAC TGGACTCGGAGCTCAGTTCACGCAGTAACAAATGAAGTGCGCGCTGCGAC $* * * * * * * * * * * * * * * * * * * * * * * * * * * * * * * * * * * * * * * * * * * * * * * * * *$

ACCTCCCAGCCCACCGAACTCCGCCGCCTTTCCTCGCTTGGCC - AACGG ACCTCCCAGCCCACCGAACTCCGCCGCCTTTCCTCGCTTGGCCTAACGG $* * * * * * * * * * * * * * * * * * * * * * * * * * * * * * * * * * * * * * * * * * * * * * * * *$

TTCGGCCAATCCCAGCGCGCATCAAGAAGGACTGGGCTCCGCCAATCGG TTCGGCCAATCCCAGCGCGCATCAAGAAGGACTGGGCTCCGCCAATCGG $* * * * * * * * * * * * * * * * * * * * * * * * * * * * * * * * * * * * * * * * * * * * * * * * *$ AGGCCGCCGATTTCGACCCTTCGCCTCGGCCCGGCCCAATCCAGGCCCCG AGGCCGCCGATTTCGACCCTTCGCCTCGGCCCGGCCCAATCCAGGCCCCG $* * * * * * * * * * * * * * * * * * * * * * * * * * * * * * * * * * * * * * * * * * * * * * * * * *$

GTCCCGCCGCCCCCGGCCCGCCCCCGCGGTGCCCTCTCTCCTCCCTCTTT GCCCCGCCGCCCCCGGCCCGCCCCCGCGGTGCCCTCTCTCCTCCCTCTTT

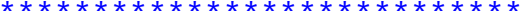

GTGCGTCTCGCGCCGCCGCCGCCCGCCGCGTGAGAGGACGGGCTCCGCGC GTGCGTCTCGCGCCGCCGCCGCCCGCCGCGTGAGAGGACGGGCTCCGCGC $* * * * * * * * * * * * * * * * * * * * * * * * * * * * * * * * * * * * * * * * * * * * * * * * * *$

GCTCCGGCAGCGCATTCGGGTCCCCTCCCCCCGGGAGGCTTGCGAAGGAG GCTCCGGCAGCGCATTCGGGTCCCCTCCCCCCGGGAGGCTTGCGAAGGAG

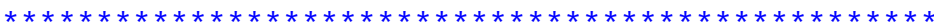

AAGCCGCCGCAGAGGAAAAGCAGGTGCCGGTGCCTGTCCCCGGGGGCGCC AAGCCGCCGCAGAGGAAAAGCAGGTGCCGGTGCCTGTCCCCGGGGGCGCC $* * * * * * * * * * * * * * * * * * * * * * * * * * * * * * * * * * * * * * * * * * * * * * * * * *$

ATG - . $\ldots$ ATGGCGACCGGAGCGAACGCCACGCCGTTGGGTAAGCTGGGCCCCCCCGG $* * *$ GCTGCCCCCGCTCCCCGGGCCCAAAGGAGGCTTCGAGCCGGGCCCTCCGC 
THE_672_PROMOTOR

SF1 original from Blast

THE_672_PROMOTOR

SF1_original_from_Blast

THE 672 PROMOTOR

SF1_original_from_Blast

THE_672_PROMOTOR

SF1_original_from_Blast

THE_672_PROMOTOR

SF1_original_from_Blast
CTGCACCCGGGCCTGGGGCGGGGCTGCTGGCTCCCGGGCCGCCGCCGCCC

CCGCCCGTGGGCTCGATGGGGGCCCTGACCGCGGCCTTCCCCTTCGCGGC

GCTGCCTCCGCCGCCTCCGCCGCCGCCCCCTC

CGCCGCCTCCACCGCCACCGTCCCCCGGCGCCTCGTACCCGCCGCCGCAG

CCGCCCCCTCCGCCGCCGCTCTACCAGCGCGTGTCGCCGCCGCAGCCGCC

Figure A6.

Zfm1 short promotor mutation 1 alignment with wildtype promotor

ZFM1 mutatation 1 ZFM1 WT promotor Mutation 1 primer

ZFM1 mutatation 1 ZFM1 WT promotor Mutation 1 primer

ZFM1 mutatation 1 ZFM1 WT promotor Mutation 1 primer
CAATCCCAGCGCGCATCAAGAAGGACTGAGGCTCCGCCAATCGGAGGCCG CAATCCCAGCGCGCATCAAGAAGGACTG - GGCTCCGCCAATCGGAGGCCG

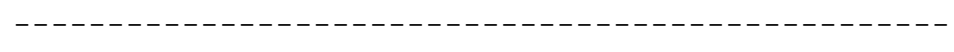

CCGATTTCGACCCTTCGCCTCGGCCCGGCCCAATCCAGGCCCCGGTCCCG CCGATTTCGACCCTTCGCCTCGGCCCGGCCCAATCCAGGCCCCGGTCCCG - - - - - - - - - -

CCG - - - - - GCCCGCCCCCGCGGTGCCCTCTCTCCTCCCTCTTTGTGCGT CCGCCCCCGGCCCGCCCCCGCGGTGCCCTCTCTCCTCCCTCTTTGTGCGT

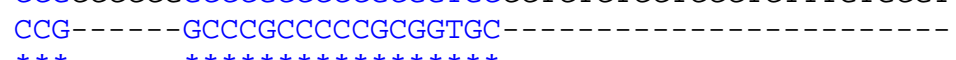

\section{Figure A7.}

\section{Zfm1 short promotor mutation 2 alignment with wildtype promotor}

Mutation 2 primer ZFM1 mutation 2

ZFM1 WT promotor

Mutation 2 primer ZFM1 mutation 2

ZFM1 WT promotor

Mutation 2 primer ZFM1 mutation 2 ZFM1 WT promotor

Mutation 2 primer ZFM1 mutation 2 ZFM1 WT promotor
CGCGGCATCAAGAAGGACTGAGGCTCCGCCAATCGGAGGCCGCCGATTTC GCG - CATCAAGAAGGACTG - GGCTCCGCCAATCGGAGGCCGCCGATTTC

GACCCTTCGCCTCGGCCCGGCCCAATCCAGGCCCCGGTCCCGCCGCCCCC GACCCTTCGCCTCGGCCCGGCCCAATCCAGGCCCCGGTCCCGCCGCCCCC

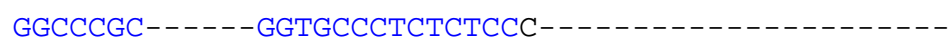
GGCCCGC - - - - - GGTGCCCTCTCTCCTCCCTCTTTGTGCGTCTCGCGCC GGCCCGCCCCCGCGGTGCCCTCTCTCCTCCCTCTTTGTGCGTCTCGCGCC $* * * * * * * \quad * * * * * * * * * * * * * *$

GCCGCCGCCCGCCGCGTGAGAGGACGGGCTCCGCGCGCTCCGGCAGCGCA GCCGCCGCCCGCCGCGTGAGAGGACGGGCTCCGCGCGCTCCGGCAGCGCA 
Figure A8.

Zfm1 short promotor double mutant alignment with wildtype promotor

Zfm1 double mutant Zfm1 WT promotor

Zfm1 double mutant Zfm1 WT promotor

Zfm1 double mutant Zfm1 WT promotor

Zfm1 double mutant Zfm1 WT promotor
CGCCTGGGCCCGGCCCAATCCAGGCCCCGGTCCCGCCG - - - - - GGCCCGC CGCCTCGGCCCGGCCCAATCCAGGCCCCGGTCCCGCCGCCCCCGGCCCGC

$* * * * * * * * * * * * * * * * * * * * * * * * * * * * * * * * * * * * *$ $\star \star \star * * * *$

- - - - - GGTGCCCTCTCTC - TCCCTCTTTGTGCGTCTCGCGCCGCCGCCG CCCCGCGGTGCCCTCTCTCCTCCCTCTTTGTGCGTCTCGCGCCGCCGCCG $* * * * * * * * * * * * * * * * * * * * * * * * * * * * * * * * * * * * * * * * * * *$

CCCGCCGCGTGAGAGGACGGGCTCCGCGCGCTCCGGCAGCGCATTCGGGT CCCGCCGCGTGAGAGGACGGGCTCCGCGCGCTCCGGCAGCGCATTCGGGT

CCCCTCCCCCCGGGAGGCTTGCGAAGGAGAAGCCGCCGCAGAGGAAAAGC CCCCTCCCCCCGGGAGGCTTGCGAAGGAGAAGCCGCCGCAGAGGAAAAGC *****t*

\section{Figure A9.}

\section{Map of the human Zfm1 promotor fragment cloned into pGL3}

$-629 \mathrm{bp}$
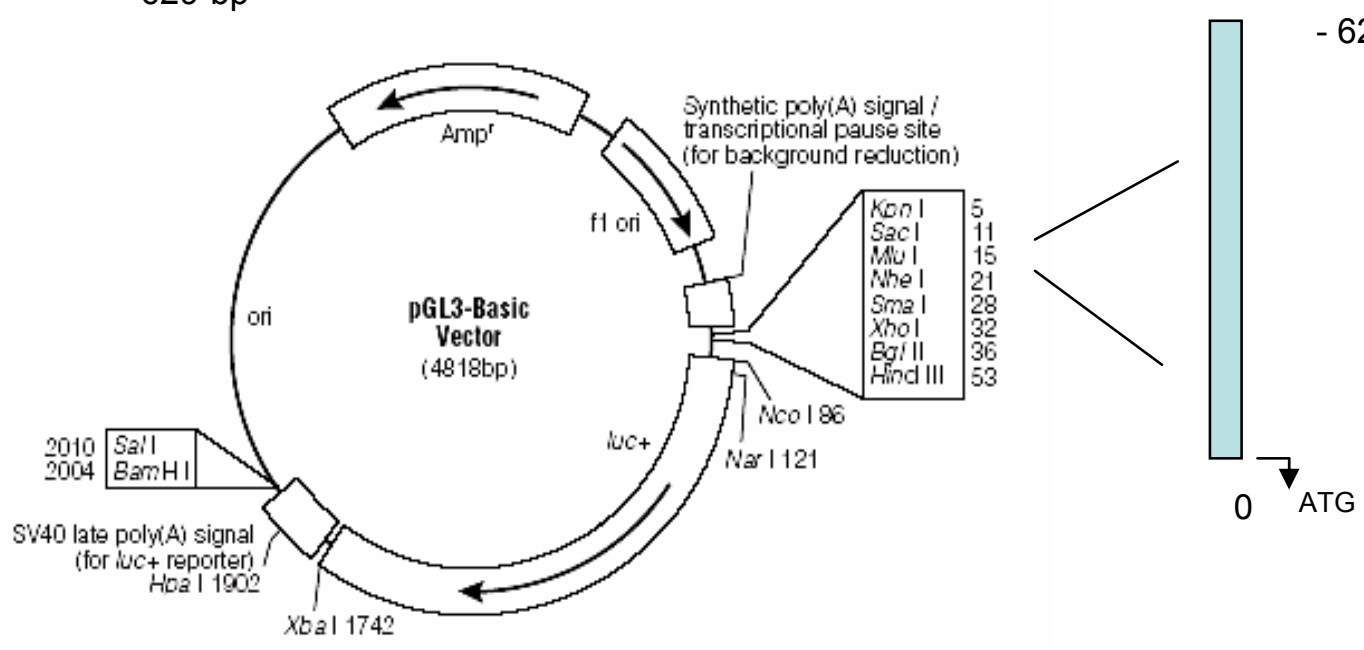

Map of the human $\mathbf{z f m} 1$ promotor fragment. The fragment was blunt cloned via Smal into the multiple cloning site (MCS) of the pGL3 basic vector (vector map, courtesy of Promega). 
Figure A10.

\begin{tabular}{|c|c|c|c|c|c|c|c|c|}
\hline p37 & p38 & p39 & p40 & p41 & p42 & P43 & p44 & \multirow{4}{*}{$\begin{array}{l}13 \text { plate pools } \\
16 \text { pooled rows }\end{array}$} \\
\hline p45 & p46 & p47 & p48 & p49 & & & & \\
\hline PP4-1 & PP4-2 & PP4-3 & PP4-4 & PP4-5 & PP4-6 & PP4-7 & PP4-8 & \\
\hline PP4-9 & $\begin{array}{l}\text { PP4- } \\
10 \\
\end{array}$ & $\begin{array}{l}\text { PP4- } \\
11 \\
\end{array}$ & $\begin{array}{l}\text { PP4- } \\
12\end{array}$ & $\begin{array}{l}\text { PP4- } \\
13\end{array}$ & $\begin{array}{l}\text { PP4- } \\
14\end{array}$ & $\begin{array}{l}\text { PP4- } \\
15\end{array}$ & $\begin{array}{l}\text { PP4- } \\
16\end{array}$ & \\
\hline $\begin{array}{l}\text { PP4- } \\
17\end{array}$ & $\begin{array}{l}\text { PP4- } \\
18\end{array}$ & $\begin{array}{l}\text { PP4- } \\
19\end{array}$ & $\begin{array}{l}\text { PP4- } \\
20\end{array}$ & $\begin{array}{l}\text { PP4- } \\
21\end{array}$ & $\begin{array}{l}\text { PP4- } \\
22\end{array}$ & $\begin{array}{l}\text { PP4- } \\
23\end{array}$ & $\begin{array}{l}\text { PP4- } \\
24\end{array}$ & \\
\hline $\begin{array}{l}\text { PP4- } \\
25\end{array}$ & $\begin{array}{l}\text { PP4- } \\
26 \\
\end{array}$ & $\begin{array}{l}\text { PP4- } \\
27\end{array}$ & $\begin{array}{l}\text { PP4- } \\
28\end{array}$ & $\begin{array}{l}\text { PP4- } \\
29\end{array}$ & $\begin{array}{l}\text { PP4- } \\
30\end{array}$ & $\begin{array}{l}\text { PP4- } \\
31\end{array}$ & $\begin{array}{l}\text { PP4= } \\
32 \\
\end{array}$ & $\begin{array}{l}24 \text { pooled } \\
\text { columns }\end{array}$ \\
\hline $\begin{array}{l}\text { PP4- } \\
33\end{array}$ & $\begin{array}{l}\text { PP4- } \\
34\end{array}$ & $\begin{array}{l}\text { PP4- } \\
35\end{array}$ & $\begin{array}{l}\text { PP4- } \\
36\end{array}$ & $\begin{array}{l}\text { PP4- } \\
37\end{array}$ & $\begin{array}{l}\text { PP4- } \\
38\end{array}$ & $\begin{array}{l}\text { PP4- } \\
39\end{array}$ & $\begin{array}{l}\text { PP4- } \\
40\end{array}$ & \\
\hline
\end{tabular}

Map of the PP4 secondary clone plate LANLc154PP4. The secondary pool comprises of 53 pools in total: 13 plate pools, 16 pooled rows and 24 pooled columns. Co-ordinates p38, PP4-13 and PP4-32 (in bold) were used to chose the tertiary clone for further analysis by PCR. 


\section{Acknowlegements}

First and foremost, I would like to express my deepest gratitude to Prof. M. Hecker for being my $\mathrm{PhD}$ supervisor, and giving me the opportunity to complete my PhD within the stimulating field of Cardiovascular Physiology. I appreciate his support, kindness, thorough scientific supervision of my PhD thesis, and encouragement and helpful suggestions with the preparation of this manuscript.

I would like to extend my gratitude to Prof. G. Burckhardt for being a positive and encouraging influence during my time in Göttingen and for being a great leader, and giving me the opportunity to be a member of the Gradiuerten Kolleg 335. I would also like to extend this gratitude to the Deutsche Forschung Gemeinschaft for their scientific financial support.

I am sincerely thankful to Prof. R. Hardeland who supervised my thesis and to Prof. D. Doenecke for being the co-supervisor. I am also grateful to Prof. G. Burckhardt for accepting to be my third examiner.

I am also extremely grateful to $\mathrm{Dr}$. M. Cattaruzza for his excellent supervision of the scientific work during the entire 3 years. Thank you for all the patience, support, guidance and amusement throughout the entire project and manuscript preparation.

I would also like to thank Prof. Laszlo Tora (Strasbourg, France) for his kind gift of the $h T A F_{\|} 68$ and $h T A F_{\|} 80$ antibodies.

I am grateful to Renate Dohrman for her excellent technical assistance and support. I am also thankful to Annette Bennemann for her technical assistance for the primary cell culture. I would also like to extend my gratitude to Sabine Krull and Sören Petzke for the amusing lab atmosphere and technical assistance during my final year.

Many thanks to Dr. Dincheng Gao and Milica Stojakovic for their friendship, support, motivation and inspiration during my early years in Göttingen. Also thank you to Ahsan Naqi and Elena Demicheva for their friendship and support. I am also grateful to Agnieska Wojtowicz for her great friendship, encouragement and technical assistance.

I would like to express my deepest appreciation and gratitude to my parents and extended family for all their support, encouragement, inspiration and for always believing in me. 


\section{Curriculum Vitae}

Name:

Date of Birth:

Place of Birth:

Nationality/ Citizenship:

Education \& Research Career:

$1984-1988$

$1989-1990$

$1991-1995$

$1996-1999$

2000

\author{
Nicole Nogoy \\ 22 February 1978 \\ Quezon City, Philippines
}

New Zealand

Johnsonville Main School

Wellington, New Zealand

Raroa Normal Intermediate School

Wellington, New Zealand

Wellington Girls' College

Wellington, New Zealand

Bachelor of Science (majors: Physiology, Biochemistry \& Molecular Biology) at Victoria University of Wellington, New Zealand

Bachelor of Science with Honours (2:1) major in Biochemistry \& Molecular Biology at Victoria University of Wellington, New Zealand

Thesis title: 'The Effect of Sporidesmin on the Microfilament Cytoskeleton in HepG2 Cells'
$2000-2001$
Research Associate with AgResearch (N.Z)
Reproductive Technologies Platform, Ruakura, Hamilton New Zealand.
$2002-2003$
Academic Visitor with the Division of Genomic Medicine, Academic Unit of Cell Biology, University of Sheffield, United Kingdom
$2003-2006$
Ph.D at the Georg-August Universität
Göttingen
Member of DFG-funded Graduierten Kolleg
335
Entitled 'Clinical, cellular \& molecular biology
of
the internal organs'.

Thesis title: 'Transcriptional Regulation of the Human Zfm1/Sf1 Gene' 